UNIVERSIDADE DE SÃO PAULO

INSTITUTO DE ENERGIA E AMBIENTE

PROGRAMA DE PÓS-GRADUAÇÃO EM CIÊNCIA AMBIENTAL

LUCIANA RUSSO CORRÊA CASTILLA

A TRANSIÇÃo ENERGÉTICA E AS PREMISSAS DO CENÁRIO RCP8.5: O “BUSINESS AS USUAL" É MENOS DRÁSTICO DO QUE PARECE

SÃO PAULO 


\section{A TRANSIÇÃO ENERGÉTICA E AS PREMISSAS DO CENÁRIO RCP8.5: O "BUSINESS AS USUAL" é menos drástico do que parece}

Dissertação apresentada ao Instituto de Energia e Ambiente da Universidade de São Paulo para obtenção do título de Mestre em Ciência Ambiental.

Orientador: Prof. Dr. Ricardo Abramovay

\footnotetext{
Versão Corrigida

(versão original disponível na Biblioteca do Instituto de Energia e Ambiente e na Biblioteca Digital de Teses e Dissertações da USP)
}

São Paulo, 2020 
AUTORIZO A REPRODUÇÃO E DIVULGAÇÃO TOTAL OU PARCIAL DESTE TRABALHO, POR QUALQUER MEIO CONVENCIONAL OU ELETRÔNICO, PARA FINS DE ESTUDO E PESQUISA, DESDE QUE CITADA A FONTE.

\section{FICHA CATALOGRÁFICA}

Castilla, Luciana Russo Correa.

A transição energética e as premissas do cenário RCP8.5: o "Business

As Usual" é menos drástico do que parece. / Luciana Russo Correa

Castilla; orientador: Ricardo Abramovay. - São Paulo, 2020.

$87 \mathrm{f} .:$ il; $30 \mathrm{~cm}$.

Dissertação (Mestrado em Ciência Ambiental) - Programa de PósGraduação em Ciência Ambiental - Instituto de Energia e Meio Ambiente - Universidade de São Paulo

1. Mudança climática. 2. Fontes renováveis de energia. I. Título.

Elaborado por Maria Penha da Silva Oliveira CRB-8/6961 
Nome: CASTILLA, Luciana Russo Corrêa

Título: A transição energética e as premissas do cenário RCP8.5: o "Business as Usual” é menos drástico do que parece

Dissertação apresentada ao Instituto de Energia e Ambiente da Universidade de São Paulo para obtenção do título de Mestre em Ciência Ambiental.

Aprovada em:

Banca Examinadora

Prof. Dr. Ricardo Abramovay

Instituição: IEE-USP

Julgamento:

Assinatura:

Prof. Dr. Carlos Afonso Nobre

Instituição: IEA-USP

Julgamento:

Assinatura:

Prof. Dr. Jacques Marcovitch

Instituição: FEA-USP

Julgamento:

Assinatura:

Prof. Dr. Adalberto Val

Instituição: IPAM

Julgamento:

Assinatura: 


\section{AGRADECIMENTOS}

Agradeço ao Prof. Dr. Ricardo Abramovay pelas orientações e contribuições durante a jornada, nem sempre fácil, de escrever uma dissertação, mas principalmente por ser sempre uma inspiração.

Agradeço aos professores por terem aceitado gentilmente meu convite para formar a banca avaliadora.

Agradeço ao Dr. Carlos Nobre, por me motivar a pesquisar sobre as mudanças climáticas, ao Prof. Dr. Jacques Marcovitch que me guiou nos primeiros passos na vida acadêmica na FEA/USP, ao Prof. Dr. Adalberto Val por me apresentar "ao vivo" os cenários climáticos no INPA.

Agradeço à Prof ${ }^{a}$. Dra. Tatiana Rotondaro pelo seu apoio, e ao Prof. Dr. José Eli da Veiga por suas orientações valiosas durante o exame de qualificação e em todos nossos encontros.

Agradeço à colega de programa Cleide Mello, pelas contribuições fundamentais nos momentos de incertezas, e a tantos outros colegas de percurso. E a Dra. Gleriani Ferreira por seu apoio nos meus primeiros passos. Também aos funcionários do IEE e, em especial, do PROCAM, que sempre foram atenciosos e solícitos com minhas demandas.

Agradeço aos diversos modeladores energéticos e climáticos sempre ativos no Twitter e que todos os dias me trazem informações e questionamentos, tanto sobre a ciência do clima quanto sobre a transição energética. E a Chris Nelder e seu podcast, fundamental para tirar dúvidas técnicas. E a Christiana Figueres por sua combinação mágica de "outrage and optimism" sem a qual não seria possível estudar as mudanças climáticas.

Agradeço aos meus filhos Isabela, Manuela, Rodrigo e Gabriela por todo apoio e pela constante troca de amor. Também aos meus pais, Lena e Fabio e meus irmãos, Fernanda, Fabio e Rodrigo; a Erika, Arthur, Tania e todos meus sobrinhos - juntos mantemos o sentido de família. E também a minha família peruana que mesmo de longe, sempre é uma fonte de carinho.

Por último um agradecimento muito especial ao meu parceiro de todas as jornadas, Juan Carlos, pelo apoio incondicional, pelas infindáveis horas de trocas de informações, opiniões, referências e pelos anos juntos baseados em tanto amor. 
Il faut faire de la catastrophe un destin. Mais attention, un destin qu'on peut choisir, ou refuser, plutôt - Jean Pierre Dupuis \#RCP8.5isbollocks - Michael Libreiech 


\section{RESUMO}

CASTILLA, Luciana Russo Corrêa. A transição energética e as premissas do cenário RCP8.5: o "Business as Usual" é menos drástico do que parece. 2020 88f. Dissertação (Mestrado) - Programa de Pós-Graduação em Ciência Ambiental (PROCAM) da Universidade de São Paulo, São Paulo, 2020.

O atual cenário mais pessimista publicado pelo IPCC, o RCP8.5, frequentemente citado como o cenário "Business as Usual", foi desenvolvido há 15 anos e suas premissas desde então não foram atualizadas. Em particular, as sobre inovação no setor energético e da adoção de tecnologias de geração de energia limpa não foram validadas pela realidade observada nos últimos 15 anos devido à transição energética em curso. Embora as emissões de gases de efeito estufa hoje estejam próximas às do caminho de emissões deste cenário, argumentamos que a mudança substancial no perfil de emissões do setor de energia deveria levar a uma revisão do cenário no próximo relatório do IPCC e que o cenário RCP8.5 não pode mais ser considerado um cenário "Business as Usual". Em termos de debate de políticas públicas entender as discrepâncias entre o que está realmente acontecendo, tanto em termos de inovação tecnológica quanto nas trajetórias de emissões, em comparação com as premissas originais do cenário RCP8.5, fornece melhor orientação para redirecionar investimentos para decisões de políticas públicas que são adequados para o propósito. O ciclo de avaliação de 7 anos do IPCC pode não ser compatível com os ciclos rápidos de inovação tecnológica que acontecem no setor de energia renovável e, portanto, cresce a probabilidade de incompatibilidade entre eles. O fato de a transição energética com foco na descarbonização estar acontecendo e de a trajetória de emissões do setor provavelmente ser menor do que a estimada pelo cenário RCP8.5 não significa que possamos ser complacentes com as mudanças climáticas. Mas não reconhecer as mudanças que tornam cada vez menos verossímeis as hipóteses deste cenário é render-se a um fatalismo que pode ser paralisante.

Palavras-chave: Transição energéticas. RCP8.5. Cenários Climáticos. Mudanças climáticas. Energia renovável. 


\begin{abstract}
CASTILLA, Luciana Russo Corrêa. The energy transition and the RCP8.5 energy premises: "Business as usual" is less dire than it seems. 2020. $88 \mathrm{f}$. Master's Dissertation - Graduate Program of Environmental Science, Universidade de São Paulo, São Paulo, 2020.
\end{abstract}

The most pessimistic scenario published by the IPCC to-date - RCP8.5 - is often cited as the "Business as Usual" scenario, but this scenario was developed 15 years ago, and its premises have never been updated since then. In particular, the premises behind the energy sector's innovation pathways and the adoption of clean energy generation technologies have not been validated by the reality observed over the last 15 years due to the ongoing energy transition. Although greenhouse gas emissions today closely match this scenario's emission pathway, we argue that the substantial change in the energy sector's emissions profile should lead to a review of the scenario in the upcoming IPCC report and that the RCP8.5 scenario can no longer be considered a "Business as Usual" scenario. In terms of the public policy debate, understanding the discrepancies between what is actually happening, both in terms of technological innovation and the emissions pathways, compared with the original premises of the RCP8.5 scenario, provides better guidance for redirecting investments for public policy decisions that are fit for purpose. The RCP 8.5 scenario sets the learning rates for renewables at a maximum of $10 \%$ and, whether from IEA, IRENA, academic articles, or specialized consultants, all measured learning rates point to much higher rates. The IPCC's 7-year assessment cycle may not be compatible with rapid technological innovation cycles happening in the renewable energy sector, and thus the likelihood of mismatch between them naturally increases. The fact that the energy transition focused on decarbonization is happening and that the sector's emissions trajectory will probably be lower than that estimated by the RCP8.5 scenario does not mean that we can be complacent with climate change. On the other hand, not recognizing that clean energy technology innovations have made this scenario much less plausible is to surrender to paralyzing fatalism.

Keywords: Energy transition. RCP8.5. Climate scenarios. Climate change. Renewable energy 


\section{LISTA DE ILUSTRAÇÕES}

Figura 1 - Relatório de cenário climático da AES utilizando as indicações da TCFD

Figura 2 - Tipologia para classificação de cenários

Figura 3 - Processo de desenvolvimento de cenários atuais do IPCC

Figura 4 - RCPs estudados pelo IPCC para o AR5.

Figura 5 - Processo sequencial de montagem de cenários

Figura 6 - A arquitetura da matriz de cenários do IPCC

Figura 7 - Os cinco caminhos socioeconômicos

Figura 8 - Projeção de fornecimento de energia primária por fonte de energia do RCP8.5

Figura 9 - Emissões totais de $\mathrm{CO}_{2}$ do setor energético

Figura 10 - Indicadores da transição energética da AIE

Figura 11 - Capacidade total de geração renovável instalada entre 2004 e 2019 (em GW)

Figura 12 - Evolução da eficiência de diversas tecnologias de geração FV

Figura 13 - Histórico de projeções da AIE para a adoção da tecnologia FV

Figura 14 - Consumo de energia per capta no mundo (2017)

Figura 15 - Trajetórias previstas de emissões em diversos cenários de políticas climáticas

Figura 16 - Evolução da utilização das termelétricas a carvão desde 2016 


\section{LISTA DE QUADROS}

Quadro 1 - Características dos quatros caminhos escolhidos

Quadro 2 - Resumo das principais características para o setor energético 


\section{LISTA DE SIGLAS}

AOGCM Atmosphere-Ocean General Circulation Model

AIE Agência Internacional de Energia

AR5 Fifth Assessment Report

AR6 Sixth Assessment Report

BAU Business as Usual

BNEF Bloomberg New Energy Finance

CCS Captura e Estocagem de Carbono

CCUS Captura, Estocagem e Uso de Carbono

CMIP Projeto de Intercomparação de Modelos Climáticos Acoplados

EROI Energia Retornada sobre Energia Investida

FAR First Assessment Report

FV Fotovoltaica

GEE Gases de Efeito Estufa

GCM General Circulation Model

IAM Modelos de Avaliação Integrados

IIASA International Institute for Applied Systems Analyses

IPCC Painel Intergovernamental sobre Mudanças Climáticas

IRENA Agência Internacional de Energia Renovável

NGFS Network for Greening the Financial System

NOC Empresa Nacional de Petróleo

NREL National Renewable Energy Laboratory

OMM Organização Mundial de Meteorologia

PNUMA Programa de Meio Ambiente da Organização das Nações Unidas 
RCP Representative Concentration Pathways

SAR Second Assessment Report

SRES Relatório Especial sobre Cenários de Emissões

SSP Shared Socioeconomic Pathways

TAR Third Assessment Report

TCFD Task Force on Climate-related Financial Discourse

VANTS Veículos Aéreos Não Tripulados

WEF World Economic Forum

WEO World Energy Outlook 
SUMÁRIO



2 Pergunta De Pesquisa E Hipotese .................................................... 18

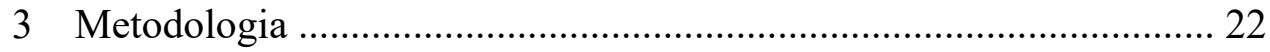

4 Modelos E Cenários - Como o clima é estudado e são simuladas as mudanças climáticas................................................ 24

4.1. Modelagem Climática .................................................................. 24

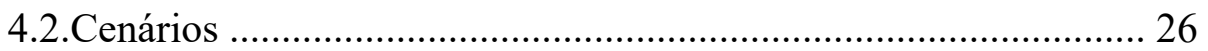

4.3. Breve Histórico do uso de cenários pelo IPCC …........................ 27

4.4. Os Cenários Atuais do IPCC ......................................................... 31

4.5. O RCP8.5 - Histórico e Premissas ............................................... 37

5 A Transição Energética Em Curso...................................................... 42

5.1. Eletrificação do Setor Energético ............................................... 47

5.2. Descarbonização da Eletricidade ................................................... 50

5.3. A Transição Energética Está Acontecendo ................................. 52

5.3.1. Estoques vs. Fluxos .................................................... 52

5.3.2. O Desenvolvimento Tecnológico no Setor Energético .... 54

5.3.3. O Papel das Políticas Públicas .......................................... 64

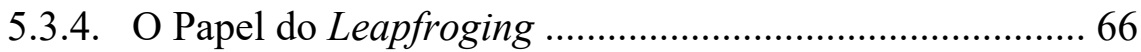

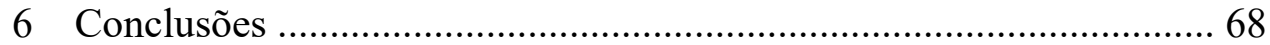

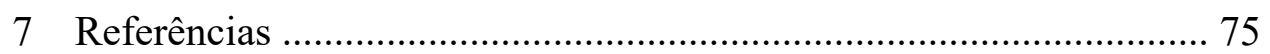




\section{INTRODUÇÃO}

Os fatos básicos sobre as mudanças climáticas já são claros há algum tempo: queimar combustíveis fósseis produz dióxido de carbono, o que altera a composição química da atmosfera e faz com que ela retenha mais calor do sol em um processo chamado de efeito estufa. A queima de combustíveis fósseis não é a única causa das mudanças climáticas, as emissões provenientes da mudança do uso da terra e da agropecuária também contribuem de forma significativa, porém a combustão dos combustíveis fósseis representa mais de $2 / 3$ das emissões antropogênicas totais (UNEP, 2019).

Os cientistas que estudam o clima e suas mudanças utilizam modelos computacionais sofisticados para gerar cenários que possam mostrar possíveis futuros climáticos. Há alguns anos o cenário mais pessimista entre os atuais publicados pelo Painel Intergovernamental sobre Mudanças Climáticas (IPCC) vem se tornando o mais utilizado na comunicação com a sociedade em geral pois este cenário, chamado de RCP8.5, ficou conhecido como o cenário Business as Usual (BAU). Isto porque ele foi definido dessa forma no artigo (RIAHI et al., 2011) no qual foi apresentado à comunidade científica. Contudo, esta definição dentro do IPCC tem um significado preciso: um cenário que não inclui nenhuma política de mitigação climática ao longo de toda o período de projeção, diferente da interpretação mais comum, de situação onde tudo seguirá como sempre.

Este cenário, como qualquer outro, se apoia em premissas. E, assim como modelagem cientifica é feita com intuito de compreender propriedades mais do que prever resultados específicos, a utilização dos cenários do IPCC com o conhecimento das premissas que estão por trás dele traz uma melhor compreensão do que está acontecendo, de quais aspectos estamos melhorando ou piorando, de próximos passos e novos indicadores necessários.

Conhecer estas premissas e validá-las periodicamente, uma vez que foram pensadas para um horizonte de 100 anos, é importante para podermos recalibrar que ações e investimentos devem ser prioritários na mitigação das mudanças climáticas. Questionar as premissas do RCP8.5 não é questionar se a Terra está esquentando (porque está), ou se sabemos o que está causando este aumento (por que sabemos), ou até mesmo se temos as tecnologias para alterar esta trajetória (porque provavelmente já temos) e sim como concentrar esforços de mitigação que precisam ser adaptados à realidade com o decorrer do tempo.

Em 2018 surgiu no Twitter uma discussão entre modeladores energéticos e consultores de energia a respeito da utilização do RCP8.5, uma vez que eles consideravam suas premissas desatualizadas e improváveis. Para contra argumentar com este grupo, um conjunto de 
modeladores climáticos, incluindo modeladores ligados ao IPCC, trouxe seus argumentos para o debate dentro da própria plataforma.

Controvérsias são a alma do método científico. No campo das mudanças climáticas uma das mais recentes é a que se deu a partir da publicação de Jacobson et. al. (JACOBSON et al., 2015) onde os autores afirmam que a descarbonização profunda, ou seja $100 \%$ do setor energético não só é possível, mas também é possível a baixo custo. Em 2017, uma coalização de pesquisadores (CLACK et al., 2017) de diversas áreas ligadas ao setor energético publicou outro artigo no mesmo periódico, o PNAS, refutando o anterior e mostrando que só seria possível chagar a um sistema energético sem emissões de Gases de Efeito Estufa (GEE) utilizando uma gama maior de tecnologias e com alto custo, principalmente para atender os últimos $20 \%$ da demanda. Após uma série de réplicas e tréplicas em periódicos revisados por pares, a controvérsia só foi encerrada em 2018 após um processo por danos morais movido, e posteriormente retirado, por Jacobson.

Em 2019, foi publicado uma série de artigos em blogs e sites (HAUSFATHER, 2019; LIBREICH, 2019; PIELKE JR., 2020) a respeito da necessidade de atualização nas premissas energéticas, que diminuiria a importância do RCP8.5 para fins de políticas públicas e comunicação com o público em geral.

Hausfather e Peters (2019) apresentaram o argumento para o público acadêmico em um artigo intitulado "Emissions - the 'business as usual' story is misleading [Emissões - a história "business as usual" é enganosa, em tradução nossa]. Neste artigo, os autores propõem que a iminente conclusão dos estudos e a publicação do $6^{\circ}$ relatório de avaliação (AR6) do IPCC, que deverá ser lançado em 2021, seja utilizada como uma oportunidade para a atualização destas premissas e da linguagem utilizada para descrever os cenários. Isso porque as trajetórias de emissões atuais foram publicadas mais de uma década atrás e são baseadas em tendências observadas na época, utilizadas como premissas de cenários qualitativos, quantificadas e projetadas para quase cem anos. Em seguida eles argumentam que o cenário RCP8.5 foi originalmente desenvolvido para explorar um futuro pouco provável e altamente arriscado, mas atualmente é usado de forma deturpada por alguns cientistas, formuladores de políticas públicas, consultorias globais, como a Mckinsey (WOETZEL et al., 2020), e parte da mídia como o cenário mais provável caso não haja nenhuma ação de descarbonização. Além disso, os autores apontam que esse cenário é usado em abundância pelo fato de ser extremo e, portanto, produzir os maiores contrastes nas pesquisas em geral, o que diminui a atenção e os estudos dos cenários intermediários que eles consideram mais prováveis (HAUSFATHER; PETERS, 2019, p. 620). 
Schwalma et al. (2020) rebatem as afirmações de Hausfather e Peters (2019) sendo seus principais argumentos: as emissões atuais são semelhantes às projetadas pelo RCP8.5 - apenas 1\% de discrepância; mesmo que aconteçam reduções das emissões do setor energético, as emissões da mudança do uso do solo do RCP8.5 foram subavaliadas; alguns feedbacks naturais, que não possuem ciência bem estabelecida, não foram incluídos; e, o mais relevante para o tema em discussão nesta dissertação, eles afirmam que ${ }^{1}$ (tradução nossa ${ }^{2}$ ):

“as premissas em que se apoia o RCP8.5 são de crescimentos econômico mais rápido, superestima a intensidade de carbono da economia, superestima agressivamente o uso de carvão, e precifica de forma excessiva os recursos renováveis em relação aos combustíveis fósseis (...) No entanto, essas diferenças ainda não estão em um limiar que degrade substancialmente as semelhanças entre as emissões cumulativas totais de $\mathrm{CO}_{2}$ e as estimadas pelo cenário de políticas atuais da AIE até meados deste século (...) Dada a similaridade das emissões históricas entre 2005 e 2020 e as projetadas pelo RCP8.5; e a congruência entre as emissões projetadas do cenário de políticas atuais da AIE e as do RCP8.5 até meados do século, o RCP8.5 continua tendo utilidade como um instrumento para explorar tanto os efeitos climáticos prováveis, bem como os riscos associados"

Schwalm, Glendon e Duffy (2020) exemplificam bem a discussão proposta nesta dissertação pois colocam os cenários do IPCC como centrais na formulação de políticas públicas, principalmente no curto e médio prazo, e, embora admitam certas falhas na modelagem original, como as emissões provenientes da mudança do uso da terra ${ }^{3}$, não veem a necessidade de atualização das premissas em relação ao setor energético.

Embora a discussão citada acima esteja acontecendo entre modeladores climáticos e energéticos, esta é uma discussão que tem implicações para a sociedade em geral. Muitos artigos científicos são produzidos sobre impactos do RCP8.5 e, através da mídia, chegam ao público amplo. Dois exemplos recentes de artigos publicados em revistas acadêmicas e depois na mídia exprimem esta visão: XU et al, 2020 - e a reportagem a respeito publicada no portal da CNN (REGAN, 2020) - sustentam que partes importantes da Terra estarão demasiado quentes para sustentar a vida em 2070. Na mesma linha, Carleton et al., 2020 - e a reportagem publicada no The Guardian (MILMAN, 2020) argumentam que a mortalidade devido ao clima pode superar a mortalidade somada de todas as doenças infecciosas atuais.

\footnotetext{
1 “.... anticipated trends the stylized facts underpinning RCP8.5 show faster economic growth, overestimates in carbon intensity, overaggressive coal use, and overpricing renewables relative to fossil fuels (...) However, these issues are not yet at the threshold to substantially degrade the similarity between total cumulative $\mathrm{CO}_{2}$ emissions and current policies to midcentury. Given the agreement of 2005 to 2020 historical and RCP8.5 total $\mathrm{CO}_{2}$ emissions and the congruence be-tween current policies and RCP8.5 emission levels to midcentury, RCP8.5 has continued utility, both as an instrument to explore mean outcomes as well as risk.

${ }^{2}$ Em caso de original em língua estrangeira a tradução será sempre nossa.

${ }^{3}$ Embora esta diferença de modelagem de emissões provenientes de mudanças do uso da terra seja bastante importante para o Brasil uma vez que nossas emissões são predominantemente provenientes daí, esta análise está fora do escopo desta pesquisa.
} 
Em termos científicos, as comunidades epistemológicas dos modeladores climáticos e energéticos precisam encontrar ferramentas e metodologias que atendam a ambos devido à grande interdependência entre estes dois fatores. Em termos de políticas públicas, compreender as discrepâncias entre o que está acontecendo, tanto em mudanças tecnológicas quanto na trajetória das emissões, e as premissas originais permite orientar e reorientar investimentos e decisões de políticas públicas. Em termos de organizações da sociedade civil, utilizar este cenário sem reavaliar as premissas pode levar, de um lado, à não-cobrança de ações prioritárias e, de outro, a aceitação de esforços demasiado pequenos pois é possível que muito pouco seja necessário para ficar aquém dos resultados extremos esperados pelo cenário.

Do lado das corporações existem mais incentivos hoje em dia para a utilização desde cenário em seu planejamento. Um exemplo é a orientação da Task Force for Climate Related Disclosures (TCFD), organização criada pelo Conselho de Estabilidade Financeira para melhorar a transparência e gestão dos riscos financeiros ligados às mudanças climáticas, utilizando cenários públicos e, de preferência, revisados por pares para que as empresas avaliem seus riscos (figura 1).

Figura 1: Relatório de cenário climático da AES utilizando as indicações da TCFD

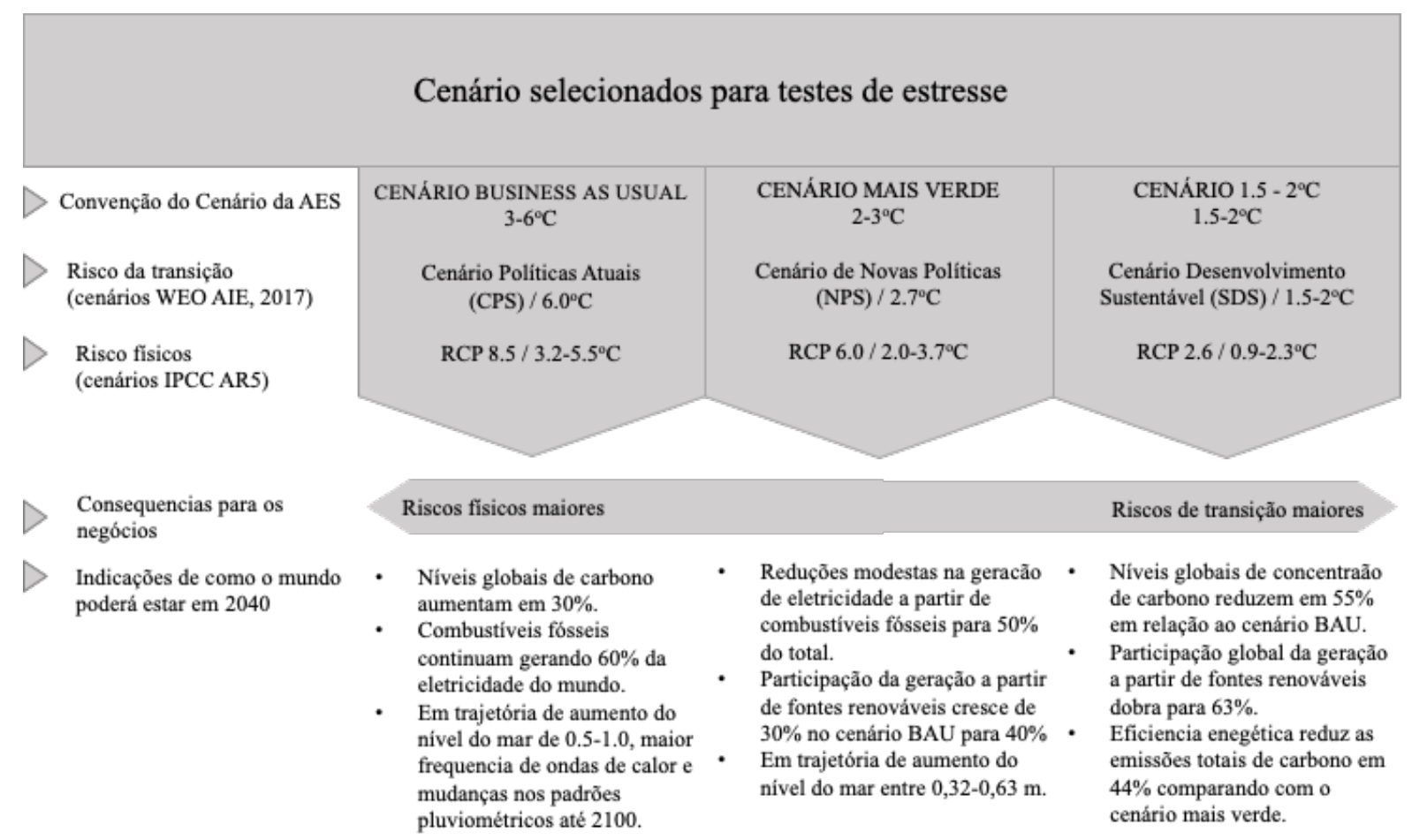


Além disso, em 2020, o Global McKinsey Institute lançou um relatório (GLOBAL MCKINSEY INSTITUTE, 2020) voltado às empresas sobre os riscos físicos do RCP8.5. Este relatório foi produzido com a ajuda de cientistas climáticos do Woods Hole Research Institute, incluindo os autores do texto citado acima de Schwalm, Glendon e Duffy (2020).

Em grande medida, a utilização de cenários climáticos pelas organizações e consultorias parte da recomendação feita pelo TCFD (2017) e é parte de uma busca por mecanismos de mercado que ajudariam na implementação de estratégias de mitigação, uma vez que esta transparência e análise dos riscos permitiriam a precificação destes (CHENET; RYANCOLlinS; VAN LERVEN, 2020). Porém, como notou a Network of Central Banks and Supervisors for Greening Finance (NGFS), grande parte dos cenários climáticos públicos existentes, incluindo os do IPCC, foram feitos visando cientistas e decisões de políticas públicas e não são adequados para empresas e o sistema financeiro em geral, por isso eles estão produzindo novos cenários de referência mais adequados a este fim. Estes novos cenários são considerados mais apropriados pois abarcam não só os riscos físicos das mudanças climáticas, mas também incluem os riscos da transição para uma economia mais limpa, como a possibilidade de stranded assets e seus impactos financeiros. Além disso, o horizonte dos cenários do IPCC é muito mais longo, até 2100, do que os dos cenários comumente utilizados pelo setor, que em geral são de 1 a 5 anos (CHENET, 2019; NGFS, 2020).

$\mathrm{O}$ princípio da precaução (PP) preconiza que frente a riscos tão extremos como o aumento de temperatura em mais de $5^{\circ} \mathrm{C}$, a atitude é evitar o cenário mais extremo. Ele opera onde há incerteza cientifica, como diz o item 15 da declaração de princípios da Conferência das Nações Unidas (CONFERÊNCIA DAS NAÇÕES UNIDAS SOBRE O MEIO AMBIENTE E DESENVOLVIMENTO, 1992) realizada no Rio, em 1992:

"de modo a proteger o meio ambiente, o princípio da precaução deve ser amplamente observado pelos Estados (...) Quando houver ameaça de danos sérios ou irreversíveis, a ausência de absoluta certeza científica não deve ser utilizada como razão para postergar medidas eficazes (...)".

No entanto, o PP não é uma rejeição à avaliação de riscos e sim incita a uma avaliação deliberada e exaustiva das trajetórias das políticas públicas e das tecnologias (STIRLING, 2007). Ele ressalta a necessidade de "atenção mais explícita, cientificamente rigorosa e socialmente sofisticada às implicações do conhecimento incompleto" (FUNTOWICZ e RAVETZ 1990, tradução nossa). 
Por isso, mesmo que a discussão atual sobre premissas de modelos matemáticos seja eminentemente uma discussão entre campos científicos e que basear as medidas de mitigação e adaptação sempre tentando conhecer o pior cenário possível seja o mais adequado, a necessidade de atualizar constantemente as premissas para que elas representem nosso melhor entendimento do processos climáticos e das fontes das emissões é fundamental e serve de justificativa para esta dissertação. 


\section{PERGUNTA DE PESQUISA E HIPÓTESE}

Desde o projeto de pesquisa original, este mestrado buscou compreender vários aspectos tecnológicos da transição energética e seus impactos na mitigação das mudanças climáticas. Durante a pesquisa duas afirmações relativas ao tema apareceram de forma recorrente:

a) transições energéticas tomam muito tempo e;

b) precisam de muito investimento e políticas públicas adequadas.

O investimento público e a implementação de políticas públicas envolvem decisões baseadas em três atributos interligados (CASH, 2003): credibilidade, saliência e legitimidade. Os relatórios do IPCC possuem credibilidade, legitimidade e a saliência do cenário RCP8.5 vem aumentando. Desta forma conhecer as premissas energéticas deste cenário e atualizá-las foi considerado um tema fundamental dentro do objeto de pesquisa inicial. As possibilidades de pesquisa dentro das premissas são variadas e incluem as premissas gerais de crescimento econômico e populacional com direto impacto na demanda por energia; premissas de geopolítica com direto impacto na difusão tecnológica; premissas sobre as emissões da mudança do uso da terra e as diversas premissas dentro do setor energético.

A escolha final foi por um trabalho que, de um lado aumentasse o conhecimento a respeito de como são feitos os modelos climáticos, os cenários do IPCC e a importância destas premissas básicas, já que se trata de um tema bastante técnico; e, por outro, a premissa escolhida trata de um dos pontos chaves da transição energética atualmente em curso, ou seja a velocidade da inovação e a queda de custo das fontes renováveis de energia frente aos combustíveis fósseis.

Desta maneira, a pergunta de pesquisa desta dissertação é:

A premissa do cenário RCP8.5 do IPCC sobre o setor enérgico, que afirma que haveria pouca inovação na geração de energia de fontes de baixa emissão e carbono, continua válida quase 1 década após sua publicação?

A hipótese a ser testada é:

O cenário RCP8.5, o mais extremo dos quatro atualmente adotados pelo IPCC, é baseado em uma série de premissas, entre elas a premissa de que no decorrer do século XXI, o setor energético promoverá pouca inovação na geração de energia de baixa emissão de carbono e dada a atual transição energética esta premissa não encontra correspondência na realidade. 
É importante ressaltar que se trata de um trabalho de pesquisa sobre o setor energético, a transição energética e as premissas adotadas sobre o setor no cenário mais pessimista do IPCC. Não é possível afirmar que as concentrações seguirão ou não qualquer das trajetórias descritas nos cenários do IPCC, inclusive o IPCC não adota probabilidades entre seus cenários. Vale lembrar que além das premissas sobre o setor energético existem várias outras como a sobre a trajetória das emissões provenientes das mudanças no uso da terra e crescimento populacional. 


\section{METODOLOGIA}

Esta pesquisa foi desenvolvida utilizando metodologia qualitativa. Segundo Creswell (2010) este tipo de pesquisa é apropriado quando o problema de pesquisa precisa ser explorado e quando um entendimento complexo é necessário. Minayo (1993, p.23), considera a pesquisa como "atividade básica das ciências na sua indagação e descoberta da realidade. (...) É uma atividade de aproximação sucessiva da realidade que nunca se esgota”.

Foi utilizada como metodologia principal a pesquisa bibliográfica. Segundo Boccato (2006, p. 266) “a pesquisa bibliográfica busca a resolução de um problema (hipótese) por meio de referenciais teóricos publicados, analisando e discutindo as várias contribuições científicas". A revisão bibliográfica feita, entretanto, não tem caráter de revisão completa ou sistemática da literatura.

Por se tratar de uma dissertação que busca compreender aspectos bastante técnicos da ciência que desenvolve modelagem climática e o impacto desta ciência sobre a formulação de políticas públicas e da comunicação com a sociedade através de diversos canais, um dos maiores desafios foi a tradução de conceitos bastantes técnicos, tanto da área de modelagem de clima como da área de energia em geral, para uma linguagem muito mais acessível ao pesquisador das ciências sociais, das políticas públicas e da comunicação em geral. As mudanças climáticas, em especial vistas através dos relatórios do IPCC, são um assunto com uma forte base nas ciências da natureza, com muita linguagem matemática, jargões próprios e que existe dentro de um processo único de fronteira entre ciência e políticas públicas (BECK E MAHONNY, 2018). Por isso, grande parte do esforço desta dissertação se concentrou em fazer esta ponte entre diferentes conhecimentos técnicos e a possibilidade de utilização destes conhecimentos por todos os interessados.

Não se trata, entretanto, de fazer comunicação científica que "compreende a utilização de recursos, técnicas, processos e produtos (veículos ou canais) para a veiculação de informações científicas, tecnológicas ou associadas a inovações ao público leigo" (BUENO, 2009, p.162). E sim, a partir deste esforço de compreensão da literatura e de conceitos em um campo acadêmico, poder fazer as análises necessárias para compreender o problema em outro campo das ciências.

Um outro aspecto que diferencia esta revisão da literatura de uma revisão mais sistemática é o uso de literatura cinzenta (grey literature) que é aquela que não é revisada por pares. Este tipo de literatura é produzido em vários níveis de governos, na academia, em corporações, think thanks, nas diversas indústrias, etc. O próprio IPCC inclui em suas diretrizes 
a aceitação deste tipo de literatura pois nela podem ser encontradas informações extremamente relevantes, contudo, seu uso requer cuidados especiais (WGI TECHNICAL SUPPORT UNIT, ). Lawrence et al. (2014) afirmam que a formulação de políticas públicas se apoia cada vez mais em uma ampla gama de recursos, como relatórios, revisões, data sets, White papers, etc. produzidos por governos, pela academia, por organizações não governamentais e pela sociedade em geral. No caso desta pesquisa foram utilizados diversos relatórios produzidos pela Agência Internacional de Energia, entidade que reúne periodicamente a maior e mais relevante base de dados sobre energia mundial; da IRENA, Agencia Internacional de Energia Renováveis; de think tanks reconhecidos na área de energia como Energy Transition Comission, Rocky Mountain Institute Carbon Tracker; da consultoria especializada em finanças e transição energética Bloomberg New Energy Finance (BNEF); entre outros.

Por fim, como a dissertação busca mostrar como o momento atual da transição energética influencia a validade das premissas do cenário descrito, a busca por informações recém-publicadas torna certos relatórios de consultorias, reportagens de jornais e revistas não acadêmicos e da própria indústria do setor energético relevantes.

A dissertação está organizada em dois grandes blocos. O primeiro bloco, que corresponde ao capítulo 4, trata do papel dos modelos e cenários para o avanço da ciência sobre as mudanças climáticas, do papel do IPCC na revisão da literatura de cenários, no histórico dos cenários publicados pelo IPCC para finalmente chegar ao cenário RCP8.5 e suas premissas em relação ao setor energético e sobre a inovação. No segundo bloco, capítulo 5, será discutida a transição energética atual e a inovação no setor. Para isso, serão levantados conceitos que ajudam a compreender e definir a transição em curso, seguido de uma análise feita a partir de quatro eixos definidos por estudo do Fórum Econômico Mundial (WEF, por suas iniciais em inglês) sobre a velocidade da transição energética.

Por fim, será feita uma discussão do levantado seguido de indicações para próximos estudos. 


\section{MODELOS E CENÁRIOS - COMO O CLIMA É ESTUDADO E SÃO SIMULADAS AS MUDANÇAS CLIMÁTICAS}

Compreender e prever o clima e as mudanças climáticas são grandes desafios científicos devido à quantidade de sistemas interconectados, incluindo atmosfera, oceanos, criosfera, biosfera e superfícies terrestres e sistemas sociais que precisam ser estudados em conjunto. Devido a esta complexidade e às diversas escalas envolvidas, este é um problema científico que não pode ser estudado de forma experimental. Então, o clima e seus componentes são estudados a partir da utilização de modelos computacionais para simulações (SCHMIDT; SHERWOOD, 2015).

Não existe uma definição estabelecida para clima na literatura (WERNDL, 2016), mas em geral as definições utilizadas envolvem uma distribuição de variáveis físicas no tempo. Para o estudo das mudanças climáticas é mais importante que o valor de alguma variável referente ao clima em um certo momento no tempo do que a distribuição desta variável para uma dada configuração dos sistemas que compõe o clima (idem). Pela necessidade de compreender os mecanismos e as propriedades que definem o clima é necessário levantar estas variáveis ao longo da história da Terra. Os conhecimentos sobre o clima são desenvolvidos a partir de conhecimentos sobre o passado climático da Terra.

A humanidade há muito tempo observa e anota dados sobre o clima e o tempo. A ciência do clima atual recupera, calibra e utiliza estes dados de estações meteorológicas (EDWARDS, 2010, p. xiv). Além disso, à medida que novas maneiras de levantar o passado climático da Terra são descobertas, mais dados são produzidos e agregados a estes modelos matemáticos. Exemplos destas novas formas de levantar dados sobre o clima no passado são medidas extraídas de eventos que dependem fortemente de condições climáticas como os anéis de crescimento de árvores e a análise das características dos núcleos de gelo extraídos da Antártida.

\subsection{Modelagem climática}

Os primeiros trabalhos de modelagem climática aconteceram na segunda metade do século XX e desde então os modelos climáticos cresceram muito em complexidade e escopo. Este crescimento aconteceu tanto pelo amadurecimento das pesquisas sobre as interações dos vários sistemas que compõem o clima quanto pelo desenvolvimento de computadores cada vez mais rápidos e potentes, capazes de executar os enormes cálculos necessários.

Os modelos climáticos possuem três tipos de componentes: o primeiro são princípios científicos bem estabelecidos (conservação de massa, energia, etc), o segundo são 
aproximações de fenômenos físicos bem compreendidos e o último são as parametrizações de processos climáticos ainda não resolvidos (SCHMIDT; SHERWOOD, 2015). O desenvolvimento constante dos modelos climáticos busca melhorar estes dois últimos componentes, aumentando a fidelidade das aproximações e buscando parametrizações mais bem-sucedidas ou mesmo a diminuição da necessidade de parametrização (idem). Parametrização é o termo utilizado para descrever uma parte fundamental da modelagem climática que consiste em encontrar parâmetros que substituem varáveis naturais não conhecidas. Nos modelos esses parâmetros substituem essas variáveis de forma que o modelo consiga rodar e representar ocorrências naturais. Além destes três componentes, os modelos necessitam de ajustes finos (tuning em inglês) que buscam minimizar pequenos erros em variáveis-chaves.

Em 1980 a Organização Mundial de Meteorologia estabeleceu o World Climate Research Programme (WCRP) cujo objetivo é coordenar as diversas iniciativas de pesquisa sobre o clima. Desde 1995 o Projeto de Intercomparação de Modelos Climáticos Acoplados (CMIP, pela sua sigla em inglês) organiza e define protocolos de experimentos com os objetivos de facilitar a comparação entre modelos e de simplificar a validação dos modelos existentes. Desta maneira é possível entender que diferenças nos resultados de diferentes modelos se devem às formas de modelagem alternativas utilizadas e estas diferenças podem ser analisadas e estudadas para aprofundar conhecimentos e no processo de melhoria contínua dos modelos (WCRP, 2020).

Os principais modelos utilizados para o estudo do clima são os modelos gerais ou globais de circulação (GCM, por suas iniciais em inglês). Esta categoria engloba modelos de balanço de energia, modelos radiativo-convectivos e vários outros. Embora os modelos GCM já tenham surgido complexos novos modelos e mais informações continuam sendo agregadas. Os modelos são construídos e, antes de serem utilizados para prever o clima futuro, precisam ser capazes de replicar o clima atual ou passado (WARNER, 2011) utilizando dados existentes. Hoje em dia os principais modelos são os AOGCM ou modelos acoplados da atmosfera e dos oceanos.

Apesar de existirem novos modelos sendo permanentemente desenvolvidos hoje em dia grande parte dos modeladores utilizam modelos já testados pela comunidade cientifica e fornecidos sem custos, com documentação completa, tutoriais etc. (idem). Modelo é o código, as equações e as premissas inscritos nele e simulação é cada uma das rodadas deste modelo utilizando variações, embora as definições sejam muitas vezes utilizadas de forma 
intercambiável (DOWLING, 1999). A simulação computacional climática imita um processo natural através de outro processo matemático (HARTMANN, 1996).

Para que estes modelos possam ser rodados são necessários dados de entradas. No caso das mudanças climáticas um dos dados fundamentais utilizado é a projeção das emissões de gases de efeito estufa. Isto ocorre pois este é o principal fator que altera o forçamento radiativo ou a perturbação do equilíbrio entre a energia que entra e a que sai de um sistema climático,no caso da Terra. Estes dados de emissões futuras saem de resultados de cenários construídos com este fim.

\subsection{Cenários}

Cenários são "esforços de fazer descrições plausíveis e consistentes de situações futuras possíveis, apresentando os condicionantes do caminho entre a situação atual e cada cenário futuro, destacando os fatores relevantes às decisões que precisam ser tomadas" (WRIGHT; SPERS, 2006; BORJESON et al., 2006; MOSS et al., 2010). O termo cenário engloba uma série de técnicas bastante variadas e a referência inicial mais comumente citada para seu uso em simulações e tomada de decisão é o trabalho de KAHN e WIENER (1967) e o planejamento da Shell a partir da crise do petróleo de 1973.

Borjeson et al (2006) desenvolveu uma tipologia para classificar os cenários em três tipos: preditivos, exploratórios e normativos (figura 2).

Figura 2: Tipologia para classificação de cenários
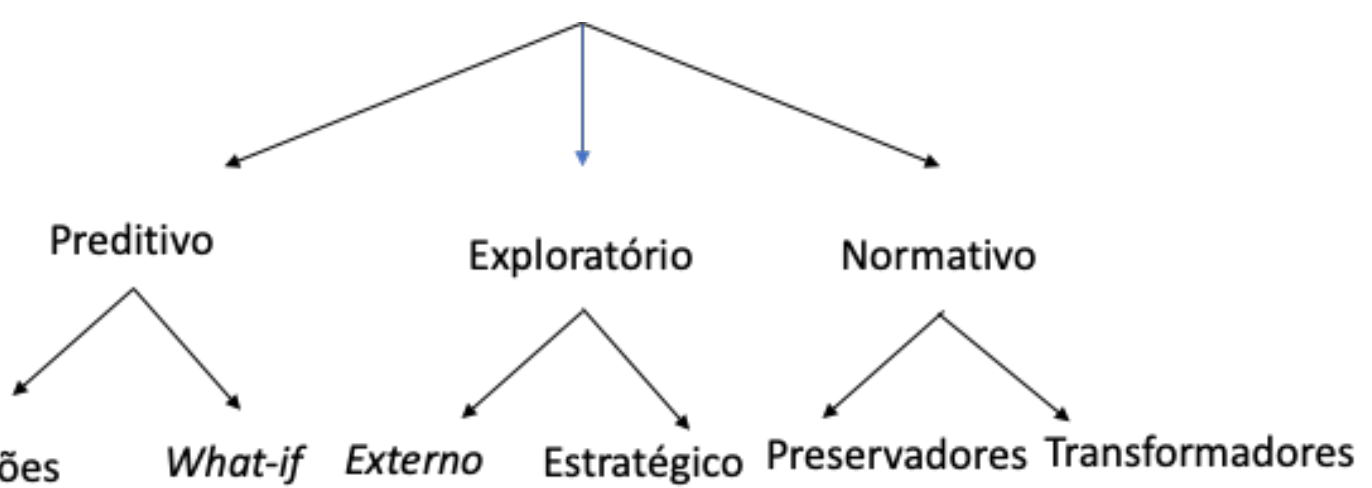

Projeções What-if Externo Estratégico Preservadores Transformadores

Fonte: Borjeson et. al, 2006, tradução nossa

Os cenários preditivos respondem a perguntas do tipo “O que vai acontecer?”. São cenários construídos principalmente para que se possa planejar e adaptar a situações que devem ocorrer caso as condições estudadas sejam atingidas. Cenários do tipo "what if" investigam o 
que ocorrerá se algumas condições específicas de grande impacto para o futuro ocorrerem a curto prazo (idem; VAN VUUREN et al., 2011).

Cenários exploratórios são cenários que respondem à pergunta “O que pode acontecer?" Eles são construídos visando longo prazo e buscando compreender os impactos de mudanças mais profundas (BORJESON et al., 2006).

Por fim, cenários normativos respondem a perguntas do tipo "Como podemos chegar a um certo resultado?”. Estes cenários desenham um objetivo futuro e buscam caminhos possíveis e decisões no presente que levariam a este resultado.

Cenários não devem ser confundidos com previsões uma vez que eles tratam de descrições plausíveis normalmente a longo prazo. Previsões costumam ser feitas em casos onde o sistema é bem conhecido e bem definido, o que não é o caso dos cenários climáticos a longo prazo como os feitos para analisar as mudanças climáticas (VAN VUUREN, 2012). A técnica de elaboração de cenários pode ser qualitativa ou quantitativa ou utilizar ambas abordagens incluindo storylines que trazem uma lógica em elementos que não podem ser puramente quantitativos.

Os Modelos de Avaliação Integrado (IAM por sua sigla em inglês) são um subgrupo de cenários que incluem aspectos sociais em modelos climáticos simples, simulando como população, crescimento econômico e uso de energia interagem com o clima. Estes IAMs geram cenários que projetam como as emissões de GEE podem variar no futuro. Eles têm um papel fundamental na integração entre diferentes comunidades científicas ao criar uma base comum a partir da qual são possíveis várias análises que podem ser comparadas e contrastadas.

A elaboração de cenários se tornou uma parte essencial na pesquisa e avaliação sobre mudanças climáticas (RIAHI et al., 2017; O’NEILL et al., 2017; MOSS et al, 2010) assim como na caracterização dos riscos para a sociedade e das respostas possíveis (O’NEILL et al. 2017).

\subsection{Breve histórico do uso de cenários pelo IPCC}

O IPCC foi formado em 1998 como uma organização híbrida pois nasceu a partir da demanda de uma organização cientifica - a Organização Mundial de Meteorologia (OMM) - e de uma organização multilateral - o Programa de Meio Ambiente da Organização das Nações Unidas (PNUMA). O Painel tem como mandato a preparação de relatórios de acompanhamento da ciência sobre todos os aspectos das mudanças climáticas e seus impactos com o objetivo de formular estratégias realistas de respostas. Para lidar com a complexidade e a diversidade das 
áreas de conhecimentos envolvidas na análise das mudanças climáticas o IPCC criou uma organização tripartite com três grupos de trabalhos (ORESKES, 2015), um com foco nas ciências físicas ou naturais, outros dois com foco nas ciências sociais e políticas públicas respectivamente. Desde sua fundação o IPCC reconheceu que as mudanças climáticas não são apenas um problema que deve ser abordado somente pelas ciências naturais, pois envolve a interação entre o sistema do clima e as atividades humanas.

Os conhecimentos acumulados e organizados nos relatórios de acompanhamento da literatura científica são repassados para os governos para servirem de base a políticas públicas. Parte importante deste processo é a caracterização da incerteza pois esta palavra "é carregada de significado e associada a diversas visões sobre a relação ciência e políticas públicas" (OPPENHEIMER et al., 2019 p. 197). Justamente para evitar fazer prescrições e sofrer resistência por parte dos políticos aos processos de avaliação científica os cientistas passaram a utilizar cenários como base dos processos de avaliação da literatura cientifica, como o do IPCC, a partir dos relatórios sobre a camada de Ozônio (idem p. 183).

Desde seu primeiro relatório de acompanhamento o IPCC utiliza cenários para suas análises. Atualmente o IPCC está no seu sexto ciclo de avaliação da literatura e o seu Sexto Relatório de Acompanhamento (AR6) deverá ser lançado em 2021. Para o primeiro relatório, o chamado First Assessment Report ou FAR, publicado em 1990, foi desenvolvido um conjunto de 4 cenários (chamados de A, B, C e D) conhecido como SA90. Para o segundo (SAR) e terceiro relatórios (TAR), publicados em 1995 e em 2001 respectivamente, foi desenvolvido um novo conjunto de 6 cenários (chamados de ISa, ISb, ISc, ISd, ISe e ISf), o IS92 devido ao ano da publicação dos cenários, 1992.

Em 2000 o IPCC lançou um relatório especial chamado Relatório Especial sobre Cenários de Emissões (SRES por sua sigla em inglês). Embora estes cenários já não sejam os atualmente em uso este é o único relatório específico sobre cenários publicado pelo IPCC e o último que foi desenvolvido pelo Painel pois, a partir dele, o Painel passou a apenas avaliar os cenários existentes e apontar alguns como referência. Ou seja, deixou de produzir ciência para voltar a sua missão inicial de apenas acompanhar a ciência produzida pelos modeladores e cenaristas.

O SRES foi feito após a revisão dos cenários publicados anteriormente. Esta revisão chegou à conclusão que, apesar de inovadores na época de seu lançamento, os cenários utilizados na época pelo IPCC poderiam ser melhorados em alguns pontos. Algumas das correções sugeridas foram ajustes sobre a evolução de políticas públicas e de aspectos 
socioeconômicos - como a diminuição da desigualdade entre países desenvolvidos e os em desenvolvimento e a rápida evolução da legislação sobre gases poluentes na Europa, Japão e EUA - e de aspectos de modelagem como a utilização de uma maior gama de cenários produzidos no lugar de apenas um. No caso do IS92, o IS92a foi tratado como cenário de referência em inúmeros estudos por ser o cenário intermediário em termos de emissões de $\mathrm{CO}_{2}$, porém não era necessariamente o mais provável nem o mais central em diversas outras características como crescimento populacional e desenvolvimento econômico global (IPCC, 2000).

A partir desta revisão o IPCC montou um comitê com mais de 50 membros de 18 países para desenvolver um novo grupo de cenários seguindo uma serie de critérios e passos. Em comum com a grande maioria de trabalhos publicados sobre cenários climáticos, o relatório enfatiza que cenários não são previsões nem projeções do futuro e sim retratos alternativos de como o futuro pode se desenvolver. Cenários de emissões de GEE são baseados em premissas, internamente consistentes e reproduzíveis, sobre fatores e relações chaves derivadas do passado e da situação atual. Sempre existem grandes incertezas nos cenários como por exemplo as descontinuidades e as mudanças tecnológicas (IPPC, 2000, p. 24). Do SERS os cenários foram criados utilizando modelos quantitativos e qualitativos sendo os qualitativos chamados de storylines que foram quantificados a posteriori para serem utilizados nos modelos de GCM. Também é importante notar que os cenários não incluem em suas projeções nenhum tipo de política pública climática pois estas devem ser feitas por cientistas e formuladores de políticas utilizando os cenários publicados pelo IPCC como base.

É interessante notar que o relatório indica que não existe cenário "business as usual" ou "melhor estimativa" e que eles não foram feitos considerando grandes surpresas nem foi desenvolvido um cenário catastrófico. O número de famílias de cenários se deve justamente a não existir um cenário central (IPCC, 2000, p. 169). O relatório chega a indicar que seria melhor aprender com a história e usar a expressão "dynamics as usual”. Além disso, eles não devem ser usados como indicações de políticas públicas (IPCC, 2000, p 27). Este último ponto ilustra as considerações feitas por Oppenheimer et al (2019) sobre o uso de cenários para evitar a politização dos trabalhos do Painel.

A análise das mudanças tecnológicas para a construção dos cenários é feita a partir da teoria das Ondas de Kondratiev embora os autores deixem claro que não é possível prever nem a forma e nem as tecnologias da próxima onda tecnológica (IPCC, 2000, p. 122). 
A seção 3.4 do relatório trata de energia e tecnologia pois "a evolução futura deste setor é de crítica importância para os níveis futuros de emissões" (IPCC, 2000, p. 128). Nela são apresentadas uma série de definições do setor energético que são bastante relevantes para entender como são elaborados os modelos energéticos que são utilizados para rodar os cenários. A distinção e definição de recurso, reserva e outras ocorrências de recursos energéticos adotadas é a descrita pela empresa de petróleo BP (1996). Recursos energéticos são definidos como ocorrências consideradas potencialmente recuperáveis, com tecnologia e custos de desenvolvimentos previsíveis em um futuro próximo. Outras quantidades que não entram nesta definição, como combustíveis fósseis de alto custo e com dificuldades de extração são considerados como "outras ocorrências". As reservas são a parte dos recursos que podem ser extraídas no momento atual, com tecnologia existente e custos aceitáveis. Desta forma, as reservas são "reabastecidas" à medida que a tecnologia de extração dos recursos avança e os custos caem.

As reservas de petróleo, gás natural e até mesmo de gás de xisto e carvão foram estimadas no relatório. As maiores são as de carvão e foram estimadas em 22.9 ZJ, ou 200 vezes a produção da época, sendo considerada como a maior reserva dos combustíveis fósseis aproximadamente $47 \%$ das reservas totais (IPCC, 2000, p. 134).

Em relação às fontes renováveis, o relatório analisa as fontes mais comuns a época: hidroeletricidade e biomassa. Energia eólica ainda era muito cara e incipiente, embora o relatório aponte para a queda de preços já em curso na época da eólica offshore. O relatório, já no ano 2000, aponta a possível queda de custo das fontes eólica e solar devido as curvas de aprendizagem e também levanta o fato destas fontes serem intermitentes e a solução apresentada é que houvesse capacidade instalada de outras fontes fósseis como back-up.

O SRES produziu um conjunto de 40 cenários divididos em 4 famílias (A1, A2, B1 e B2) alternativas e 6 grupos. Cada família inclui uma parte descritiva, storyline, e um número de diferentes interpretações e quantificações para cada storyline. Para quantificar as emissões dos cenários e calcular as emissões foram utilizados 6 modelos quantitativos de diversos centros de pesquisa espelhados pela Europa, Estados Unidos e Japão.

É importante ressaltar que o SRES foi a última publicação detalhada do IPCC sobre o tema. 


\subsection{Os atuais cenários do IPCC}

Como os processos do IPCC estão sujeitos ao processo de aprovação dos países membros em quatro momentos (no desenho, na segunda revisão, na última revisão do relatório e na plenária final) sempre existiu a possibilidade de que o desenvolvimento de cenários dentro dos processos do IPCC pudesse ser de alguma forma afetado por decisões políticas. Além disso o mandato do IPCC é de avaliação da literatura científica existente e não de produção de pesquisa (MOSS et al., 2010; VAN VUURUN et al., 2012). Desta forma, o desenvolvimento de cenários para os relatórios do IPCC passou a ser feito pela comunidade cientifica após o último conjunto de cenários publicados no SRES.

MOSS et al. (2010) explicam a necessidade de uma nova geração de cenários climáticos para o Quinto Relatório de Acompanhamento (AR5) pois quase uma década de novas informações econômicas, novos desenvolvimentos tecnológicos e novas observações sobre fatores ambientais deveriam ser considerados nos cenários (idem, p. 750). O processo de preparação do SRES havia tomado quase 10 anos (idem, 751) por ter sido feito de maneira linear: os cenaristas desenvolveram os cenários, as saídas destes cenários serviram de input para os modelos climáticos e este conjunto de dados, cenários e as emissões e evolução das concentrações foi utilizado pela comunidade cientifica que analisa impactos, adaptação e vulnerabilidades. A comunidade cientifica responsável pelos novos cenários resolveu tentar um novo formato com partes do processo em paralelo (figura 3 ) para tentar fazer todo o ciclo em apenas 5 anos para o lançamento do AR5 em 2013.

Figura 3: Processo de desenvolvimento dos cenários atuais do IPCC

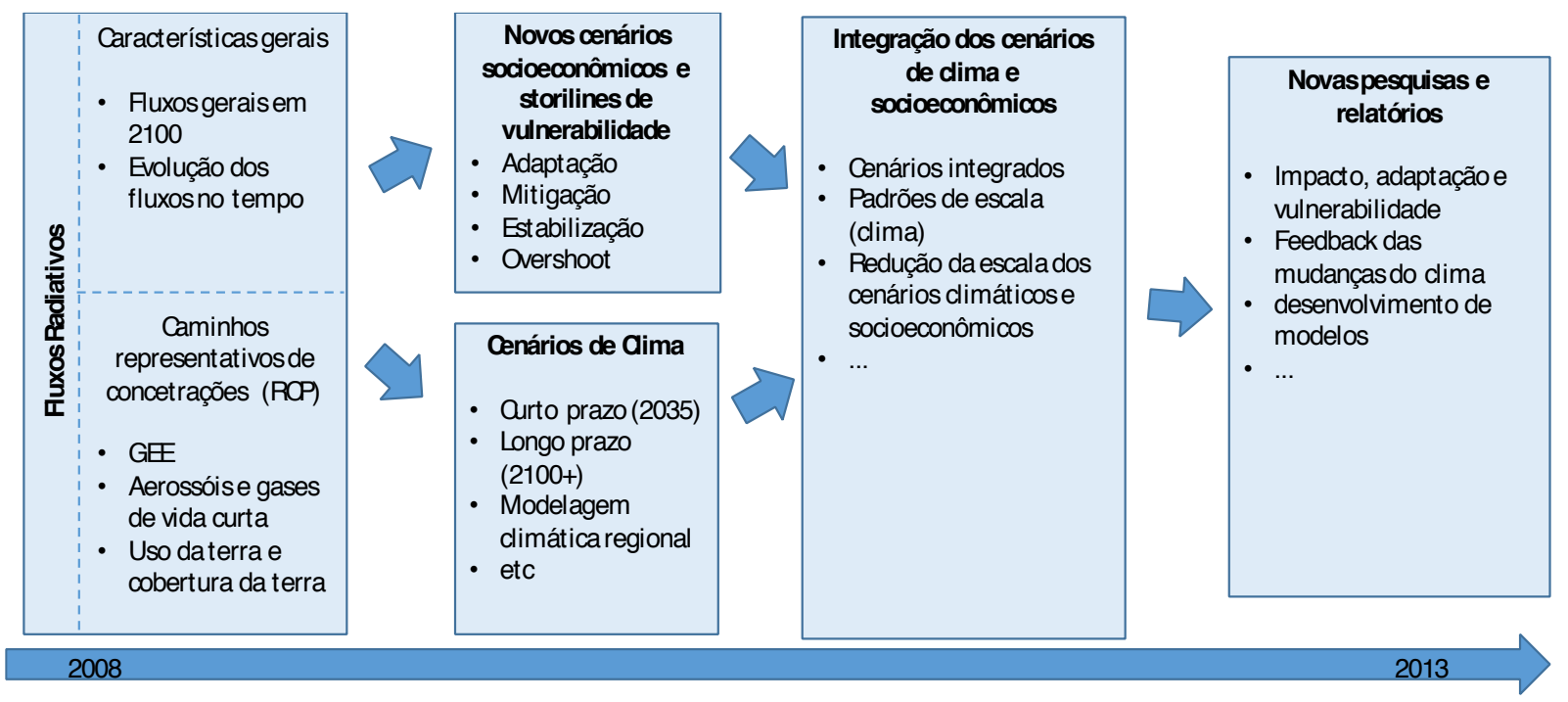

Fonte: adaptado de Moss et al. 2010 
Neste novo processo o primeiro passo seria a determinação de algumas características para os cenários sendo a mais importante delas a decisão do nível de forçamento radiativo. Para cada trajetória de forçamento radiativo inúmeras combinações de futuras trajetórias econômicas, tecnológicas, demográficas e de políticas públicas são possíveis. Como vimos acima os modelos climáticos precisam de uma série temporal de emissões futuras para usar como dados de entrada, além de alguns outros dados como cobertura vegetal para alguns modelos o que gera um processo iterativo e paralelo.

A primeira fase do processo foi então o desenvolvimento dos Caminhos Representativos de Concentrações (Representative Concentration Pathways ou RCP). Foram escolhidos quatro RCPS com fluxos radiativos diferentes entre mais de 1000 RCPs analisados (figura 4). Estes RCPs foram escolhidos dentro da literatura já revisada por pares. A nomenclatura, Caminhos Representativos de Concentrações seguidas de um número, foi escolhida para ser autoexplicativa. São caminhos, ou pathways, pois não só a concentração final é importante, mas também a evolução das concentrações de GEE na atmosfera. São Representativos pois são um de vários cenários possíveis, rodados em vários modelos possíveis e já existentes na literatura. Os números finais $2.6,4.5,6.0$ e 8.5 significam o valor total do forçamento radiativo na estabilização em $\mathrm{W}^{\mathrm{m}-2}$. Estes forçamentos foram escolhidos em parte pela necessidade de que existisse uma diferença de forçamento entre eles que respeitasse a sensibilidade dos modelos, ou seja, a diferença de forçamento mínima era predefinida.



Fonte: Fuss et al. 2014

\footnotetext{
${ }^{4}$ Tradução do original eixo x: Emissões líquidas de $\mathrm{CO}_{2}\left(\mathrm{GtCO}_{2} \mathrm{yr}^{-1}\right)$ e eixo y: Ano.
} 
A partir destes quatro RCPs (quadro 1) os modeladores climáticos podem fazer simulações e os cenaristas que trabalham com os IAMs desenvolveram cenários socioeconômicos e de emissões (MOSS, 2010 p. 752).

Quadro 1: Características dos quatros Caminhos escolhidos:

\begin{tabular}{|c|c|c|c|c|c|}
\hline Nome & $\begin{array}{l}\text { Forçamento } \\
\text { Radiativo }\end{array}$ & Concentração PPM & Trajetória & $\begin{array}{l}\text { Modelo } \\
\text { usado }\end{array}$ & Instituição \\
\hline RCP8.5 & $\begin{array}{l}>8,5 \mathrm{~W} \mathrm{~m}^{-2} \mathrm{em} \\
2100\end{array}$ & $\begin{array}{l}>1370 \mathrm{CO}_{2 \mathrm{eq}} \mathrm{em} \\
2100\end{array}$ & Ascendente & MESSAGE & IAASA, Áustria \\
\hline RCP6.0 & $\begin{array}{l}\sim \quad 6 \text { W } \mathrm{m}^{-2} \text { na } \\
\text { estabilização após } \\
2100\end{array}$ & $\begin{array}{l}\sim 850 \mathrm{CO}_{2 \text { eq }} \text { na } \\
\text { estabilização após } \\
2100\end{array}$ & $\begin{array}{l}\text { Estabilização } \\
\text { sem } \\
\text { ultrapassagem }\end{array}$ & AIM & $\begin{array}{l}\text { Instituto Japonês } \\
\text { de Estudos } \\
\text { Ambientais }\end{array}$ \\
\hline $\mathrm{RCP} 4.5$ & $\begin{array}{l}\sim 4.5 \text { W } \mathrm{m}^{-2} \text { na } \\
\text { estabilização após } \\
2100\end{array}$ & $\begin{array}{l}\sim 650 \mathrm{CO}_{2 \text { eq }} \text { na } \\
\text { estabilização após } \\
2100\end{array}$ & $\begin{array}{l}\text { Estabilização } \\
\text { sem } \\
\text { ultrapassagem }\end{array}$ & GCAM & $\begin{array}{l}\text { Pacific } \\
\text { Northwest } \\
\text { National } \\
\text { Laboratory, } \\
\text { EUA }\end{array}$ \\
\hline $\mathrm{RCP} 2.6$ & $\begin{array}{l}\text { Pico de } \sim 3 \mathrm{~W} \mathrm{~m}^{2} \\
\text { antes de } 2100 \\
\text { seguido por } \\
\text { declínio }\end{array}$ & $\begin{array}{l}\text { Pico de } \sim 490 \mathrm{CO}_{2 \mathrm{eq}} \\
\text { antes de } 2100 \\
\text { seguido por declínio }\end{array}$ & $\begin{array}{l}\text { Pico e } \\
\text { declínio }\end{array}$ & IMAGE & PBL, Holanda \\
\hline
\end{tabular}

Adaptado de MOSS, 2010.

Um dos problemas deste novo método é que os RCPs possuem suas próprias premissas socioeconômicas e tecnológicas já que estes dados são cruciais para calcular as emissões. $\mathrm{Ou}$ seja, os RCPs, que deveriam ser parte de um esforço de criação de cenários e integrados com cenários socioeconômicos ao final do processo já trazem dados socioeconômicos próprios embutidos criados no processo sequencial (fig. 5). A ideia original era que estas premissas seriam menos importantes uma vez que os RCPs seriam combinados no final nos cenários que seriam publicados.

Figura 5: Processo sequencial de montagem de cenários

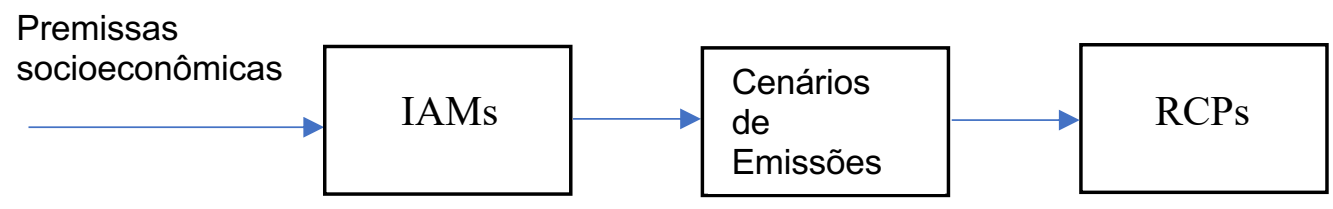

Fonte: elaborado pela autora 
O próximo passo foi o desenvolvimento dos cenários socioeconômicos os chamados Shared Social Pathways (SSP). No entanto este processo tomou muito mais tempo do que o esperado e os 5 SSPs só foram publicados em janeiro de 2017 (O’NEILL et al., 2017), ou seja, após o relatório AR5 em 2014.

O objetivo final de uso de ambos os caminhos (pathways) juntos foi explicado por Van Vuuren et al. (2014) onde foi apresentada a arquitetura da matriz de cenários (figura 6).

Figura 6: A arquitetura da matriz de cenários do IPCC

\section{Trajetoria socioeconômica de referência}

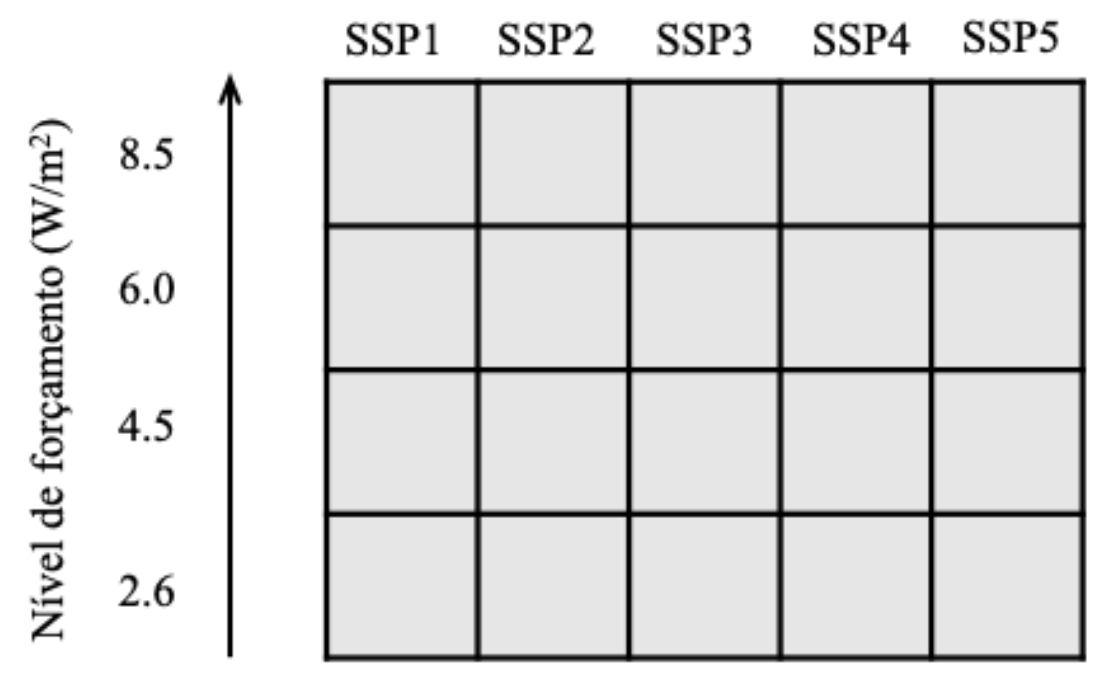

Adaptado de Van Vuuren 2014

No eixo do nível de mudanças climática devem ser utilizados os pathways RCPs (MOSS et al., 2010) e no eixo de premissas socioeconômicas devem ser utilizados os pathways SSPs (O’NEILL et al., 2017). O termo cenário “especificamente refere-se à integração de premissas socioeconômicas, de mudanças climáticas e de políticas públicas do clima dentro de cada célula da matriz" (VAN VUUREN, 2014 p. 377). Ou seja, os dois pathways seriam utilizados para descrever condições das linhas e colunas da matriz e não são cenários completos. Desta maneira nem sempre será possível preencher todas as células ou um mesmo SSP pode, dependendo das políticas climáticas, levar a diferentes caminhos de concentração de emissões ou um certo caminho de concentração de emissões pode ser atingido por diferentes caminhos socioeconômicos com diferentes políticas climáticas aplicadas.

O próprio artigo que apresenta a matriz (VAN VUUREN et al., 2014) aponta algumas limitações da matriz de arquitetura de cenários: ela é difícil de comunicar, a introdução de 
cenários comuns a todos os cientistas pode limitar o desenvolvimento de cenários ad hoc, existem dificuldades de padronização de termos entre as diversas comunidades cientificas para as quais foram desenvolvidos os cenários e, por último, os SSPs foram desenvolvidos para atender à comunidade científica ligada às mudanças climáticas e não às comunidades cientificas em geral.

Em 2017 os SSPs foram finalmente publicados em periódico revisado por pares. Eles foram desenhados para servirem a duas comunidades cientificas diferentes, a que estuda mitigação e a que estuda adaptação às mudanças climáticas. Desta forma foram montados dois eixos (fig. 7) um para cada um dos desafios. Contrariamente aos cenários anteriores do IPCC, além dos 4 SSPs foi proposto um central, que não “representa o caso mais provável” (O’NEILL, 2017, p. 172). Os cinco SSPs foram desenvolvidos com foco principal não nos inputs mas sim nos outputs portanto trata-se de um processo de backcasting onde, após identificado um output específico, as principais varáveis para alcançá-lo são encontradas.

Figura 7: Os cinco caminhos socioeconômicos:

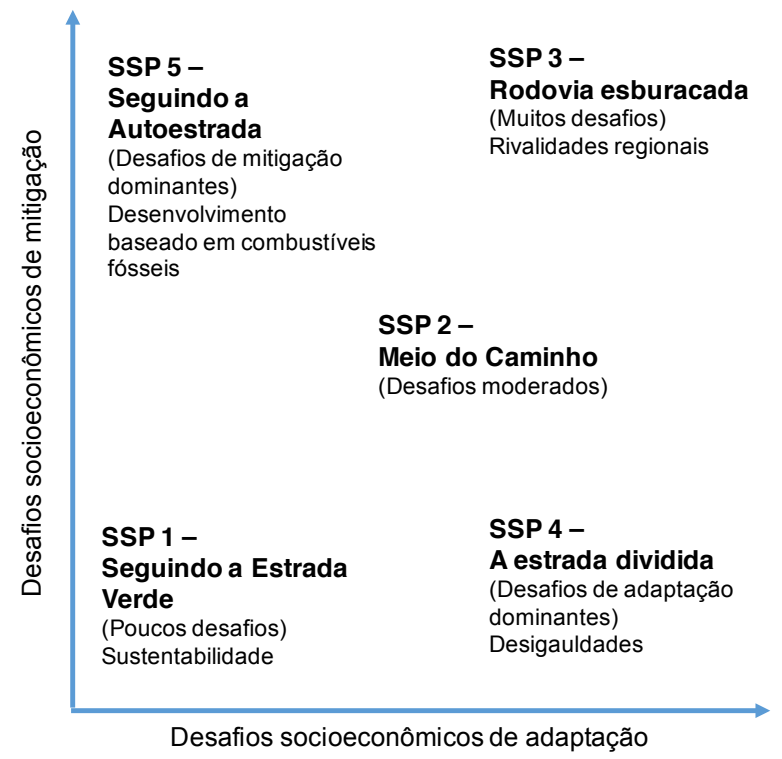

Fonte: adaptado de O’NEILL et al, 2017

O Quinto relatório de Acompanhamento (AR5) do IPCC foi lançado em 2014, ou seja, antes do lançamento dos SSPs e, portanto, antes do fim do processo de criação dos cenários a partir da matriz de arquitetura. Como apenas os cenários RCP estavam prontos, eles passaram a ser considerados os cenários mais atualizados. Para o próximo relatório, o AR6, que deverá ser publicado a partir de 2021, espera-se que novos cenários do tipo RCP sejam lançados (ROGELJ et. al, 2018). 
Os Caminhos Representativos de Concentrações, RCPs, foram desenvolvidos para fazer parte de uma matriz de arquitetura de cenários e não como um cenário completo, embora eles próprios tenham sido desenvolvidos como cenários. Apesar disso eles se tornaram as referências de cenários revisados por pares e publicados pelo IPCC para serem utilizados por cientistas e também pela sociedade em geral por serem os publicados no último relatório.

A complexidade deste novo processo trouxe algumas dificuldades para sua comunicação e utilização. O primeiro deles, sem dúvida, é o já levantado por Van Vuuren et al. (2014): as definições existentes nos cenários. O artigo cita a dificuldade de diversas comunidades epistemológicas - cenaristas de IAM, modeladores climáticos e pesquisadores de políticas públicas e seus impactos - que utilizam diferentes termos e definições o que torna necessário que essas definições sejam mais padronizadas. Entretanto, o problema de definições não se restringe às comunidades epistemológicas, ele aparece também para os leitores dos relatórios do IPCC na sociedade em geral.

No Sumário para os Formuladores de Politicas do AR5 (IPCC, 2014) em sua primeira menção os RCPs são apresentados como: um cenário com rigorosas medidas de mitigação, o RCP2.6; dois intermediários - o RCP4.5 e o RCP6.0 ; e um com emissões de GEE muito altas, o RCP8.5. O próprio sumário alterna as nomenclaturas como por exemplo:

"Cenários sem esforços adicionais de para conter as emissões (cenários de base -
baseline) levam a caminhos que variam entre o RCP6.0 e o RCP8.5 (...) RCP2.6 é
representativo de um cenário que busca manter o aquecimento global provavelmente
em até $2.0^{\circ} \mathrm{C}$ acima das temperaturas pré-industriais.” (IPCC, 2014, p. 8,).

E introduz o conceito de cenários baseline ou cenários de referência ou business-asusual (BAU). Embora este conceito seja utilizado em toda a literatura de cenários (SUTTER; CARVALHO; POLO, 2012), para os cenários de estudos climáticos em geral o cenário de base é aquele que não inclui nenhuma política climática (ALCAMO, 2001). Contudo, é muito difícil encontrar esta situação controle. Um exemplo disso aconteceu durante o desenvolvimento do SRES (IPCC, 2000) quando os cientistas se depararam com questões como as políticas antipoluição que, embora não sejam consideradas políticas climáticas, combatem o NO2 que é um GEE. A solução encontrada foi incluir qualquer política que regulasse a emissão de GEE por qualquer outro motivo que não o de diminuição das mudanças climáticas nestes cenários de referência.

Os cenários de referência são a linha que conecta os três grupos de trabalho do IPCC pois eles são produzidos por cientistas do Grupo de Trabalho 3 - que avaliam as opções de mitigação e limitações de emissões de GEE; seus resultados servem de entrada para os cientistas 
cujos pares estão no Grupo de Trabalho 1 - os que avaliam os impactos físicos dos sistema climático e das suas alterações; e finalmente chegam aos cientistas do Grupo de Trabalho 2 que avalia a vulnerabilidade dos sistemas sócio econômicos e naturais para análise dos impactos (HO et al., 2019).

O segundo ponto, também levantado por Van Vuuren (2014) para o caso dos SSPs, é que estes cenários foram feitos para servirem às necessidades de uma comunidade científica ampla, porém específica, os pesquisadores que trabalham com mudanças climáticas. Ou seja, é necessário conhecimento sobre o tema, sobre os limites destes cenários e sobre as premissas de um destes cenários para que sejam aplicados de forma adequada.

\subsection{O RCP8.5 - histórico e premissas}

O RCP8.5 é um cenário de referência, ou seja, sem nenhuma política climática. No artigo onde foi publicado (RIAHI et al., 2011) ele foi descrito como um cenário Business as Usual (idem, p. 43), então é importante esclarecer o conceito de BAU do IPCC.

O IPCC define o cenário BAU, ou de referência ou base, como aquele cenário que serve de referência para a avaliação de outros cenários. Por isso é um cenário que não inclui políticas climáticas em suas projeções. Ou seja, um cenário sem nenhuma política climática implementada, mas sem implicar que outras variáveis sócio econômicas, como crescimento populacional, tecnologias disponíveis, etc. sigam iguais aos atuais. Os cenários BAU não são feitos como previsões de futuro. O termo BAU, ainda segundo o glossário do IPCC, caiu em desuso devido à ideia de que BAU em projeções para os próximos 100 anos são difíceis de compreender como possíveis (IPCC, ).

No entanto, esta não é uma definição padrão da literatura. A Agência Internacional de Energia (AIE), por exemplo, utiliza as políticas climáticas já adotadas e publicadas, mesmo que ainda não estejam completamente implementadas, em seus cenários anuais. Por isso, desde 2010 ela não publica um cenário de referência e sim o chamado de Políticas Atuais (current policies scenario) (TENG; XU, 2012) uma vez que estas políticas evoluem no tempo. Também é comum encontrar o termo BAU definido como projeções baseadas na hipótese que todas as práticas operacionais e políticas continuaram iguais a do momento presente (TCFD, 2017). No dicionário OxfordReference (OXFORD UNIVERSITY PRESS, ) a entrada BAU significa que os padrões de atividade futuros não serão significativamente diferentes dos atuais, de forma que as circunstâncias atuais devem continuar sem mudanças. 
Ou seja, existe uma diferença entre como o IPCC define Business as Usual e como a sociedade em geral utiliza o termo. Além do mais, mesmo na definição mais ampla do termo, o atual se modifica.

Uma outra característica do RCP8.5 relevante para esta pesquisa é o fato que o RCP8.5 não foi publicado como um cenário completo e sim como um caminho de concentração de GEE. Desta maneira as premissas socioeconômicas do cenário ficaram perdidas e, ao contrário dos SSPs, não existem mecanismos de acompanhamento para a avaliação da plausibilidade e consistência interna (RIAHI et al., 2017).

O RCP8.5 (RIAHI et al., 2011) é baseado em uma revisão do cenário IPCC SRES A2 chamada de A2r. Este cenário revisado, o A2r, foi feito a partir de premissas socioeconômicas baseadas em cenários anteriormente publicados. Riahi, Grübler, Nakicenovic (2007) apresentam três cenários revisados do SRES (IPCC, 2000) que serviriam como cenários de referência, ou seja, de base para os três experimentos de modelagem. Dos três cenários apresentados o A2r foi desenvolvido para estar no quadrante superior da literatura de cenários, ou seja, com as concentrações mais altas. Como em todos os cenários do IPCC não são estimadas as probabilidades nem objetivas nem subjetivas de ocorrência de nenhum dos três cenários.

O cenário A2r é um cenário que descreve um mundo heterogêneo, fragmentado, com alto crescimento populacional e com lento desenvolvimento tecnológico, que leva a menores crescimentos econômicos e de produtividade, e com grande demanda de energia e recursos naturais. A oferta de energia é suprida basicamente por combustíveis fósseis de baixa qualidade e localizados regionalmente como carvão, e tecnologias pós-fósseis como a nuclear, para regiões do mundo com pouco combustível fóssil. As fontes renováveis estudadas são basicamente as bioenergias e sua oferta é avaliada segundo a lógica dos combustíveis fósseis. O cenário traz uma visão sobre a falta de recursos fósseis que implica em uma diferenciação entre recursos de fácil acesso, limpos, e de difícil acesso, sujos.

Em termos de energia o cenário A2r descreve um mundo extremamente dependente do carvão - até mesmo como combustível líquido na forma de synfuels - uma vez que a demanda por energia é alta e o desenvolvimento tecnológico é lento. Isto porque o carvão seria um combustível de custo mais baixo, principalmente após a exaustão das reservas de mais fácil acesso de petróleo e gás (RIAHI; GRÜBLER; NAKICENOVIC, 2007). 
As principais revisões metodológicas do A2r feitas para o RCP8.5 são a inclusão explícita de legislação sobre a qualidade do ar, já que muitos dos poluentes também são GEE, novas abordagens metodológicas sobre poluentes e uma contabilidade mais refinada sobre o uso da terra. O artigo explicita a abordagem metodológica que utilizou as ferramentas do International Institute for Applied Systems Analysis (IIASA) que combina diversos modelos de disciplinas variadas em distintas resoluções espaciais dos principais setores emissores energia, indústria, agricultura e florestas.

O modelo energético utilizado para o RCP8.5 mapeia o setor energético global, com todas suas interdependências desde a extração até a distribuição e usos finais e calcula a solução ideal de menor custo para o setor segundo um conjunto de premissas sobre fatores chaves como demanda, performance tecnológica e restrições ambientais. Foi feita a calibração do cenário para 2005 e uma revisão sobre as tendências energéticas a curto prazo, principalmente dos países em desenvolvimento (RIAHI et al., 2011 p. 42).

As tendências demográficas do cenário preveem 12 bilhões de pessoas em 2100 com uma renda per capita global com lento crescimento e muito heterogênea em termos globais. Os sistemas de inovação e difusão tecnológica não são internacionalmente integrados, o que dificulta o progresso tecnológico. O desenvolvimento econômico lento leva a uma alta demanda por energia, já que não há progresso em termos de eficiência energética. Estas características do setor tecnológico e energético combinadas apontam para uma grande dependência de recursos energéticos locais, levando ao esgotamento de reservas de óleo e gás de fácil acesso.

O sistema energético descrito pela storyline e quantificado no modelo inclui um aumento da demanda de energia por um fator de 3 vezes que é suprida basicamente por combustíveis fósseis. Estes combustíveis continuam sendo os de custo mais baixos e a extração tanto das reservas convencionais quanto das não convencionais são consideradas nos seus limites superiores. O uso do carvão cresce em até 100 vezes em 2100, principalmente após 2050, quando as reservas de óleo começam a se esgotar (figura 8). Isso leva ao uso de novas tecnologias fósseis avançadas, inclusive com desenvolvimento de combustíveis líquidos sintéticos a partir do carvão para o transporte e ao uso de "carvão limpo" com Captura e Estocagem de Carbono (CCS por suas iniciais em inglês). A demanda por eletricidade continua crescendo e se transforma no modo dominante de energia no setor residencial e parcialmente no setor industrial. Após 2050, a eletricidade vem em grande escala de fontes não fósseis como nuclear e biomassa (idem, p. 45). 
Figura 8: projeção do fornecimento de energia primária por fonte do RCP8. 5
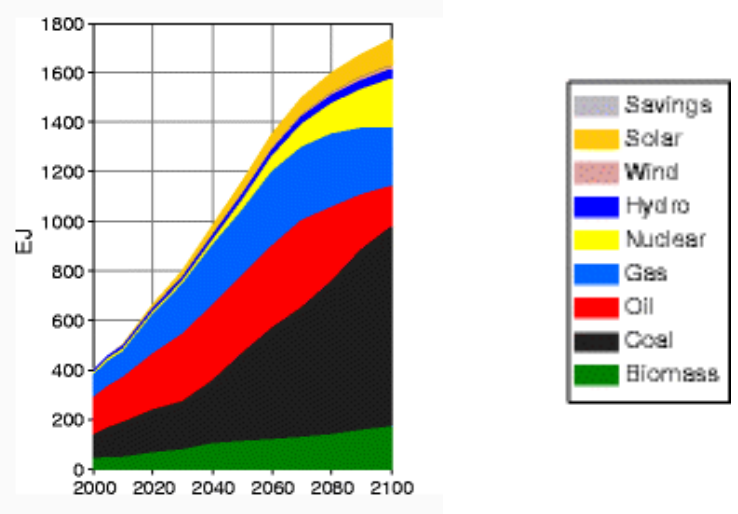

Fonte: Riahi et al. (2011)

Em relação à inovação no setor energético, o cenário se divide em dois grandes grupos: a cadeia de produção dos combustíveis fósseis, onde existe inovação tecnológica e as tecnologias de baixo carbono, onde a inovação é pequena. Segundo Riahi et al. (2011):

"O cenário assume um ritmo relativamente lento de inovação em tecnologias não
fósseis, levando a melhoras modestas de custos e performance (...por exemplo curvas
de aprendizagem abaixo de $10 \%$ por cada vez que a capacidade instalada dobra (...)
Em contraste com a maioria das tecnologias, acontecem significativa melhorias
acontecem nas alternativas fósseis além da penetração de um número de novas
tecnologias fósseis avançadas"

Quadro 2: resumo das principais características para o setor energético

- Aumento da demanda por energia primária entre os anos de 2000 e 2100 da ordem de 5 vezes

- Aumento do uso de carvão para suprir a demanda em 10 vezes do consumo de 2005, incluindo tecnologias de carvão limpo

- Lentos ganhos de eficiência energética no setor energético

- Baixa inovação no setor energético nas tecnologias de baixo carbono: curvas de aprendizagem abaixo de $10 \%$ por cada dobra de capacidade instalada levando a pequenas quedas de custo e pequenos ganhos de produtividade

- Inovação no setor energético dos combustíveis fósseis incluindo:
- Aumento das reservas de fósseis não convencionais pelo desenvolvimento tecnológico que permitem explorar mais recursos.
- Ganhos de eficiência e de performance de extração
- Produção de combustíveis líquidos a partir do carvão
○ Descolamento entre emissões de GEE e poluição ambiental

\footnotetext{
5 Tradução da legenda em ordem de cima para baixo: ganhos de eficiência, solar, eólica, hidro, nuclear, gás, petróleo, carvão e biomassa.
} 
- Alterações no setor elétrico incluindo:

○ Aumento da geração a partir de carvão limpo

- Crescimento na geração nuclear e hidro - tecnologias consolidadas - devido ao aumento do preço do petróleo

- Crescimento da demanda por eletricidade tornando-se o modo dominante de energia no setor residencial e parte do setor industrial

- A partir de 2050, há um aumento da eletricidade produzida a partir de fontes não fósseis (biomassa e nuclear, especificamente) 


\section{A TRANSIÇÃO ENERGÉTICA EM CURSO}

A assinatura do Acordo de Paris deixou claro o papel da tecnologia no processo de redução das emissões do setor energético mundial (ABRAMOVAY, 2016). Embora tenha sido um acordo assinado na esfera diplomática, não é possível deixar de notar que tal acordo só foi possível devido ao desenvolvimento tecnológico e queda dos custos das novas fontes renováveis de eletricidade (ABRAMOVAY, 2014; ABRAMOVAY, 2016; SCHMIDT; SEWERIN, 2017). E é este desenvolvimento tecnológico das fontes energéticas limpas que é descrito como não possível nas premissas do RCP8.5.

O setor energético pode ser descrito como um setor consolidado, ou seja, um setor em que é difícil a chegada de novos entrantes por conta de todo um paradigma tecnológico, econômico, político e social. Desta maneira barreiras e imperfeições de mercado favorecem as tecnologias existentes e obstruem o desenvolvimento e a penetração no mercado de novas tecnologias.

Entre estas barreiras estão subsídios, padrões regulatórios, infraestrutura, instituições acadêmicas e tecnologias voltadas para o setor que foram desenvolvidas durantes décadas e provocam um lock-in tecnológico. É importante notar que existe sim inovação dentro do setor consolidado, mas ela fica majoritariamente restritas ao paradigma, sendo ele resistente a ideias e avanços que possam resultar em mudanças estruturais no setor (BONVILLIAN; WEISS, 2015).

A infraestrutura do setor energético voltada para a exploração dos combustíveis fósseis é imensa pois compreende desde a exploração, extração, refino, distribuição e uso de carvão, petróleo e gás natural até a infraestrutura para o uso destes combustíveis pela indústria petroquímica, a de fertilizantes, as estradas, os aeroportos, os postos de combustíveis e os aparelhos elétricos em geral. Mas além desta infraestrutura física temos outras características sociais e econômicas que também são responsáveis pela manutenção do setor energético como consolidado. Exemplos destas características são a dependência de alguns países de suas empresas nacionais de petróleo (HELLER; MIHALYI, 2019), a presença de investimentos no setor de grandes fundos, inclusive de pensão (UNEP FINANCE INITIATIVE, ; AMELI et al., 2020) a expectativa por parte da população - criada ao longo de anos - de energia abundante e barata, e principalmente o fato de que as empresas emissoras de GEE não precisam pagar pelas externalidades geradas uma vez que uma taxa de carbono nunca foi implementada de forma mandatória. Uma outra característica importante do setor energético é que ele engloba diferente componentes como por exemplo: transporte - aéreo, marítimo, terrestre leve e pesado; geração, 
transmissão e distribuição de eletricidade; energia para processos industriais como cimento ou aço. Cada um destes componentes utiliza diferentes tecnologias e modelos de negócios portanto têm diferentes barreiras à inovação.

É justamente o tamanho desta infraestrutura e o quão consolidada e diversificada ela é que faz com que vários pesquisadores afirmem que a transição energética atual que busca a descarbonização vai tomar muito tempo assim como as anteriores - da biomassa para o carvão e do carvão para o petróleo (GRUBLER, 2012; SMIL, 2017).

O processo de inovação é comumente descrito como linear e suas fases seriam: Pesquisa, Desenvolvimento, Demonstração e Adoção da tecnologia. E esta ideia está por trás de quase todas as discussões sobre inovação no setor energético (FRI, 2003). Contudo este processo na realidade é incremental, acumulativo, assimilativo (idem) e combinatório (ARTHUR, 2009). Segundo Arthur (2009) a evolução da tecnologia acontece de forma combinatória, ou seja, novas tecnologias surgem a partir de tecnologias já existentes, em um processo de recombinação contínua, onde tecnologias de uma área podem servir para formar tecnologias em outras e até mesmo novas áreas podem surgir destas combinações. Um exemplo desta transposição de tecnologias no setor energético é a utilização de turbinas adaptadas da aeronáutica para a geração de eletricidade em usinas termoelétricas com aumento da eficiência.

Além da combinação constante de tecnologias já existentes criando novas tecnologias, a inovação é estimulada quando existe uma demanda pois a presença de "nichos de oportunidade chama o desenvolvimento de novas tecnologias" (ARTHUR, 2009 p. 174, tradução nossa). Estas demandas não vêm apenas das necessidades humanas, mas também de necessidades das tecnologias existentes. E existem necessidades que provêm do fato de que tecnologias trazem problemas, e, no caso do setor energético atual, ser um grande emissor de GEE demanda soluções e novas tecnologias.

Outra característica da evolução combinatória das tecnologias é que, apesar de "ser razoavelmente possível prever as tecnologias que estarão disponíveis na próxima década, (...) o coletivo de tecnologias disponíveis não é previsível" (idem, p. 186). Um exemplo disso é a evolução das baterias dentro do setor elétrico, cuja produção cresceu nos últimos anos voltada para o mercado automobilístico, porém hoje em dia estão sendo utilizadas nos grids elétricos com várias funções (BLOCH et al., 2019).

Sem dúvida a inovação acontece no setor energético na parte dos combustíveis fósseis. As técnicas de recuperação terciária de petróleo e a chamada Revolução do Gás de Xisto, que 
aconteceu nos EUA a partir do fim dos anos 1990 são um exemplo notório desta inovação. Normalmente, as reservas de petróleo e gás são dívidas entre convencionais e não convencionais, sendo as não-convencionais todas aquelas que têm baixa permeabilidade e exigem estimulação para a extração dos hidrocarbonetos. Nas reservas tradicionais, a extração se dá em três fases: a recuperação primária, na qual óleo e gás saem pela pressão natural do reservatório, a recuperação secundária, na qual é necessário a injeção de um fluido ou gás e a recuperação terciária. Esta última fase era demasiado cara para ser feita e então estes hidrocarbonetos eram considerados irrecuperáveis. Porém, com o desenvolvimento de novas técnicas, parte destas reservas se tornaram recuperáveis e são exploradas. Já para as fontes não convencionais, aquelas onde não existe um reservatório e onde os hidrocarbonetos estão distribuídos entre as rochas, as inovações tecnológicas - incluindo as digitais como análise de dados usando inteligência artificial - que levaram às técnicas de fraturamento hidráulico dos reservatórios de gás de folheto desenvolvidas principalmente nos últimos 20 anos produziram uma revolução no setor de combustíveis fósseis no mundo (HASSANI; SILVA, 2018). A produção de petróleo dos Estados Unidos praticamente dobrou entre 2007 e 2014, transformando o país de importador de petróleo para um exportador em valores absolutos (WANG et al., 2014).

A inovação também acontece na exploração e na utilização de carvão. As principais inovações neste setor se referem à busca do chamado "carvão limpo". Este objetivo, utilizar carvão como fonte primária de energia e limitar ou diminuir a emissão de GEE, pode ser alcançado de duas maneiras: melhorando a eficiência da queima do carvão ou capturando as emissões desta queima, a chamada Captura e Armazenamento de Carbono (CCS) ou Captura, Uso e Armazenamento de Carbono (CCUS). A primeira maneira tem tido avanços significativos com processos mais eficientes de pré-combustão e combustão. A melhora da tecnologia nas usinas termoelétricas trouxe um grande avanço na eficiência média delas, de por volta de 36\% em 2000 para 40\% em 2018, chegando a 55\% de eficiência térmica para as turbinas mais modernas (BP, ). Já o desenvolvimento de tecnologias de CCS vem encontrando obstáculos devido ao alto custo da tecnologia, em termos energéticos e financeiros, principalmente para a geração de eletricidade onde já existem outras fontes mais baratas como a solar fotovoltaica e eólica (SGOURIDIS et al., 2019).

Se de um lado, o setor energético é um setor consolidado, o que coloca entraves à inovação fora das fontes fósseis de energia, por outro o fato de a evolução da tecnologia ser fundamentalmente combinatória faz com que nenhuma inovação fique estanque em uma parte 
do setor energético apenas. Além disso existe a necessidade de descarbonizar o setor, ou seja, existe demanda por novas tecnologias que possam suprir esta demanda. E a pressão social nesta direção acaba influenciando o comportamento das próprias licenças e interfere de maneira decisiva em sua licença para operar.

Trata-se de um momento onde coexistem dois paradigmas em oposição e o RCP8.5 traz a narrativa do ponto de vista de apenas um deles. E a adesão a este paradigma ao que vem acontecendo nos últimos dez anos em termos de inovação tecnológica é cada vez menor.

A transição energética em curso se apoia nesta necessidade de descarbonização para mitigar as mudanças climáticas (KERN; ROGGE, 2016; SOVACOOL, 2016).

Não existe uma definição formal para transição energética na literatura acadêmica, porém, em termos gerais, as definições envolvem mudanças no setor energético normalmente com a substituição de uma fonte primaria de energia por outra.

Smil (2017) afirma que o termo transição energética é comumente utilizado para “descrever a mudança na composição da fonte primária de energia, a mudança gradual de um padrão especifico de provisão de energia para um novo estado do sistema energético". Ele também afirma que a transição é “o tempo entre a introdução de uma nova fonte primária de energia ou um novo mecanismo conversor de energia (prime movers) e o momento onde ela atinge uma participação significativa no mercado total” (SMIL, 2017).

Para Grubler (1991), a definição é a mudança de estado no sistema energético em oposição a uma mudança em uma tecnologia individual ou fonte primaria de energia. Fouquet e Pearson (2012) expandem esta definição pois incluem a mudança de todo o sistema econômico dependente de uma ou uma série de fontes de energia e tecnologias para outro sistema.

Se considerarmos apenas a troca da fonte primária de energia, Ausubel (2003) revela que o estudo da história mostra que nos últimos 200 anos, o mundo tem seguido uma trajetória de descarbonização uma vez que a relação entre toneladas de carbono na oferta de energia sobre o total de energia ofertada vem caindo. Isto se dá devido à troca das fontes primarias, já que feno e madeira têm uma alta quantidade de carbono em comparação à mesma massa de metano utilizado hoje em dia, por exemplo. Além desta lenta descarbonização pela troca de energia primária, também está acontecendo um processo de descolamento entre o crescimento da demanda por energia e a emissão de GEE devido a ganhos de eficiência energética e ao aumento do uso da eletricidade proveniente das fontes renováveis que não passam por transformações. 
Entretanto o crescimento populacional, econômico e da demanda total por energia em termos globais ainda são maiores que estes ganhos, tornando relativo este descolamento entre economia e emissões (ABRAMOVAY, 2012; JACKSON, 2017; SMIL, 2019).

A transição energética tem sido um fenômeno permanente (SINGH et al. 2019) porém se nas outras, de biomassa para carvão e de carvão para óleo e gás, elas aconteceram baseadas primordialmente em fatores como preço e abundância de recursos e novas fontes de energia sendo descobertas (SOVACOOL, 2016; KERN e ROGGE, 2016), a atual tem toda uma gama de atores que buscam influenciar a transição na direção da descarbonização (KERN e ROGGE, 2016; GEELS et al., 2017). Ademais grande parte dos avanços tecnológicos que fazem parte da transição atual são parte de uma revolução tecnológica que vem acontecendo nas últimas décadas, com inovações digitais, físicas e biológicas com velocidade, profundidade e interação inéditas (SCHWAB, 2016) e não apenas de inovações no setor energético. Estas características da chamada $4^{\mathrm{a}}$ revolução industrial aceleram não só a inovação, mas a difusão das novas tecnologias (ABRAMOVAY, 2014). Por último, o avanço da tecnologia acontece de forma combinatória (ARTHUR, 2009) e desta maneira cada vez existem mais componentes tecnológicos que podem se combinar trazendo tanto inovações incrementais como radicais que facilitam a transição em curso.

Não existe um indicador único que possa capturar a complexidade da transição energética global em curso. Um indicador recomendado pela AIE é a intensidade de $\mathrm{CO}_{2 \text { eq }}$ do setor energético. Por este indicador a transição global ainda é lenta e não foi capaz de dobrar a curva de emissões (fig. 9). Segundo a AIE, as emissões globais do setor subiram 1,7\% em 2018 em relação ao ano anterior. Este é o segundo aumento consecutivo após 3 anos de estabilidade.

Figura 9: emissões totais de $\mathrm{CO}_{2}$ do setor energético, entre 1990 e 2017

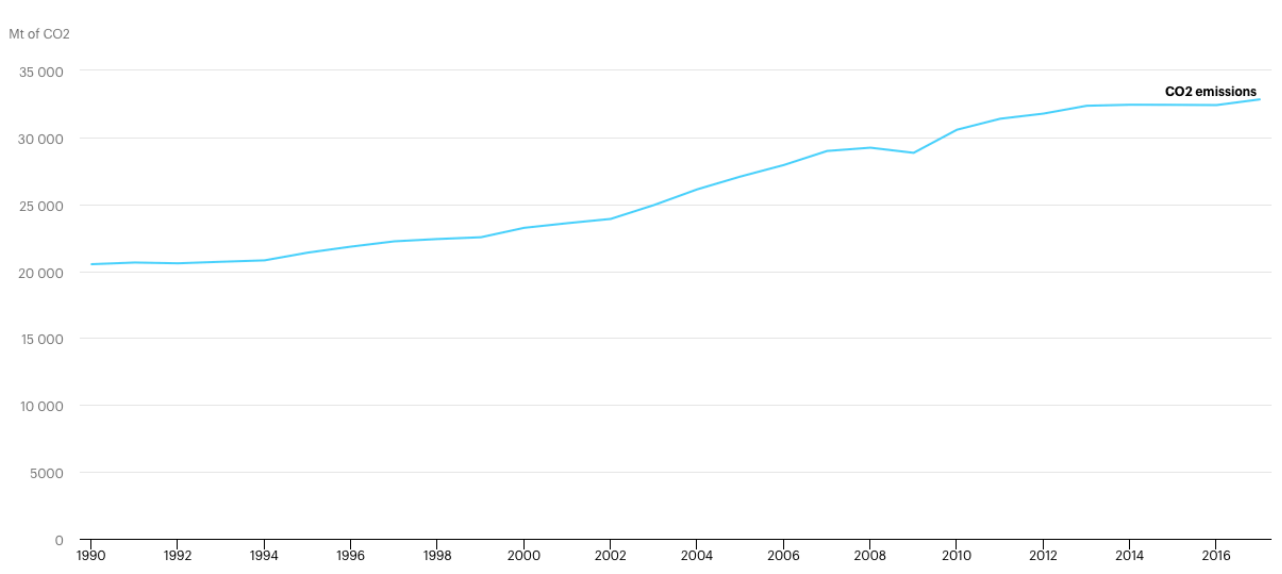

Fonte: IEA estatísticas 
A AIE montou um esquema (fig. 10) onde as emissões de GEE do setor são decompostas para analisar a evolução da atual transição em indicadores do lado da demanda e da oferta.

Figura 10: Indicadores da transição energética da AIE



Fonte: IEA, 2019a

Nos indicadores intermediários temos como determinantes no lado da demanda: a participação da eletricidade na demanda total e a eficiência energética; e no lado da oferta: a intensidade de carbono da energia final e a intensidade de carbono da geração de eletricidade. Em ambos os lados os investimentos são considerados determinantes. A eletrificação e a diminuição da intensidade de carbono da eletricidade, ou descarbonização, serão detalhadas a seguir pois este é o setor da geração de energia onde a inovação não acontece segundo o RCP8.5, como já foi visto. E o que será visto é que os dados não confirmam este ponto de vista.

\subsection{Eletrificação do setor energético}

A eletrificação é a maneira mais rápida de zerar as emissões do setor energético (WILLIAMS et al., 2012; ROGELJ et al., 2018a; SEPULVEDA et al., 2018). Em 2018 o World Energy Outlook (WEO), principal relatório anual da AIE, teve como foco especial a eletricidade. Nele, a AIE aponta que a eletricidade é a parte da demanda por energia com maior crescimento mundial e que ela deverá seguir crescendo. Ele afirma que a "eletricidade é o 
combustível preferido" da sociedade e que uma grande transformação está em curso neste setor. Entre 2005, ano base do RCP8.5, e 2018 a demanda por eletricidade cresceu 37,5\%, superando o crescimento de qualquer outra fonte. Ainda assim, a eletricidade atende somente a cerca de $20 \%$ do consumo mundial de energia, ainda segundo dados WEO 2018. E além disso, parte importante da energia elétrica, 65\%, é obtida a partir de fontes fósseis (IEA, 2018).

A eletricidade é a mais versátil e mais controlável fonte de energia, por isso ela está no centro das economias modernas. E é essa versatilidade que permite que outras partes do setor energético, atualmente dependente de outras fontes de energia, sejam eletrificados. Alguns exemplos são a eletrificação da geração de calor e frio, que hoje muitas vezes é feita utilizando gás natural, e a eletrificação da mobilidade que hoje é feita baseada em uma gama de derivados do petróleo principalmente gasolina e óleo diesel.

Máquinas elétricas são mais eficientes que a suas contrapartes movidas à queima de combustíveis. Em um veículo com motor a combustão interna com ciclo de Otto, que tem uma eficiência de cerca de 22\% (GOLDENBERG, 2020), quase 70\% da energia utilizada é perdida em forma de calor. O mesmo ocorre na geração de termeletricidade.

Comparar as propriedades da eletricidade e dos combustíveis fósseis pode ser bastante complicado pois se de um lado a eletricidade é mais fácil de transportar, utilizando apenas cabos, e pode ser usada para uma variedade muito maior de usos finais, por outro lado ela é mais difícil de armazenar. Além disso, a forma como fazemos a contabilidade da energia, criada originalmente para fazer cálculos de combustíveis fósseis, infla a quantidade total da demanda por energia. Isso porque a energia fóssil requer múltiplos processos como extração, transporte, refino, etc. que consomem energia antes que ela seja utilizada como energia final.

Uma das métricas de avaliação de quanta energia é utilizada é o Energia Retornada sobre Energia Investida (EROI, por suas iniciais em inglês), que é uma relação simples que divide a produção (output) de energia pela utilização (input) de energia (KUNZ; HAGENS; BALOGH, 2014) Esta métrica é utilizada também para avaliar a qualidade de uma fonte de energia (HALL; LAMBERT; BALOGH, 2014). O conceito de EROI é importante pois define o quanto de energia fica disponível para uso depois de sua extração. Se utilizarmos a mesma quantidade para extrair a energia que ela é capaz de fornecer teremos um EROI igual a 1. Quanto maior o esforço energético para extrair uma fonte de energia menor o EROI. Ou seja, quanto menor a qualidade de uma fonte mais energia será necessária para explorá-la (JACKSON; 2017 p. 12, ABRAMOVAY; 2012, p. 101). 
Existe toda uma literatura que argumenta que não será possível manter o padrão de vida atual com fontes de energia renováveis devido ao seu baixo EROI (HALL; LAMBERT; BALOGH, 2014; KING; VAN DEN BERGH, 2018). Entretanto, novos estudos sobre EROI de muitas das fontes de energia mostram que o EROI dos combustíveis fósseis vem caindo (HALL; LAMBERT; BALOGH, 2014) e, se considerarmos a energia final, ou seja, pronta para uso, em lugar da energia primária, os EROIs de combustíveis fósseis são mais baixos do que os comumente reportados.

Em geral as comparações entre as diversas fontes de energia são feitas utilizando energia primária, o que gera grandes distorções. Isso acontece porque a eletricidade gerada pelas fontes renováveis como eólica, hidro ou solar é considerada como primária mesmo sendo já final pois não passa por conversões ${ }^{6}$. Já no caso dos combustíveis fósseis o EROI é historicamente calculado na "boca da mina" ou na "cabeça do poço", onde é calculada a energia primária. Ainda quando calculado os EROIs da energia primária dos combustíveis fósseis, eles vêm historicamente caindo (BROCKWAY et al., 2019), uma vez que apenas as reservas não convencionais de petróleo estão crescendo e a extração destas reservas demanda um maior investimento de energia (BENTLEY; MUSHALIK; WANG, 2020). As comparações entre o EROI no estágio de energia final entre os combustíveis fósseis e as fontes renováveis mostram que já não existe grande diferença entre eles pois além da queda do EROI dos combustíveis fósseis - de em torno de 10\% entre 1990 e 2011, os EROIs das fontes solar e eólica vêm subindo devido às inovações no setor (DIESENDORF; WIEDMANN, 2020).

Esta discussão trás uma conclusão para a avaliação da importância da eletrificação do setor energético para sua descarbonização: para eletrificar o setor energético totalmente não é preciso gerar tanta eletricidade quanto a energia total consumida hoje em dia. Isto porque historicamente as análises no setor energético são feitas utilizando quantidades primárias de energia e a eletricidade de fontes renováveis permite oferecer os mesmos serviços energéticos (luz, calor, computação, etc.) por menos energia primária uma vez que ela já é final. O processo termoelétrico de combustão de combustíveis fósseis para a geração de eletricidade inclui uma grande perda da energia na forma de calor mesmo nas mais eficientes termoelétricas, além dos gastos energéticos de extração, transporte e refino - quando necessário (GRIFFITH; FRASER; CALISCH, 2020)

\footnotetext{
${ }^{6}$ Energias primárias são aquelas extraídas diretamente da fonte natural. No caso da eólica, solar e hidro as fontes são sol, vento e água respectivamente e não passam por conversão.
} 


\subsection{Descarbonização da eletricidade}

A eletrificação é a maneira mais rápida de descarbonizar o setor energético pois é possível gerar eletricidade sem emissão de GEE. Porém, segundo a AIE, em 2018 os combustíveis fósseis, principalmente carvão e gás natural, foram responsáveis por $64 \%$ da geração de eletricidade mundial, somente 1\% abaixo do total em 2017.

Uma série de estudos (JACOBSON et al., 2019) feitos em diversos países aponta para a possibilidade de setores energéticos $100 \%$ baseados em energia renovável e sem emissões. Este tipo de cenário é conhecido na literatura como cenários de descarbonização profunda (deep decarbonization). Estes estudos de modelagem teórica são bastante controversos em termos acadêmicos devido à quantidade de premissas que precisam ser definidas arbitrariamente, mas têm se mostrado bastante importantes como uma plataforma para pressão da sociedade civil sobre governos em busca da decarbonização (HEARD et. al, 2017).

Nos últimos anos governos de 87 países publicaram, seja em leis ou políticas públicas, objetivos de instalação de capacidade de geração de eletricidade de baixo carbono até 2030 somando $721 \mathrm{GW}$ de renováveis sem contar com grandes hidrelétricas (UNEP; BNEF; FRANKFURT SCHOOL, 2020 p. 12). Além disso, várias corporações - inclusive 19 das maiores do mundo em faturamento - já tornaram publico seus compromissos com a transformação de suas matrizes energéticas em 100\% renováveis. Desta maneira o relatório da UNEP (idem) estima que pelo menos $826 \mathrm{GW}$ de capacidade de geração deverá ser construída somente para suprir estes compromissos. Entre 2010 e 2019 foram construídas algo em torno de $1200 \mathrm{GW}$ de geração de eletricidade a partir de fontes renováveis (excluindo as grandes hidroelétricas) e a instalação de nova capacidade em 2019 foi a maior até hoje na história em GW (fig 11).

Em diversos países no mundo a geração elétrica a carvão vem caindo de maneira acelerada. No Reino Unido, país onde começou a Revolução Industrial baseada na queima de carvão, ele gerava 70\% de toda a eletricidade em 1990, em 2019 foi responsável por apenas $2.1 \%$ e em 2020 o país ficou 60 dias corridos sem utilizar nenhuma termelétrica a carvão pela primeira vez na história (THOMAS, 2020). Nos EUA o consumo de carvão em abril de 2020 foi o menor desde que o governo americano começou a sistematizar esta informação em 1973, segundo a própria Agência de Informação de Energia americana (U.S. ENERGY INFORMATION ADMINISTRATION, 2020) e a geração de eletricidade a partir de renováveis ultrapassou a geração a partir de carvão pela primeira vez em maio de 2020. 
Figura 11: Capacidade total de geração renovável instalada entre 2004 e 2019 (em GW)

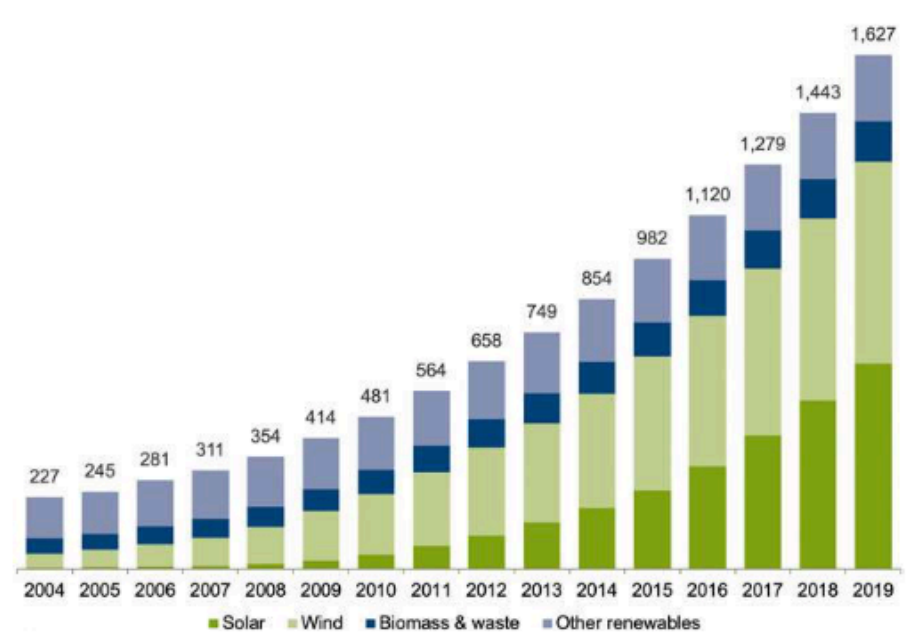

Fonte: UNEP; BNEF; FRANKFURT SCHOOL, 2020

Já em países em desenvolvimento como a China e a Índia, o número de termelétricas a carvão continua crescendo (SHEPHERD; FINDLAY, 2020), embora muitos analistas insistam que estas usinas não serão economicamente competitivas já nos próximos anos (BODNAR et al., 2020).

Como as emissões de $\mathrm{CO}_{2}$ proveniente da queima de gás natural são menores do que as da queima de carvão, durante a década de 2010 o gás natural foi chamado de ponte para um futuro mais sustentável. Entre os anos 2000 e 2016 a produção de gás natural produzida nos Estados Unidos aumentou em 35\% através do desenvolvimento da tecnologia de fracking o que tornou o país um exportador de gás. Além disso, como as termelétricas a gás podem ser despachadas $^{8}$, elas serviriam de complemento para as renováveis variáveis. Embora as emissões de $\mathrm{CO}_{2}$ sejam menores, o Gás Natural é um GEE e a sua utilização requer muito cuidado devido à possibilidade de fugas de metano que é um potente GEE. Caso estas fugas estejam acima dos $5,2 \%$, os ganhos em termo de forçamento radiativo em relação a queima de carvão deixam de existir (HAUSFATHER, 2015).

Como a possibilidade tecnológica de descarbonização do sistema elétrico já existe é necessário estender esta possibilidade a um número cada vez mais amplo de atividades que requerem energia. A combinação do aumento da produtividade energética através da redução das perdas de conversão e de ganhos de eficiência e da forte redução da intensidade de carbono

\footnotetext{
${ }^{7}$ Tradução da legenda da direita para a esquerda: solar, eólica, biomassa e resíduos, e outras renováveis.

${ }^{8}$ Fontes de eletricidade despacháveis são aquelas que o operador escolhe quando vai gerar, ou seja estão sempre disponíveis
} 
do setor energético é a estratégia apontada pelo esquema da AIE (fig. 9 acima) para a diminuição total das emissões do setor.

\subsection{A transição energética está acontecendo?}

O indicador sugerido pela AIE não permite uma análise com muitas nuances do que está acontecendo no setor devido ao caráter agregado das informações. Uma das questões mais importantes sobre a transição energética é a velocidade em que ela está acontecendo. Ela é importante porque a velocidade da descarbonização é fundamental para a concentração das emissões de GEE na atmosfera, pois quanto mais rápido a descarbonização acontecer menor

será a emissão acumulada de GEE do setor. É possível dizer que hoje em dia coexistem duas narrativas a respeito da atual transição energética: a narrativa gradual e a narrativa acelerada (WORLD ECONOMIC FORUM, 2019). E as principais diferenças entre elas advêm de posições em quatro grandes temas: se o que importa são os estoques ou os fluxos; como a tecnologia e a inovação se difundem; o papel das políticas públicas e a trajetória do setor energético dos mercados emergentes (idem). Alguns outros temas que são fundamentais para a transição como ganhos de eficiência energética são vistos de maneira mais homogênea nas duas narrativas.

\subsubsection{Estoques vs. fluxos}

A discussão entre estoques e fluxos se refere a qual seria o melhor indicador para a velocidade da transição energética. Dois indicadores possíveis são o quanto da demanda por energia ainda é suprida por combustíveis fósseis no caso de uma análise por estoque; ou através da taxa da mudança nas fontes deste suprimento no caso da análise por fluxo.

Grubler, Wilson e Nemet (2016) avaliam que a mudança do estoque envolve a mudança de todo o capital tecnológico e de infraestrutura do setor energético, o que é um processo necessariamente lento devido ao tamanho desta infraestrutura. A velocidade da mudança vista pela taxa de mudança tende a ser muito mais rápida, pois normalmente analisa a mudança da fonte sem analisar todo a infraestrutura do setor. Um exemplo desta transição é a introdução de etanol como combustível de veículos leves no Brasil que aconteceu de forma rápida (SMIL, 2017; SOVACOOL, 2016) pois não houve muitas mudanças na infraestrutura, como postos, veículos, estradas etc. A narrativa lenta, que afirma que a velocidade da transição será determinada pelo estoque da infraestrutura e pela demanda total de energia primária, se baseia 
em estatísticas e, em 2017, apenas 246 $\mathrm{Mtoe}^{9}$ dos 13,475Mtoe de demanda total global por energia foi fornecida por renováveis segundo o Boletim Estatístico da BP (2019).

Já a narrativa acelerada também acredita que a mudança de estoque tomará tempo, mas não vê na mudança de fluxo apenas uma mudança de fonte de energia primária. Esta mudança de fontes, contudo, tem grandes impactos pois mudanças significativas começam a acontecer quando o principal mercado consumidor das produtoras de combustíveis fósseis começa a decair. Além disso esta narrativa vê o mercado financeiro como catalizador de mudanças uma vez que a partir do momento em que as entidades percebam que existem sério riscos aos ativos das empresas de combustíveis fósseis, o custo de capital aumenta ou até mesmo o fluxo pode ser interrompido.

Este processo já pode ser visto em empresas do setor elétrico da Europa e também em muitas empresas de carvão que perderam valor de mercado, utilizado para a geração de eletricidade, como a Peabody Energy que tirou de seu balanço contábil o valor da maior mina de carvão do mundo em U\$ 1.4 bilhões (MEYER; HUME, 2020).

Por fim, a narrativa acelerada olha os combustíveis fósseis por fonte e afirma que o pico de uso do carvão é apenas o primeiro que será seguido provavelmente pelo pico de óleo e por fim de gás natural.

Segundo o relatório Gap Emissions Report (UNEP, 2019) em 2019, a capacidade nova instalada de geração de eletricidade de fontes renováveis (excluindo grandes hidroelétricas) foi a maior registrada e a capacidade total mundial instalada destas fontes representou 13,4 \%, um pequeno crescimento em relação a 2018 quando era 12,4\%. Isso representa um crescimento significativo em relação a 2009 quando era apenas 5,9\%. Este crescimento é lento devido ao tamanho enorme da infraestrutura dos combustíveis fósseis, embora os investimentos nas fontes renováveis (excluindo grandes hidroelétricas) seja 3 vezes maior em dólares do que os investimentos em infraestrutura para combustíveis fósseis em 2019.

Enquanto a narrativa acelerada coloca ênfase na expansão da eletricidade de baixo carbono, a gradual lembra que eletricidade era apenas 19\% da demanda em 2017 (IEA, 2018) portanto pequena parte do estoque do setor.

\footnotetext{
${ }^{9}$ Milhões de toneladas de equivalentes de petróleo. Medida comumente usada pelo setor petrolífero e que foi abandonada pela BP em seu último "Statistical Review" em favor da Joules, parte do Sistema Internacional de Unidades. 1 Mtoe $=41.868 \mathrm{Mj}$.
} 


\subsubsection{O desenvolvimento tecnológico no setor energético}

O segundo grande tema trata se o desenvolvimento tecnológico das fontes renováveis será linear ou exponencial. A discussão aborda o quão consolidado o setor energético ainda é, o que dificultaria inovação fora de seu paradigma. A narrativa gradual afirma que as novas tecnologias têm custos altos e impedimentos técnicos, como a intermitência, que dificultam sua adoção em escala massiva. A evolução da tecnologia é um processo lento e que demanda muito capital portanto só é possível planejar o futuro a partir do conhecido e não do que pode acontecer de novo.

Já a narrativa rápida acredita na possibilidade de curvas de aprendizagem aceleradas e na evolução combinatória das tecnologias. Com o aumento da oferta de eletricidade de fontes sem emissões de GEE e baratas uma serie de novas tecnologias serão desenvolvidas. E, à medida que as tecnologias atuais sem emissão de GEE do setor vão se consolidando, tecnologias voltadas aos elementos do setor energético e industrial mais difíceis de carbonizar vão se desenvolvendo.

Curvas de aprendizado ou de aprendizagem ${ }^{10}$ (learning curves) tecnológico são utilizadas como proxy para medir a difusão de uma inovação, uma vez que elas medem a queda dos custos de produção como função da experiência acumulada a partir da produção acumulada (JAMASB, 2007). Elas são baseadas no fato de que experiência, conhecimento e outros fatores melhoram a performance de uma tecnologia e logo reduzem seu preço. Elas são bastante usadas por pesquisadores e analistas de políticas públicas para prever tendências futuras tanto no setor energético como em temas relativos às mudanças climáticas (RUBIN et al., 2015).

O cálculo destas curvas é feito, em geral, a partir de um fator identificado que leva a queda de custos e preços. A equação ${ }^{11}$ é uma relação logarítmica linear ente o custo da tecnologia e sua produção acumulada ou capacidade de produção instalada acumulada. Este cálculo também é conhecido como o "aprender fazendo" ou learning by doing. No entanto uma série de estudos mostrou que existem outros fatores que influem na queda de preço além do aprendizado fabril. Além da decomposição de fatores da variável “aprender fazendo" entre melhorias no processo, mudanças no produto (por exemplo a diminuição da espessura dos

\footnotetext{
${ }^{10}$ Ambas traduções foram encontradas para a expressão original learning curves em inglês. Neste trabalho a tradução escolhida foi curvas de aprendizagem.

${ }^{11} \mathrm{Y}=\mathrm{a} \cdot \mathrm{x}^{\mathrm{b}}$ (onde $\mathrm{Y}$ é o custo da tecnologia, $\mathrm{x}$ e a experiência acumulada, a constante o custo da primeira unidade e a b a taxa de redução de custos)
} 
wafers dos painéis fotovoltaicos) e reduções de preços de insumos; novos fatores foram levantados como a disseminação de conhecimentos e gastos em pesquisa e desenvolvimento ("aprender pesquisando" ou learning by research). Desta maneira hoje em dia o mais comum são curva de aprendizagem de dois fatores ou mesmo curvas de um fator onde este fator representa uma somatória ponderada de fatores (idem). A maior dificuldade para o cálculo destas curvas é a falta de dados para validação e uso pois muitos destes dados são de propriedade privada dos diversos atores da cadeia produtiva.

Rubin et al (2015) fizeram uma extensa revisão sistemática da literatura sobre as curvas de aprendizagem das tecnologias de geração de eletricidade e encontraram dois tipos de uso em modelagem complexa de economia e energia: os que caracterizam a curva como endógena ou como exógena. Em modelos onde as curvas de aprendizagem são colocadas como fator endógeno o custo futuro da tecnologia não depende do tempo e sim da capacidade instalada. Em muitos destes modelos, principalmente os de longo prazo - entre 10 e 100 anos, é colocado um piso para a redução de preços das tecnologias para que elas não fiquem com valores irrealistas (idem). Esta metodologia é comumente usada nos estudos de tecnologias com evolução em forma de "S" porém os pisos não são comumente discutidos ou publicados (idem). Nos modelos que incluem as curvas de aprendizagem como exógenas o custo passa a depender do tempo pois os investimentos são retardados até que a nova tecnologia se torne competitiva. A utilização das curvas como endógena ou exógena ao modelo produz diferenças significativas nos resultados da modelagem, embora faltem estudos para compreender estas diferenças de forma mais detalhada. O estudo ressalta a importância da escolha das curvas de aprendizagem e seus fatores como custo inicial, desenho da curva, piso de custo etc., por parte dos modeladores (idem, p. 213).

As complexidades associadas ao cálculo das curvas de aprendizagem experiência geram uma grande quantidade de estudos com resultados com certa variação não sendo possível encontrar um número preciso para a curva de aprendizagem de cada tecnologia energética não fóssil atual.

Ainda assim nas últimas décadas houve uma queda de preços contundente nas tecnologias de geração elétrica. Segundo a IRENA (2020) as curvas de aprendizagem, entre 2010 e 2019, da fonte solar fotovoltaica é de $36 \%$, de eólica on-shore é $23 \%$, muito acima dos 10\% previstos pelo RCP8.5 (RIAHI, 2011 p. 43).

A geração fotovoltaica apresentou as maiores quedas de custo entre as tecnologias de geração elétrica e sua adoção mundial continua crescendo rapidamente. Nemet (2019) aponta 
vários fatores que influenciaram esta queda começando pelas contribuições científicas dos séculos XIX e XX. Ele narra o desenvolvimento e barateamento da tecnologia desde o primeiro uso comercial na década de 1950, passando pelo esforço de desenvolvimento da tecnologia pelo governo dos EUA na década de 1970, pelo desenvolvimento de nichos de mercado por corporações japonesas na década de 1980, pela adoção das tarifas feed-in na Alemanha a partir dos anos 2000, pelos cientistas e empreendedores chineses - muitos treinados na Austrália que construíram grandes fábricas na China a partir dos anos 2000 e principalmente nos últimos 10 anos.

A geração fotovoltaica através de placa de silício cristalino vem se consolidando mundialmente principalmente pela maturidade da tecnologia e pelo extenso parque industrial instalado principalmente na China e a queda do preço da matéria prima básica (IRENA, 2019a). Diferentes materiais têm diferentes taxas de eficiência e o National Renewable Energy Laboratory (NREL) mantém uma base de dados com a evolução das diversas tecnologias (fig. 12)

Figura 12: Evolução da eficiência de diversas tecnologias de geração FV ${ }^{12}$



Fonte: (NREL, 2020)

Os painéis de silício mono e multicristalino correspondem a $95 \%$ da produção mundial (IRENA, 2019a). E mesmo após anos de melhorias, que levaram a quedas de preço de 77\% entre 2010 e 2018 (idem), ainda existem caminhos para a melhora da eficiência destes painéis,

\footnotetext{
12 Tradução do gráfico. Em cima: Melhores eficiências de células fotovoltaicas em pesquisa. No eixo Y a legenda diz: Eficiência da célula (\%)
} 
como as novas arquiteturas para os painéis e novos formatos para os painéis que se adaptam à diversos usos, desde flutuantes até já integrados em telhas e outros matérias de acabamento. A demanda por prata para as placas solares vem se mantendo estável mesmo com o aumento da produção de painéis em um processo de redução de materiais e de custo (THE SILVER INSTITUTE, 2020). Tecnologias para manutenção de fazendas solares via veículos aéreos não tripulados (VANTS) com análise das imagens automáticas e melhores previsões de insolação a partir de ferramentas de inteligência artificial também estão sendo utilizadas e melhoradas (DAS et al., 2018). Existe, entretanto, o risco de que estejamos entrando em um lock in tecnológico e tecnologias comerciais promissoras, como a de perovskite, que tem mais flexibilidade no uso com maior eficiência, não se desenvolvam devido à consolidação dos painéis de silício como tecnologia dominante (SIVARAM, 2017).

No caso da geração eólica os estudos das curvas de aprendizagem têm grandes variações que vão de 33\% de queda até aumento de 3\% (RUBIN et al., 2015). Variações geográficas e metodológicas podem causar diferentes resultados para este tipo de estudo. Embora a fonte eólica onshore já seja considerada uma indústria madura, o custo por unidade de geração de energia segue caindo devido principalmente ao aumento de tamanho e de eficiência das turbinas.

Entre 2000 e 2018, o total instalado de eólica onshore cresceu de 17GW para 542 GW (IRENA, 2019b). Segundo análises da consultoria BNEF (MOORE; BULLARD, 2020) o custo da eletricidade proveniente de eólica onshore é o mais baixo entre toda as fontes de eletricidade em países onde vivem 2/3 da população mundial inclusive o Brasil. Um exemplo da evolução da geração eólica é o complexo de Mesa, no Estados Unidos, onde será feita a troca de 460 turbinas instaladas em 1983 por apenas 11 novas com mesma capacidade total nominal de geração, porém com maior geração total esperada pelas melhorias não só nos equipamentos em si, mas na gestão automatizada dos equipamentos que permite um melhor aproveitamento do vento (BULLARD, 2020a)

O desenvolvimento das tecnologias que permitem a geração de eletricidade em turbinas offshore, principalmente em águas profundas, vem começando a ter curvas de aprendizagem relevantes também, como pode ser visto no Reino Unido, onde os últimos contratos assinados bateram recordes de preço baixo (EVANS, 2018).

A IEA calcula que o potencial de geração off-shore apenas para localizações a até $60 \mathrm{~km}$ da costa e com profundidade de até 60 m corresponde à 1,5 vezes a demanda total mundial por energia (IEA, 2019b). 
Nos projetos de eólica offshore os rotores são maiores uma vez que há menores limitações de tamanho tanto por poluição sonora quanto por transporte e instalação. Com o aumento da área coberta pelo rotor existe um ganho de capacidade de geração e com o aumento da altura da torre a possibilidade de alcançar ventos mais constantes. Além disso novas tecnologias que permitem que as turbinas sejam flutuantes e não tenham fundações no fundo do oceano permitem que melhores ventos sejam utilizados. Várias destas tecnologias vêm de adaptações de tecnologias da indústria de exploração de combustíveis fósseis em alto mar. $\mathrm{O}$ fator de capacidade destas fazendas offshore também é mais alto e com menor variabilidade.

Espera-se que os custos continuem caindo pois as tecnologias vêm sendo aperfeiçoadas, inclusive com a utilização de tecnologias digitais que permitem não só manutenção preventiva, mas principalmente a previsão mais assertiva dos ventos e o controle automatizado das turbinas (IRENA, 2019b).

Na Europa, onde atualmente está instalada $90 \%$ da capacidade mundial, os custos da eletricidade gerada por esta fonte caíram 14\% entre 2010 e 2018, embora com um pico de custos durante a transição entre o desenvolvimento do offshore de águas rasas para águas fundas pois novas tecnologias precisaram ser desenvolvidas (idem). Somente no primeiro semestre de 2020 o investimento feito em eólica offshore foi maior que no total do ano anterior liderado por investimentos nos Estados Unidos (BNEF, 2020).

As características da eólica offshore a colocam em uma categoria única, segundo a AIE (IEA, 2019b), pois são fonte de eletricidade variável mas também podem ser consideradas como geração de base ${ }^{13}$.

Como está colocado no relatório SRES (IPCC, 2000) as fontes renováveis solar e eólica são variáveis, ou seja, eles não são despacháveis. Na realidade, mesmo a fonte hidroelétrica com reservatório tem certa variabilidade que tende a ser exacerbada pelas mudanças climáticas como vimos no período de seca no Brasil entre 2013 - 2015 (BRASIL. EPE, 2015; SAE PRESIDÊNCIA DA REPÚLICA, 2015).

Esta variabilidade sempre foi apontada como uma das barreiras à penetração destas fontes nos sistemas elétricos. O setor elétrico atual foi construído e otimizado para funcionar em torno de grandes usinas despacháveis, incluindo algumas que demandam tempo para começarem a produzir, como as termoelétricas a carvão e a nuclear. Os sistemas elétricos foram

\footnotetext{
${ }^{13}$ Geração de base corresponde ao nível mínimo de demanda em uma rede elétrica durante um período de tempo determinado.
} 
estruturados, desde os meros cabos até as maiores subestações, para garantir o trânsito de eletricidade de alguns poucos geradores de grande porte para um número infinito de consumidores espalhados. A rede elétrica tem que estar balanceada a todo momento; o consumo deve sempre ser igual à geração. Como as tecnologias de armazenamento ainda estão sendo desenvolvidas a eletricidade é sempre consumida em, no máximo, segundos após ser gerada. A demanda sempre foi variável, mesmo dentro de um padrão mais ou menos esperado, o que exigia um tipo de flexibilidade da rede, mas agora geração e demanda são flexíveis, adicionando mais uma camada de complexidade à rede elétrica.

O setor também sempre foi planejado como uma premissa de demanda crescente, pois historicamente houve uma forte correlação entre crescimento do Produto Interno Bruto e crescimento da demanda por energia, mas também de escassez, pois produzir apenas o necessário, uma vez que existem custos variáveis e dificuldades para o armazenamento.

O grande desafio técnico para a integração das fontes solar FV e eólica sempre foi a intermitência, que não é compatível com o desenho da rede elétrica. No relatório SRES (IPCC, 2000) há uma menção as tecnologias renováveis solar fotovoltaica e eólica, mas ele apresenta como condição para a adoção delas que houvesse 100\% de backup da geração em fontes fósseis e firmes. Este é um argumento que vem principalmente pelo fato de o setor ser consolidado e, portanto, todo o aparato técnico, organizacional e mesmo acadêmico tem profundas resistências à mudança (BONVILLIAN; WEISS, 2015). Os operadores das redes elétrica foram formados em uma época onde a possibilidade de integrar variáveis não era nem discutida e os sistemas de previsão de demanda e despacho da geração foram desenvolvidos há anos e com foco no despacho da geração (idem).

A integração das renováveis intermitentes às redes é um desafio técnico. O WEO 2018 (IEA, 2018) apresenta os desafios desta integração em 6 fases, dependendo do grau de penetração. Eles estimaram que até $10 \%$ de renováveis não teriam grande impacto para a estabilidade do sistema nem a necessidade de investimentos em um aumento da flexibilidade da rede. Na época Alemanha, Reino Unido e Itália já tinham mais de 10\% de penetração das variáveis nas suas redes elétricas (idem). No relatório do ano seguinte, o WEO de 2019 (IEA, 2019c) a média mundial de penetração de renováveis variáveis na geração de eletricidade já era superior a $25 \%$.

Os contra-argumentos sobre as dificuldades de insertar cada vez mais eletricidade de fontes variáveis na rede incluem (HEPTONSTALL; GROSS; STEINER, 2017; DIESENDORF; ELLISTON, 2018; CARDEN; DOMBROWSKY; WINKLER, 2020): vários 
países já produziram inclusive mais de $100 \%$ das suas necessidades a partir de fontes renováveis - como a Holanda - e não houve colapso do setor elétrico;

a) a variação não é tão randômica, segundo a segundo, e cada vez mais as tecnologias de aprendizado de máquina e inteligência artificial associadas a sensores é capaz de prever com precisão estas variações;

b) a interligação através de linhas de transmissão permite a distribuição da eletricidade entre locais produzindo e demandando energia;

c) o valor econômico das variáveis vem aumentando já que com a evolução das tecnologias eólicas e solar fotovoltaica é necessário cada vez menos espaço para a instalação das turbinas e placas solares e, devido às perdas de transformação que acontecem na combustão, essas fontes geram 3 x mais eletricidade por energia primária do que as fontes fósseis;

d) a produção de eletricidade a partir de fontes sem custos variáveis, mesmo quando não há demanda, não configura um problema pois havendo eletricidade barata disponível, mesmo que em horários específicos, ela será utilizada para novos usos;

e) as baterias estão se tornando capazes de absorver grande parte da intermitência e manter a oferta mesmo durante picos de demanda.

Rolnick et al. (2019) é um extenso relatório sobre aplicações de Aprendizado de Máquina para mitigação e adaptação às mudanças climáticas. Entre as possibilidades listadas no setor elétrico estão a utilização de aprendizado de máquina para acelerar a pesquisa de novos materiais e aperfeiçoá-los; para melhorar a previsão da demanda e da oferta, programação e controle da geração de eletricidade para que a integração das fontes intermitentes e fontes flexíveis possam se acomodar em um mercado avançado. Em 2020 a Google anunciou que está utilizando sistemas inteligentes que, a partir de previsões de produção de eletricidade solar e eólica adaptam seus centros de dados para consumirem mais eletricidade nestes períodos, garantido assim o uso de eletricidade sem emissão de GEE.

Uma das maneiras de absorver a variabilidade da geração de eletricidade das fontes renováveis é o desenvolvimento de tecnologias de armazenamento de energia. A necessidade de armazenar energia não é nova nem restrita à eletricidade de fontes renováveis devido a sua intermitência. A AIE, quando foi formada em 1974, após a $1^{\text {a }}$ crise do petróleo, estabeleceu que todos seus países membros deverão ter em estoque 90 dias de demanda de petróleo para cobrir eventuais quebras na cadeia de suprimento. 
A principal tecnologia que vem sendo desenvolvida e utilizada atualmente, tanto para absorver a intermitência das fontes renováveis solar e eólica como para a diminuição das emissões do transporte a partir da troca de automóveis com motores a combustão interna por automóveis elétricos, são as baterias de íons de lítio.

Elas foram desenvolvidas para o mercado de equipamentos eletrônicos e depois para veículos elétricos, mas hoje em dia elas já estão sendo utilizadas dentro do setor elétrico, seja para armazenamento antes do medidor, ou seja, disponível apenas para o usuário que a instalou, ou na rede elétrica como um todo (BLOCH et al., 2019).

A descarbonização do transporte é parte importante da transição energética uma vez que ele é responsável por aproximadamente 1/4 das emissões do setor energético (SIMS et al., 2015). A eletrificação do transporte terrestre se dá em ônibus, triciclos, motos e veículos leves dependendo das características dos mercados. Geograficamente, a China é onde está o maior número de veículos elétricos de qualquer tipo. Embora apenas em 20 países no mundo, o total de novos veículos elétricos registrados superou a marca de $1 \%$ do total e o crescimento da frota de elétricos foi de 17.000 unidades em 2010 para 7.2 milhões em 2019 (IEA, 2020a). O preço da bateria caiu de U\$1160/kWh para U\$156/kWh entre 2010 e 2019 (BNEF, 2019) ao mesmo tempo que a densidade energética e número de ciclos de vida útil continuam subindo e o peso delas vem caindo (BLOCH et al., 2019).

O armazenamento de energia vem sendo utilizado na rede elétrica para prover eletricidade de forma mais contínua, contrabalançando a intermitência, e também para prover vários dos chamados serviços ancilares, que são aqueles serviços necessários ao bom funcionamento da rede, como fornecimento de eletricidade em momentos de demanda excessiva, regulação de frequência, energia de reserva etc. Estes serviços até então só eram ofertados por fontes firmes, em muitos dos casos emissoras de GEE. Com a queda do custo das baterias e a possibilidade de carregá-las, quando existe excesso de oferta na rede elétrica, a preços baixos, as baterias na rede estão começando a substituir termelétricas a gás natural que funcionam apenas para suprir os picos de demanda em países como os Estados Unidos (BULLARD, 2020b).

Além da queda de preços das fontes renováveis e sua intermitência alterando a estrutura do mercado elétrico outra grande mudança no setor energético vem do fato de que as fontes solar e eólica são deflacionárias, ou seja, o custo desta energia decresce pois as tecnologias estão ficando cada vez mais baratas e os custos variáveis são muito mais baixos uma vez que 
as fontes primárias, sol e vento, não têm custos, não precisam de exploração, de transporte nem de transformação.

A geração de eletricidade com baixo custo e não despachável faz com que seja comum que a geração eólica e solar seja superior à demanda em vários momentos. Isso significa que eletricidade barata e variável é uma característica deste novo modelo elétrico. Até agora este aspecto foi visto como defeito das novas renováveis, porém, conforme a inserção das renováveis vai amadurecendo, fica cada vez mais evidente que existe um mercado para eletricidade variável com custo muito baixo. Este não é o perfil energético de todas as demandas mas funcionariam, por exemplo, para a eletrólise de hidrogênio ou para armazenar a eletricidade barata e abundante como calor para usos industriais (FORSBERG et al., 2017).

O relatório "Mission Possible" da Energy Transition Comission (ENERGY TRANSITION COMISSION, 2018) - uma coalização de empresas e ONGs, aponta 3 soluções para ofertar energia aos chamados setores "mais difíceis de mitigar" (harder to abate): o uso de biomassa como fonte de energia, a captura e estocagem de carbono e a utilização de eletricidade ou combustíveis gerados a base de eletricidade, como hidrogênio ou amônia (idem). Pelas análises do relatório seria possível descarbonizar $80 \%$ destes setores utilizando eletricidade, amônia e hidrogênio. O hidrogênio é o vetor energético conhecido mais eficiente e pode ser obtido de diversas fontes, mas a eletrólise da água é considerada a mais sustentável pois a quebra da molécula emite apenas oxigênio como produto da reação. A produção de hidrogênio através da hidrólise da água é um processo que demanda muita energia por isso foi visto como economicamente inviável (SHIVA KUMAR; HIMABINDU, 2019).

Segundo relatório da AIE (IEA, 2019d) esta tecnologia está passando por um momento de impulso sem precedentes e pode fazer com que a eletricidade proveniente das fontes renováveis contribua ainda mais para a transição energética. Um estudo da BNEF indica que produzir hidrogênio a partir de eletrólise com eletricidade renovável, o chamado hidrogênio verde, é possível com custos muito baixos e a médio prazo em países com fontes potenciais abundantes de eletricidade solar e eólica como o Brasil (PANIK, ; BNEF, 2020). Apesar da recente evolução das tecnologias e das quedas de custo, muitas tecnologias fundamentais para a transição energética ainda não estão maduras.

A IEA lançou um relatório sobre as perspectivas tecnológicas da transição energética (IEA, 2020b) onde analisa as tecnologias necessárias para a transição segundo seu grau de maturidade. Ela classificou estas tecnologias desde a fase de pequenos pilotos até maduras em uma escala de 5 níveis. Segundo seus cálculos para que seu cenário, chamado Desenvolvimento 
Sustentável e atualizado todos os anos, se realize apenas 25\% das tecnologias necessárias já são maduras e 34\% ainda estão em projetos pilotos ou na fase intermediária, da escala a demonstração.

O relatório divide as cadeias de redução das emissões em três grandes grupos. O primeiro é a de eletrificação com baixo carbono, que representa $40 \%$ das reduções totais e nesta cadeia as que estão mais atrás no seu desenvolvimento são as relacionadas à captura de $\mathrm{CO}_{2}$, como geração de eletricidade a partir de gás natural e biomassa, e à eletrificação da indústria pesada como cimento, aço e química, os chamados setores difíceis de mitigar.

A segunda é a cadeia de valor do $\mathrm{CO}_{2}$ incluindo as várias formas de captura e uso que corresponde a $15 \%$ da redução das emissões. A maioria das tecnologias citadas está na etapa de projetos de demonstração e poucas já são consideradas maduras - como amônia para absorção química e recuperação terciária de petróleo - ou em começo de adoção, entre elas dutos para condução de $\mathrm{CO}_{2}$ e hidrogênio azul, produzido a partir de metano.

A terceira cadeia é a do hidrogênio com baixa emissão de $\mathrm{CO}_{2}$, que começa na produção de hidrogênio azul na cadeia de captura de $\mathrm{CO}_{2}$ e do hidrogênio verde na cadeia da eletrificação de baixo carbono. Esta cadeia é considerada como responsável por $20 \%$ das reduções de emissões. Nela apenas algumas infraestruturas como tanques e dutos são consideradas maduras.

O relatório nota que tecnologias modulares, como solar e eólica, e a digitalização são tecnologias que escalam mais rapidamente e com menor custo devido às curvas de aprendizagem e por serem parte de uma cadeia que tem uma grande difusão de conhecimento. Do outro lado, para projetos de grande escala como CCS cada avanço da tecnologia custa muito mais, logo menos unidades são construídas e as curvas de aprendizagem e as possibilidades de difusão de conhecimento são muito menores.

Embora a AIE seja frequentemente criticada pelo seu excesso de prudência e por superestimar os custos das tecnologias não fósseis (fig. 13) este relatório é parte de um esforço de atualizar suas premissas tecnológicas. 
Figura 13: histórico de projeções da AIE para a adoção da tecnologia $\mathrm{FV}^{14}$

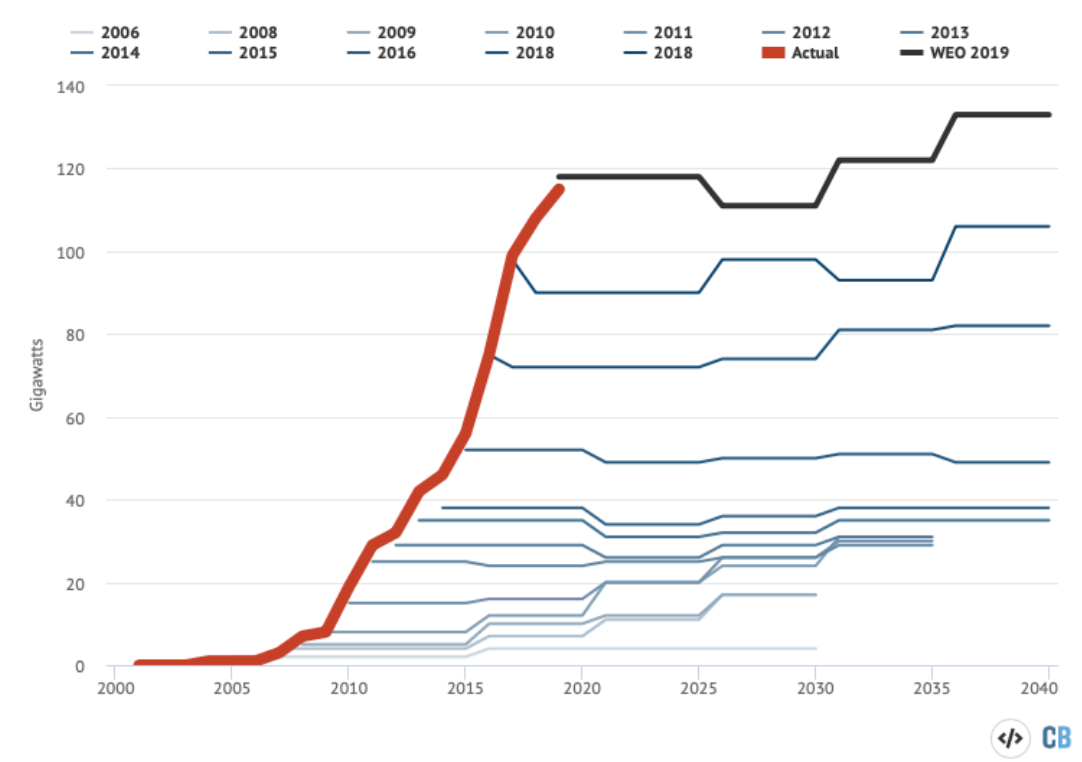

Annual net additions of solar capacity around the world, gigawatts. Historical data and an estimate for 2019 are shown in red while central outlooks from successive editions of the WEO are shown in shades of blue. The WEO 2019 STEPS is shown in black. Source: IEA World Energy Outlook 2019 and previous editions of the outlook. Chart by Carbon Brief using Highcharts.

Fonte: Evans, 2020

\subsubsection{Papel das políticas públicas}

Não é possível compreender a transição energética sem reconhecer que se trata de uma coevolução entre tecnologia, políticas públicas e política (SCHMIDT; SEWERIN, 2017). Desta forma, a outra face da transição energética, além do desenvolvimento tecnológico, são as políticas públicas que aceleram ou atrasam a transição, bem como as pressões sociais numa ou noutra direção. A narrativa gradual da transição aponta a necessidade de implementação de políticas públicas como um fator que torna a transição energética lenta (HELM, 2010; JOHNSTONE; STIRLING; SOVACOOL, 2017; STOKES; BREETZ, 2018) e citam como exemplo o fato que após anos de discussão sobre uma taxa de carbono ela ainda não foi implementada de forma generalizada (WORLD BANK, 2019) .

A narrativa acelerada vê as pressões da sociedade, no momento atual, a favor de políticas públicas climáticas com um aumento da consciência sobre os riscos climáticos. Além do mais as políticas públicas também se adaptam às realidades econômicas ou se aproveitam delas para se aproximarem das demandas da sociedade. Com a queda do custo da eletricidade proveniente de fontes renováveis, fica cada vez mais difícil aprovar e implementar políticas

\footnotetext{
${ }^{14}$ Tradução do gráfico. Adições liquidas anuais de capacidade instalada de solar FV no mundo em gigawatts. Dados históricos e uma estimativa para 2019 estão em vermelho e as estimativas dos cenários centrais da AIE em tons de azul. O cenário da AIE chamado STEPS está em preto. As fontes são as diversas edições do WEO.
} 
climáticas que beneficiam as fontes não fósseis. Por último, uma vez que uma nova tecnologia se torna competitiva e o mercado começa a adotá-la, todo o ambiente onde ela opera e interage muda para adaptar-se. Ou seja, para os propositores desta narrativa, o papel das políticas climáticas é claro e importante, porém eles acreditam que a transição energética em curso, apesar de ainda poder se beneficiar de políticas públicas, já está acontecendo baseada em fatores econômicos e expectativas sociais (EKINS, 2019) .

O número de países e cidades apoiando a transição energética, seja através do compromisso de tornarem-se neutros em carbono ou através da proibição gradativa da venda e uso de veículos de combustão interna, já é relevante e existe um número crescente de corporações fazendo o mesmo tipo de compromisso. (UNEP; BNEF; FRANKFURT SCHOOL, 2020). Segundo o relatório da UNEP (idem) já são 77 países, 10 regiões e mais de 100 cidades que se comprometeram a tornar-se neutros em emissões de GEE até 2050, além de centenas de corporações, incluindo 19 das 100 maiores do mundo em receita. Além disso 17 países já anunciaram a proibição de vendas de veículos a combustão interna nos próximos 20 anos (IEA, 2020a).

Os reguladores dos mercados financeiros já estão estimulando que os mercados conheçam os riscos climáticos a que não só as instituições financeiras, mas também os clientes delas estão expostos (TCFD, 2017). Isto inclui os chamados "stranded assets" - ativos que não poderão ser utilizados ou explorados no futuro devido às emissões de GEE associadas. Somente no primeiro semestre de 2020, grandes empresas produtoras de petróleo como BP e Shell anunciaram um corte em seus ativos devido a possibilidade de que não seja possível explorar estas reservas pelas restrições aos combustíveis fósseis (RAVAL, 2020a, 2020c). Outro exemplo desta tendência é a saída da EXXON do índice Dow Jones e a queda da participação do setor energético do índice (LANGLEY, 2020). Seguindo esta tendência, um número cada vez maior de empresas no mundo todo estão se comprometendo a serem neutras em emissões em horizontes que vão de 2020 a 2030. Inclusive empresas petrolíferas como a Repsol, que se comprometeu a se tornar neutra até 2050 (RAVAL, 2020b).

A transição energética trás enormes benefícios coletivos como a mitigação das mudanças climáticas e melhora da qualidade do ar, porém ela trás custos privados muitas vezes mal distribuídos, incluindo investimentos financeiros frequentemente repassados para contribuintes ou consumidores de energia e perdas de empregos (BREETZ; MILDENBERGER; STOKES, 2018). Existe uma vasta literatura que discute a existência de relações entre as instituições políticas e os atores econômicos e que mostram como, através 
destas relações, as instituições articulam os interesses corporativos nos processos de tomada de decisões políticas nas áreas de energia e clima e assim definem a habilidade dos diversos atores de negociar a transição energética (idem).

Em grande parte, a impressionante queda nos custos da geração de eletricidade das fontes eólica e solar foi baseado em subsídios governamentais e aumento do custo para os consumidores, principalmente na Alemanha (NEMET, 2019). Quando estas políticas públicas de apoio à transição energética começam a afetar financeiramente os operadores consolidados, sejam as distribuidoras de eletricidade, as empresas geradoras de eletricidade a carvão, ou as produtoras de petróleo, a oposição a estas políticas por parte destes operadores cresce e alcança suas relações políticas. As instituições políticas que apoiam o desenvolvimento de novas tecnologias para que elas se tornem vencedoras no novo modelo não são as mesmas que permitem que os setores consolidados tenham perdas econômicas (BREETZ; MILDENBERGER; STOKES, 2018).

É importante ressaltar que muitos dos perdedores desta transição energética são empresas governamentais. Desde grandes empresas de petróleo como a Petrobrás até geradoras e transmissoras como a Eletrobrás e distribuidoras de eletricidade. As empresas nacionais de petróleo são gigantes econômicos que controlam pelo menos USD 3 trilhões em ativos e produzem em torno de $60 \%$ do gás e petróleo do mundo (IEA, 2020c) Estas empresas são pouco transparentes e, normalmente, grandes fontes de recursos para seus governos nacionais e de emprego para população. Existem dúvidas se a maioria destas empresas participará ativamente da transição energética (HELLER; MIHALYI, 2019) e, por enquanto, elas investem menos em energias renováveis que as empresas privadas (IEA, 2020c).

\subsubsection{O Papel do Leapfroging}

O último dos quatro aspectos importantes que diferencia as narrativas é como os mercados emergentes desenvolverão seus setores energéticos. Segundo a AIE, quase 1 bilhão de pessoas no mundo não têm acesso à eletricidade enquanto em países mais desenvolvidos a demanda por eletricidade está estável ou decaindo (IEA, 2019c). O objetivo 7 dos Objetivos do Desenvolvimento Sustentável da ONU é “assegurar o acesso confiável, sustentável, moderno e a preço acessível à energia para todas e todos”. Além do acesso à energia existe a questão do consumo per capita que também é muito desigual ao redor do mundo (fig. 14). 
Figura 14: Consumo de eletricidade per capta no mundo (2017)

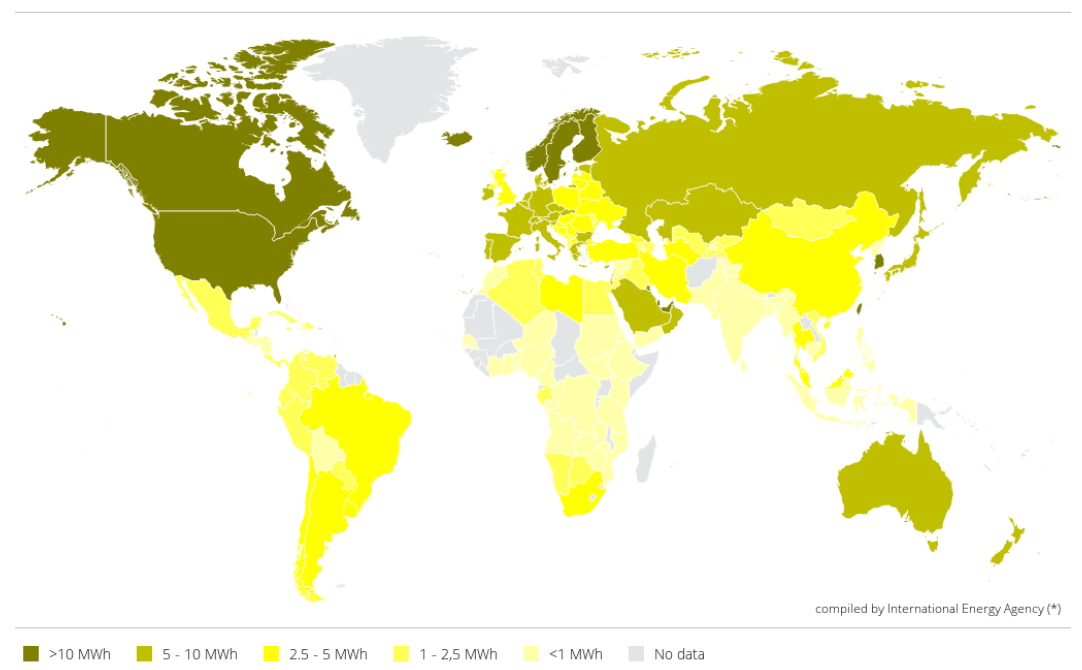

Fonte: IEA, 2019

A importância e a necessidade de universalização da eletricidade são reconhecidas por ambas as narrativas. As diferenças aparecem na visão de como o setor energético de países onde o acesso à energia ainda não é universal irá se desenvolver. A narrativa gradual acredita que estes países seguirão o mesmo caminho trilhado pelos países desenvolvidos e o setor crescerá baseado em combustíveis fósseis, com termoelétricas a carvão e automóveis com motores à combustão interna.

A narrativa acelerada acredita que estes países, incluindo China e Índia, vão fazer um leapfroging tecnológico. Goldenberg (2020) faz uma análise da intensidade energética e de emissões de GEE entre 1990 e 2014 e encontra um declínio contínuo para todos os grupos de países, desde os de maior renda até os de menor, com poucas exceções. Segundo ele, entre os fatores de maior peso para este descolamento está o leapfrogging tecnológico, além do aumento da eficiência do setor devido à eletrificação e ao aumento da participação de fontes renováveis.

Abramovay (2014) também mostra que existem condições técnicas e econômicas para este leapfroging energético nos países em desenvolvimento

O argumento é que as fontes renováveis já são mais baratas que os combustíveis fósseis, são construídas mais rapidamente e de maneira modular e os recursos - sol e vento - são locais, sem necessidade de importação de combustíveis fósseis. Além do mais o nível de poluição ambiental de países como China e Índia torna menos atraente a utilização de combustíveis fósseis. Embora China e outros países continuem construindo termoelétricas a carvão, no primeiro semestre de 2020, pela primeira vez na história, a capacidade total instalada de carvão diminuiu no mundo. 


\section{CONCLUSÕES}

O objetivo desta dissertação foi avaliar a premissa (RIAHI et al., 2011, tradução nossa ${ }^{15}$ ) do cenário RCP8.5:

“O cenário assume um ritmo relativamente lento de inovação em tecnologias não fósseis, levando a melhoras modestas de custos e performance (...) por exemplo curvas de aprendizagem abaixo de $10 \%$ por cada vez que a capacidade instalada dobra (...) Em contraste com a maioria das tecnologias, acontecem significativa melhorias acontecem nas alternativas fósseis além da penetração de um número de novas tecnologias fósseis avançadas"

E quando utilizamos como métrica as curvas de aprendizagem citadas no RCP8.5 (idem) podemos dizer que sim existe inovação na geração de energia através de fontes não fósseis e esta inovação é pujante e capaz de levar a quedas de preços e aumento da performance expressivas, o que contraria as premissas do cenário.

Com base no levantamento de dados e na revisão da literatura acadêmica e cinzenta, a hipótese levantada é corroborada já que a premissa claramente expressa do cenário não pode ser validada na realidade dos últimos 15 anos e não existem indicações de que haverá uma mudança significativa na trajetória da atual transição energética. A tecnologia não parece ser uma barreira aos esforços de transição (JAFFE; NEWELL; STAVINS, 2005; ENERGY TRANSITION COMISSION, 2018; STOKES; BREETZ, 2018; MAZUR et al., 2019).

A sugestão dada por pesquisadores da área de energia, modeladores e profissionais de diversas áreas do setor energético, incluindo Hausfather e Peters (2020), para que as premissas energéticas sejam reconsideradas e o cenário mais extremo do IPCC seja reescrito deveria ser considerada pelo Painel porque estes cenários têm muita influência, tanto na academia quanto na comunicação com a população em geral. Os chamados à atualização destes cenários de referência para que eles se tornem mais condizentes com a realidade energética e de políticas climáticas atuais (“Business as unusual”, 2017) já aparecem na literatura há alguns anos.

\footnotetext{
15 "(...) the scenario assumes consistent with its storyline a relatively slow pace for innovation in advanced nonfossil technology, leading for these technologies to modest costs and performance improvements (e.g. learning rates for renewables are below $10 \%$ per doubling of capacity). (...) In contrast to most other technologies, there are significant improvements in existing fossil alternatives as well as the penetration of a number of new advanced fossil technologies (...)"
} 
A avaliação periódica da literatura científica sobre as mudanças climáticas do IPCC não é apenas uma revisão independente de trabalhos publicados. Ela também é produto de um processo interativo que continuamente formula questões e busca respostas; onde autores avaliadores são muitas vezes autores dos artigos; onde o conhecimento é ativamente refinado durante o processo de avaliação (OPPENHEIMER et al., 2019). Vasileiadou, Heimeriks e Petersen (2011) fazem uma análise do impacto dos relatórios do IPCC na ciência em geral e descrevem o Painel como um "monstro epistemológico" pela sua influência, medida em citações, em múltiplas disciplinas.

Quando o IPCC publica os seus cenários, embora o Painel não diga aos formuladores de políticas públicas quais escolhas fazer, ele não apresenta todas as opções de futuro existentes e sim um conjunto de opções que eles, cientistas do IPCC, acreditam ser razoáveis. Instituições como o IPCC funcionam como tradutores e mediadores entre os modelos, as avaliações e as projeções feitas pelos cientistas e os documentos relevantes para políticas públicas (O'REILLY; ORESKES; OPPENHEIMER, 2012). Nas últimas décadas, o IPCC, junto com um conjunto de iniciativas globais, se tornou uma parte fundamental da interface entre ciência, políticas públicas e sociedade (KOWARSCH et al., 2017) Beck e Mahoney (2018) afirmam que o desenvolvimento dos RCPs são fatos científicos sobre possíveis futuros climáticos, mas também são intervenções políticas que definem a liberdade de escolha de políticas climáticas e a gama de tecnologias possíveis. Desta maneira o IPCC não só imagina futuros, mas também cria estes futuros ao escolher trajetórias de referência e suas tecnologias (idem).

Pindyck (2017) afirma que analisar políticas climáticas baseando-se em cenários cria uma sensação ilusória de conhecimento e de precisão. Este tipo de análise é enganosa pois pode dar a sensação de que os futuros gerados pelos modelos têm algum tipo de legitimidade científica e aponta, entre outras falhas, o fato de que premissas são arbitrárias e têm efeito enorme sobre os resultados dos modelos. Embora Pindyck (idem) esteja se referindo a modelagem econômica de políticas climáticas, ele mesmo expande sua crítica ao afirmar que todos os modelos e cenários têm falhas por serem simplificações da realidade, ainda que cenários sejam úteis ao organizarem de maneira consistente e lógica as relações entre variáveis e permitirem compreender relações e implicações.

O ciclo de 7 anos de avaliação do IPCC é longo para um momento de rápidas inovações tecnológicas como o atual no setor energético. A AIE, frequentemente criticada pelo seu conservadorismo quanto as tecnologias renováveis em seus cenários energéticos (CARRINGTON; STEPHENSON, 2018; MOHN, 2020), publica, todos os anos, 3 cenários 
diferentes com premissas atualizadas. Inclusive os nomes dos cenários são atualizados quando necessário. O World Energy Outlook é uma publicação extensa com muitos detalhes sobre as premissas de cada cenário apresentado. Já os RCPs do IPCC foram publicados em 2011 e somente em 2021, no novo ciclo, serão atualizados e mesmo assim somente com a inclusão de novas trajetórias, mas já com publicação de cenários feitos com a matriz das duas trajetórias de emissões e socioeconômicas (“The CMIP6 landscape”, 2019). O RCP8.5 (RIAHI et al., 2011) é uma adaptação publicada em 2007 (RIAHI et. al, 2007) de um cenário de 2000 (IPCC, 2000).

Além disso a nomenclatura utilizada em Riahi et al. (2011, p. 43) para descrever o cenário como "relatively conservative business as usual case with low income, high population growth and high energy demand due to only modest improvements in energy intensity", (grifo nosso) causa uma desconexão entre o que está escrito e como é frequentemente utilizado por várias razões.

A expressão BAU utilizada aqui tem significado particular para o IPCC. São cenários de referência, ou seja, que não têm nenhuma política climática, nenhum esforço para reduzir as emissões de GEE, durante o decorrer do período modelado. Como o cenário RCP8.5 é utilizado como BAU ele representa as políticas climáticas de 2005, seu ano de referência, e ele já correspondia ao percentual de 90 dos cenários publicados como BAU (VAN VUUREN et al., 2011). A expressão BAU cristaliza o cenário no tempo, em 2005, mas não significa que é a continuação do mundo como existe hoje. Schawlm (2020) compara o cenário da AIE de Políticas Atuais - Current Policies - como "business as usual” e do Políticas Declaradas Stated Policies - como “business as intended". Porém não é possível comparar o BAU de um cenário estático de 15 anos atrás com um cenário atualizado anualmente.

É justamente nesta expressão que talvez esteja o cerne da discussão entre os modeladores climáticos e os pesquisadores de energia. Se o RCP8.5 fosse apenas um desenho de concentrações de emissões muito elevadas para que cientistas pudessem avaliar o impacto desta curva de emissões em seus diversos campos, mas sem uma storyline por detrás que envolvesse premissas energéticas - que não estão se materializando acompanhada da expressão BAU - o RCP8.5 não seria questionado por estes pesquisadores de energia. Como estes modelos são baseados em cenários normativos, ou seja, define-se onde se quer chegar primeiro e depois se busca como chegar lá, as premissas energéticas para um cenário tão extremo são necessariamente extremas já que elas são $2 / 3$ do total (incluindo o setor industrial) e as mais simples de modelar. Outro exemplo, na mesma linha, é a construção do cenário $1.5^{\circ} \mathrm{C}$ (ROGELJ 
et al., 2018b) e a ampla utilização das tecnologias de emissões negativas como Bioenergia com Captura e Estocagem de Carbono (BECCS), uma tecnologia ainda em fase de pequenos protótipos, claramente com o intuito de chegar ao objetivo do cenário (FRIDAHL; LEHTVEER, 2018; HAIKOLA; HANSSON; ANSHELM, 2019).

O relatório da UNEP Emission Gap (UNEP, 2019), publicado todos os anos, trás cenários atualizados com as políticas climáticas adotadas no mundo e utiliza como cenário base o Cenário de Políticas Climáticas de 2005. A figura 15 mostra a diferença entre trajetória prevista pelas políticas climáticas de 2005, ano base do RCP8.5 e 2019.

Figura 15: Trajetórias previstas de emissões em diversos cenários de políticas climáticas ${ }^{16}$

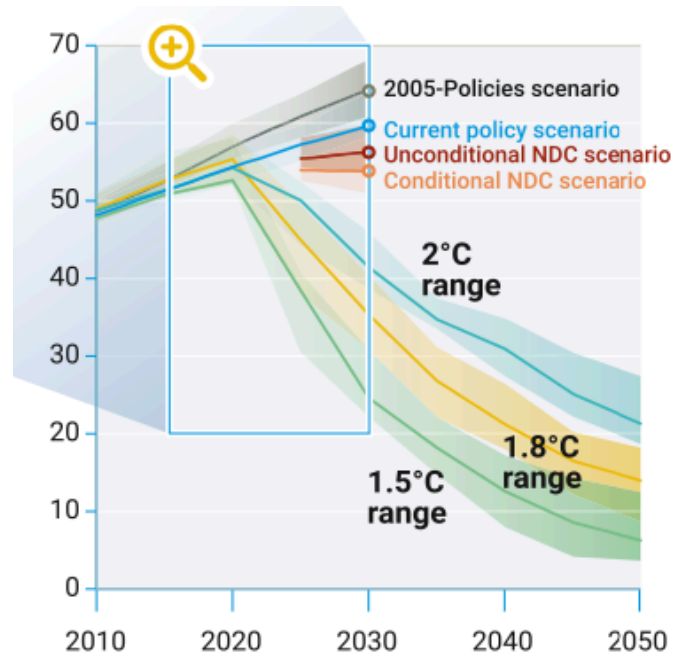

Fonte: UNEP, 2019

É inegável que as emissões continuam subindo e que até agora não fomos capazes de “dobrar a curva" das emissões de GEE da maneira necessária para mantermos o aumento da temperatura em até $2^{\circ} \mathrm{C}$. É inegável também que, por enquanto, as emissões reais estão próximas da trajetória de emissões previstas no RCP8.5. No entanto, isso não quer dizer que a trajetória atual seja representativa do cenário desenhado há 15 anos.

A atual controvérsia sobre o RCP8.5 entre modeladores climáticos e energéticos se concentra basicamente na transição energética que aconteceu nestes últimos 15 anos. A discussão não é na viabilidade de uma trajetória de emissões conforme a descrita neste cenário e sim no que está por trás desta trajetória. Os pesquisadores e modeladores de energia afirmam

\footnotetext{
16 Tradução do gráfico. Em negro cenários de políticas de 2005; em azul cenário das políticas atuais; em vermelho cenário das CND incondicionais; em laranja cenário das CND com condições. As áreas abaixo são as faixas de $2^{\circ} \mathrm{C}, 1.8^{\circ} \mathrm{C}$ e $1.5^{\circ} \mathrm{C}$ nesta ordem.
} 
que o cenário descrito dificilmente representa a realidade que já estamos vivendo. Os ganhos de custos e as inovações tecnológicas não serão revertidas. A importância de ter um cenário de emissões muito altas comum a todos os cientistas não é questionado. A questão aqui trata de apropriação correta das fontes de emissões.

Uma das justificativas de termos um cenário com trajetória de emissões tão alta é a possibilidade de tipping points. Os feedbacks bióticos e os tipping points são vistos como cruciais para a evolução do clima na Terra (SCHEFFER et al., 2001) pois podem se tornar processos decisivos que controlariam a trajetória do clima (STEFFEN et al., 2018), porém não fazem parte do cenário RCP8.5. Além disso, as emissões provenientes da mudança do uso da terra são de difícil medição pois são o resultado de dois processos - as emissões menos as absorções - e podem ter sido subestimadas no RCP8.5 (NOBRE; NOBRE, 2002; HANSEN; STEHMAN; POTAPOV, 2010; ARNETH et al., 2017; YUE et al., 2020).

Das várias premissas listadas no quadro 2 a escolhida para a análise foi sobre a dissociação entre a inovação nas tecnologias energéticas fósseis e a não inovação nas fontes não fósseis. Contudo, desta premissa advêm outras: a de que iremos utilizar toda a reserva conhecida de petróleo e, ao final, nossa matriz se voltará totalmente para o carvão com inovações como a conversão de carvão para combustível líquido para transporte. Nenhuma destas premissas parece válida em um momento onde as fontes renováveis são cada vez mais as mais baratas e as tecnologias que permitem o aumento da inserção delas nos sistemas energéticos cada vez mais desenvolvidas e economicamente viáveis. Mesmo o aumento do número de termoelétricas a carvão, principalmente na China, parece estar sendo movido mais por política e pelo fato do setor ser tão consolidado do que por fatores econômicos (BODNAR et al., 2020). Estudo da consultoria Ember mostrou que as termelétricas estão produzindo eletricidade durante cada vez menos tempo (figura 16) e em 2020 em média só foram utilizadas $51 \%$ do tempo. O pico da utilização de carvão como combustível parece ter acontecido em 2013 (JONES; GRAHAM; TUNBRIDGE, 2020). A transição energética em direção a descarbonização está acontecendo, mas não na rapidez necessária para evitar as trajetórias de emissões compatíveis com o RCP4.5 ou o RCP6.0 (HAUSFATHER; PETERS, 2020).

Na premissa analisada, a métrica indicada era a curva de aprendizagem, estabelecida em no máximo 10\% para as renováveis (RIAHI et al., 2011 p. 43). Todos os indicadores, seja da IEA, IRENA, de artigos acadêmicos ou das consultorias especializadas apontam para números muito superiores a este, principalmente para a fonte solar fotovoltaica e mais recentemente para as baterias de íons de lítio. Entretanto, a análise da inovação da transição energética feita 
somente através de curvas de aprendizagem não reflete as barreiras políticas e interesses econômicos envolvidos na transição que implicará em ganhadores e perdedores. As barreiras políticas, econômicas, sociais e as impostas por grupos de interesses contrários à transição energética atual também precisam ser estudadas, porém é muito difícil quantificá-las para poder incluí-las em modelagens quantitativas por isso muitas vezes elas apenas são representadas em cenários qualitativos.

Figura 16: Evolução da utilização das termelétricas a carvão desde $2010^{17}$

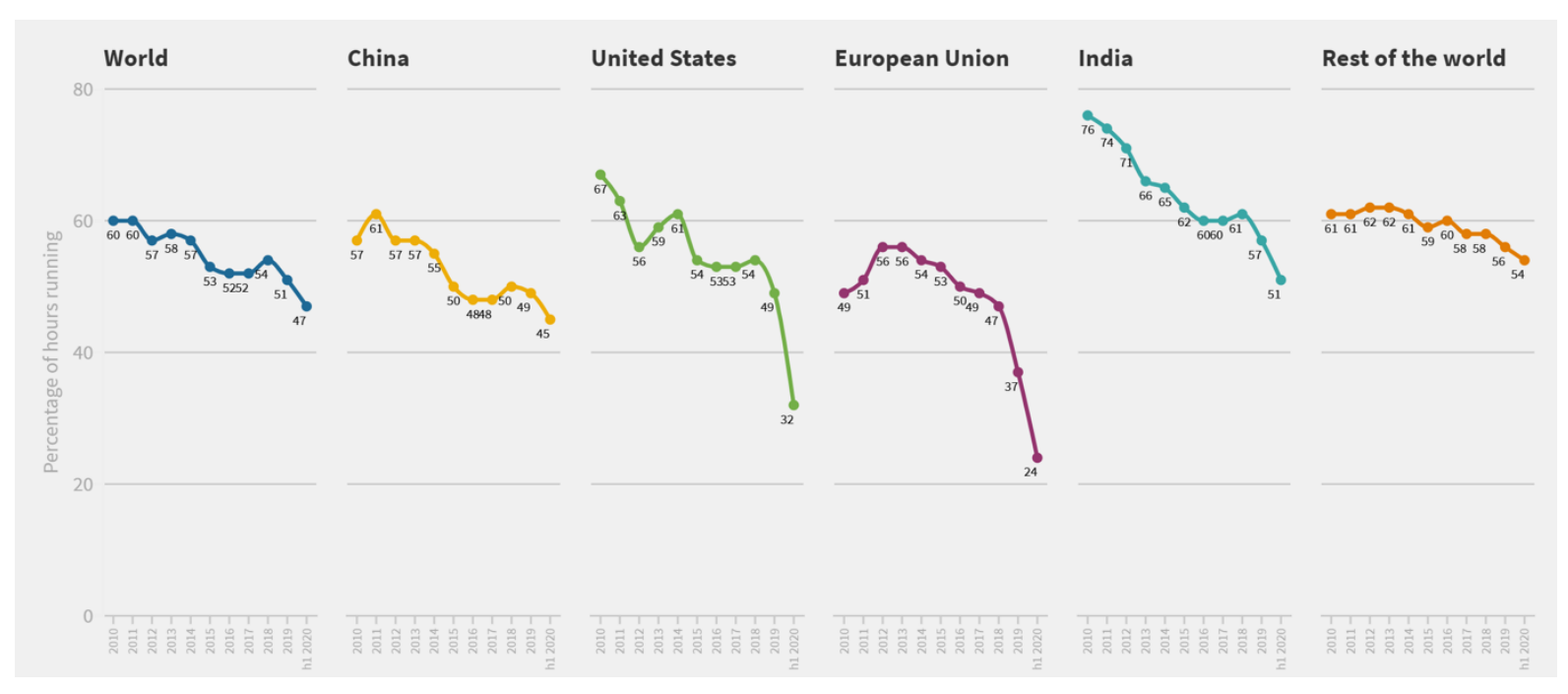

Fonte: Jones, Graham; Tunbridge, 2020

Supran e Oreskes (2017) mostram a estratégia dos executivos das empresas petrolíferas americanas de difundir desinformação sobre as mudanças climáticas e suas causas buscando preservar seu modelo de negócio de exploração de combustíveis fósseis. As empresas de petróleo nacionais (NOC, por suas iniciais em inglês), ou seja, empresas que pertencem a governos de países, são responsáveis pela grande maioria da extração de petróleo no mundo. Relatório (HELLER; MIHALYI, 2019) publicado em 2019 levantou 71 NOCs localizadas em 61 países, inclusive o Brasil, e entre estes países, em 25 deles a NOC era responsável por pelo menos $20 \%$ de toda a fonte de renda do governo. Estas empresas repassam grande parte de suas receitas para os governos de seus países e, no mais recente boom do petróleo, entre 2011 e 2014, a maior parte dela reinvestiu estes ingressos em mais infraestrutura de exploração de petróleo. Para termos $50 \%$ de probabilidade de ficarmos dentro do objetivo de $2^{\circ} \mathrm{C}$ máximo de aumento da temperatura, cientistas calculam que o orçamento de carbono é equivalente a um terço das reservas de combustíveis fósseis, o que implicaria em 33\% do petróleo, $49 \%$ do gás

\footnotetext{
17 Tradução do gráfico. No eixo Y: percentagem de horas gerando. Da esquerda para a direita os gráficos são referentes a: mundo, China, Estados Unidos, União Europeia, Índia e resto do mundo.
} 
natural e $82 \%$ das reservas de carvão que devem ficam no subsolo (MCGLADE; EKINS, 2015) e transforma estes investimentos em ativos irrecuperáveis (stranded assets) e grande parte destes ativos pertence a NOCs (ABRAMOVAY, 2020).

Se em 2020, BP e Shell cortaram parte de suas reservas de seu balanço de ativos, desde 2008 empresas europeias de eletricidade perderam em torno de 500 bilhões de Euros em termos de valor de mercado (HELMS, 2016) em processo chamado de destruição de valor dos acionistas. Esta destruição se deve a uma diminuição no consumo de eletricidade devido a ações de aumento de eficiência energética e ao estímulo à geração distribuída principalmente com solar FV de microescala; e à perda de valor das unidades de geração, principalmente a carvão destas empresas que não conseguem concorrer com preços mais baixos das fontes renováveis (idem).

Como recomendação de trabalhos futuros dois grandes temas relevantes para o Brasil advêm desta dissertação.

O primeiro é sobre as premissas e a modelagem das emissões decorrentes da mudança do uso da terra que parecem ter sido subestimadas pelo RCP8.5 (SCHAWALM et al., 2020). Os avanços, tanto de conhecimento científico e modelagem quanto de tecnologias de medição de emissões, estão levando a informações cada vez mais precisas das fontes e da localização das emissões. Como as emissões brasileiras são primordialmente provenientes de mudança do uso da terra (44\%) e da agropecuária (25\%) (SEEG BRASIL, )o país estará cada vez mais em evidência mundial em termos de emissões de GEE.

O segundo é o papel da Petrobras, empresa que está entre as 20 maiores emissoras de GEE acumulados desde 1965 (TAYLOR; WATTS, 2019), na transição energética. Ela é uma empresa nacional de petróleo, com grandes reservas, grandes transferências financeiras para o governo com destinação em parte obrigatória à saúde e à educação, e sem planos de investimentos em energias renováveis (FOLHA DE SAO PAULO, 2019). 


\section{REFERÊNCIAS}

ABRAmOVAY, R. Muito Além da Economia Verde. 1. ed. Sao Paulo: Abril, 2012.

ABRAMOVAY, R. "Inovações para que se democratize o acesso à energia, sem ampliar as emissões." ambiente \& sociedade 17.3 (2014).

ABRAMOVAY, R. Polarization no longer sets the tone in climate negotiations. In: LEONARDO PAZ NEVES (Ed.). The World After the Paris Climate Agreement of December 2015. Rio de Janeiro: Cebri Dossiê Special Edition, 2016. pp. 51-60.

ABRAMOVAY, R. Opinião: empresas de petróleo seguem produzindo alheias à crise climática. UOLTab. 2020. Disponível em: https://tab.uol.com.br/noticias/redacao/2020/02/12/opiniao-a-corrida-maluca-das-empresasde-petroleo-e-gas.htm. Acesso em 07 set. 2020.

ALCAMO, J. Scenarios as tools for international environmental assessments. 2001. Disponível em: https://www.eea.europa.eu/publications/environmental_issue_report_2001_24/file

AMELI, N. et al. Climate finance and disclosure for institutional investors: why transparency is not enough. Climatic Change, v. 160, n. 4, pp. 565-589, 2020.

ARNETH, A. et al. Historical carbon dioxide emissions caused by land-use changes are possibly larger than assumed. Nature Geoscience, v. 10, n. 2, pp. 79-84, fev. 2017. Disponível em: http://www.nature.com/articles/ngeo2882.

ARTHUR, W. B. The Nature of Technology: what it is and how it evolves. 1. ed. Nova Iorque: Free press, 2009.

AUSUBEL, J. H. Decarbonization: The next 100 years. 50th Anniversary Symposium of the Geology Foundation, n. June, 2003. Disponível em: http://phe.rockefeller.edu/AustinDecarbonization/.

BENTLEY, R. W.; MUSHALIK, M.; WANG, J. The Resource-Limited Plateau in Global Conventional Oil Production: Analysis and Consequences. Biophysical Economics and Sustainability, v. 5, n. 2, p. 10, 24 jun. 2020. Disponível em: https://doi.org/10.1007/s41247020-00076-1.

BLOCH, C. et al. Breakthrough Batteries - Powering the Era of Clean Electrification. Rocky Mountain Institute. 2019. Disponível em: http://www.rmi.org/breakthrough-batteries.

BNEF. Battery Pack Prices Fall As Market Ramps Up With Market Average At \$156/kWh In 2019. 2019. Disponível em: https://about.bnef.com/blog/battery-pack-pricesfall-as-market-ramps-up-with-market-average-at-156-kwh-in-2019/. Acesso em: 1 jul. 2020.

BNEF. Colossal Six Months for Offshore Wind Support Renewable Energy Investment in First Half of 2020. 2020. Disponível em: https://about.bnef.com/blog/colossal-six-months-foroffshore-wind-support-renewable-energy-investment-in-first-half-of-2020/. 
BNEF. Hydrogen Economy Outlook. 2020b. Disponível em: https://data.bloomberglp.com/professional/sites/24/BNEF-Hydrogen-Economy-Outlook-KeyMessages-30-Mar-2020.pdf. Acesso: 08 ago. 2020

BOCCATO, V. R. C. Metodologia da Pesquisa Bibliográfica na Área Odontológica e o Artigo Científico como Forma de Comunicação. Revista de Odontologia da Universidade Cidade de São Paulo, v. 18, n. 3, p. 265-274, 2006. Disponível em: <http://www.pubmed.gov>.

BODNAR, P. et al. How to Retire Early: Making Accelerated Coal Phaseout Feasible and Just. Rocky Mountain Institute - RMI, p. 60, 2020.

BONVILLIAN, W. B.; WEISS, C. Technological Innovation in Legacy Sectors. New York: Oxford University Press, 2015.

BÖRJESON, L. et al. Scenario types and techniques: Towards a user's guide. Futures, v. 38, n. 7, pp. 723-739, set. 2006.

\section{BP. BP Statistical Review of World Energy. 1996}

BP. BP Statistical Review of World Energy. 2019. Disponível em: https://www.bp.com/content/dam/bp/business-sites/en/global/corporate/pdfs/energyeconomics/statistical-review/bp-stats-review-2019-full-report.pdf. Acesso em 07 set. 2020.

BP. Updated methodology for converting non-fossil electricity generation to primary energy. Disponível em: https://www.bp.com/content/dam/bp/businesssites/en/global/corporate/pdfs/energy-economics/statistical-review/methodology-forconverting-non-fossil-fuel-primary-energy.pdf. Acesso em: 1 ago. 2020.

BRASIL. EPE. BEN - Balanço energético nacional 2014. Rio de Janeiro: 2015. Disponível em: https://www.epe.gov.br/pt/publicacoes-dados-abertos/publicacoes/Balanco-EnergeticoNacional-2015.

BREETZ, H.; MILDENBERGER, M.; STOKES, L. The political logics of clean energy transitions. Business and Politics, v. 20, n. 4, p. 492-522, 19 dez. 2018. Disponível em: https://www.cambridge.org/core/journals/business-and-politics/article/political-logics-ofclean-energy-transitions/3EBB1887089929B48CD623309C6751A9.

BROCKWAY, P. E. et al. Estimation of global final-stage energy-return-on-investment for fossil fuels with comparison to renewable energy sources. Nature Energy, v. 4, n. 7, pp. 612621, 2019. Disponível em: http://dx.doi.org/10.1038/s41560-019-0425-z.

BULlarD, N. As They Reach Retirement Age, Wind Farms Become Prime Investments. 2020a. Disponível em: <https://www.bloomberg.com/news/articles/2020-06-18/as-they-reachretirement-age-wind-farms-become-prime-investments>. Acesso em: 8 ago. 2020

BUllard, N. ' Peaker' Gas Plants May Have Peaked After All. 2020b. Disponível em: https://www.bloomberg.com/news/articles/2020-07-16/new-california-study-is-good-newsfor-certain-solar-companies. Acesso em 8 ago. 2020.

Business as unusual. Nature Energy, v. 2, n. 9, p. 17150, 12 set. 2017. Disponível em: http://www.nature.com/articles/nenergy2017150. 
CASH, D. et al. Salience, Credibility, Legitimacy and Boundaries: Linking Research, Assessment and Decision Making. SSRN Electronic Journal, 2003.

CARDEN, K.; DOMBROWSKY, A. K.; WINKLER, C. 2020 Joint IOU ELCC Study. 2020. Disponível em: https:/library.sce.com/content/dam/scedoclib/public/regulatory/filings/pending/electric/ELECTRIC_4243-E.pdf.

CARLETON, Tamma. Valuing the global mortality consequences of climate change accounting for adaptation costs and benefits: working paper 27599. Cambrigde: Nber, 2020. Disponível em: https://www.nber.org/papers/w27599.pdf. Acesso em: 07 ago. 2020.

CARRINGTON, G.; STEPHENSON, J. The politics of energy scenarios: Are International Energy Agency and other conservative projections hampering the renewable energy transition? Energy Research \& Social Science, v. 46, pp. 103-113, dez. 2018. Disponível em: https://linkinghub.elsevier.com/retrieve/pii/S2214629618307242.

CLACK, Christopher T. M. et al. Evaluation of a proposal for reliable low-cost grid power with 100\% wind, water, and solar. Proceedings Of The National Academy Of Sciences, [s.1.], v. 114, n. 26, p.6722-6727, 19 jun. 2017. Proceedings of the National Academy of Sciences. http://dx.doi.org/10.1073/pnas.1610381114.

CHENET, Hugues; RYAN-COLLINS, Josh; VAN LERVEN, Frank. Climate-Related Financial Policy in a World of Radical Uncertainty: towards a precautionary approach. SSRN Electronic Journal, 2019. Elsevier BV. http://dx.doi.org/10.2139/ssrn.3520224.

CHENET, H. Climate Change and Financial Risk. SSRN Electronic Journal, 2019. Disponível em: https://papers.ssrn.com/sol3/papers.cfm?abstract_id=3407940

\section{CONFERÊNCIA DAS NAÇÕES UNIDAS SOBRE O MEIO AMBIENTE E DESENVOLVIMENTO. Declaração do Rio. 1992}

CRESWELL, J. W. Projeto de pesquisa - metodos qualitativo, quantitativo e misto: métodos qualitativo, quantitativo e misto. 3a. ed. [s.1.] Artmed, 2010

DAS, U. K. et al. Forecasting of photovoltaic power generation and model optimization: A review. Renewable and Sustainable Energy Reviews, v. 81, pp. 912-928, jan. 2018. Disponível em: https://linkinghub.elsevier.com/retrieve/pii/S1364032117311620

DIESENDORF, M.; ELLISTON, B. The feasibility of $\mathbf{1 0 0 \%}$ renewable electricity systems: A response to criticsRenewable and Sustainable Energy Reviews. [s.1.] Elsevier Ltd, 2018. Disponível em: https://doi.org/10.1016/j.rser.2018.05.042.

DOWLING, D. Experimenting on Theories. Science in Context, v. 12, n. 2, p. 261-273, 26 set. $1999 . \quad$ Disponível em: https://www.cambridge.org/core/product/identifier/S0269889700003410/type/journal_article.

EDWARDS, P. N. A vast machine: computer models, climate data, and the politics of global warming. cambridge: The MIT Press, 2010.

EKINS, P. REPORT TO THE COMMITTEE ON CLIMATE CHANGE OF THE ADVISORY GROUP ON COSTS AND BENEFITS OF NET ZERO. 2019. Disponível em: 
https://www.theccc.org.uk/wp-content/uploads/2019/05/Advisory-Group-on-Costs-andBenefits-of-Net-Zero.pdf. Acesso em 08 ago. 2020.

ENERGY TRANSITION COMISSION. Reaching net-zero carbon emissions from harderto-abate sectors by mid - century. 2018. Disponível em: http://energytransitions.org/sites/default/files/ETC_MissionPossible_FullReport.pdf.

EVANS, S. Analysis: Record-low price for UK offshore wind cheaper than existing gas plants by 2023. 2018 Disponível em: https://www.carbonbrief.org/analysis-record-low-ukoffshore-wind-cheaper-than-existing-gas-plants-by-2023. Acesso em: 10 ago. 2020.

EVANS, Simon. Profound shifts' underway in energy system, says IEA World Energy Outlook. 2020. Carbon Brief. Disponível em: https://www.carbonbrief.org/profound-shiftsunderway-in-energy-system-says-iea-world-energy-outlook. Acesso em: 08 ago. 2020.

FOLHA DE SAO PAULO. Presidente da Petrobras afirma que não investirá na operação de energia renovável. Folha de Sao Paulo, 2 ago. 2019. Disponível em: https://www1.folha.uol.com.br/mercado/2019/08/presidente-da-petrobras-afirma-que-naoinvestira-na-operacao-de-energia-renovavel.shtml. Acesso em 07 set. 2020

FORSBERG, C. W. et al. Converting excess low-price electricity into high-temperature stored heat for industry and high-value electricity production. Electricity Journal, v. 30, n. 6, pp. 42$52,2017$.

FOUQUET, R.; PEARSON, P. J. G. Past and prospective energy transitions: Insights from history. Energy Policy, v. 50, pp. 1-7, 2012.

FRI, R. W. The Role of Knowledge: Technological Innovation in the Energy System. The Energy Journal, v. 24, n. 4, pp. 51-74, 2003.

FRIDAHL, M.; LEHTVEER, M. Bioenergy with carbon capture and storage (BECCS): Global potential, investment preferences, and deployment barriers. Energy Research and Social Science, v. 42, n. March, pp.155-165, 2018. Disponível em: https://doi.org/10.1016/j.erss.2018.03.019.

FUNTOWICZ, S.; RAVETZ, J. Post-normal science: A new science for new times. Scientific European, n. October, pp. 20-22, 1990.

FUSS, S. et al. COMMENTARY: Betting on negative emissions. Nature Climate Change, v. 4, n. 10, p. 850-853, 2014. Disponível em: http://dx.doi.org/10.1038/nclimate2392.

GEELS, F. W. et al. Sociotechnical transitions for deep decarbonization. Science, v. 357, n. 6357, pp.1242-1244, 22 set. 2017.2 Disponível em: https://www.sciencemag.org/lookup/doi/10.1126/science.aao3760.

GOLDEMBERG, J. The evolution of the energy and carbon intensities of developing countries. Energy Policy, v. 137, n. November 2020.

GRIFFITH, S.; FRASER, L.; CALISCH, S. REWIRING AMERICA. [s.1.] Pushan Panda, 2020 . 
GRÜBLER, A. Diffusion. Technological Forecasting and Social Change, v. 39, n. 1-2, pp. 159-180, mar. 1991. Disponível em: https://linkinghub.elsevier.com/retrieve/pii/004016259190034D.

GRUBLER, A. Energy transitions research: Insights and cautionary tales. Energy Policy, v. 50, pp. 8-16, nov. 2012. Disponível em: https://linkinghub.elsevier.com/retrieve/pii/S0301421512002054.

GRUBLER, A.; WILSON, C.; NEMET, G. Apples, oranges, and consistent comparisons of the temporal dynamics of energy transitions. Energy Research \& Social Science, v. 22, pp. 1825, dez. 2016. Disponível em: https://linkinghub.elsevier.com/retrieve/pii/S2214629616301980.

HAIKOLA, S.; HANSSON, A.; ANSHELM, J. From polarization to reluctant acceptancebioenergy with carbon capture and storage (BECCS) and the post-normalization of the climate debate. Journal of Integrative Environmental Sciences, v. 16, n. 1, pp. 45-69, 1 jan. 2019. Disponível em: https://www.tandfonline.com/doi/full/10.1080/1943815X.2019.1579740.

HALL, C. A. S.; LAMBERT, J. G.; BALOGH, S. B. EROI of different fuels and the implications for society. Energy Policy, v. 64, pp. 141-152, 2014. Disponível em: http://dx.doi.org/10.1016/j.enpol.2013.05.049.

HANSEN, M. C.; STEHMAN, S. V.; POTAPOV, P. V. Quantification of global gross forest cover loss. Proceedings of the National Academy of Sciences, v. 107, n. 19, pp. 8650-8655, 11 maio 2010. Disponível em: http://www.pnas.org/cgi/doi/10.1073/pnas.0912668107.

HARTMANN, S. The World as a Process. In: Modelling and Simulation in the Social Sciences from the Philosophy of Science Point of View. Dordrecht: Springer Netherlands, 1996. pp. 77-100.

HASSANI, H.; SILVA, E. S. Big Data: a big opportunity for the petroleum and petrochemical industry. OPEC Energy Review, v. 42, n. 1, pp. 74-89, mar. 2018. Disponível em: http://doi.wiley.com/10.1111/opec.12118.

HAUSFATHER, Z. Bounding the climate viability of natural gas as a bridge fuel to displace coal. Energy Policy, v. 86, pp. 286-294, 2015. Disponível em: http://dx.doi.org/10.1016/j.enpol.2015.07.012.

HAUSFATHER, Z. Explainer: The high-emissions 'RCP8.5' global warming scenario. 2019. Disponível em: https://www.carbonbrief.org/explainer-the-high-emissions-rcp8-5global-warming-scenario. Acesso em: 29 jul. 2020.

HAUSFATHER, Z.; PETERS, G. Emissions - the 'business as usual' story is misleading. Nature, v. 577, n. 7792, pp. 618-620, 2020.

HEARD, B. P. et al. Burden of proof: A comprehensive review of the feasibility of $100 \%$ renewable-electricity systems. Renewable and Sustainable Energy Reviews, v. 76, n. February, pp. 1122-1133, 2017. Disponível em: http://dx.doi.org/10.1016/j.rser.2017.03.114.

HELLER, P. R. P.; MIHALYI, D. Massive and Misunderstood Data-Driven Insights into National Oil Companies. 2019.2 Disponível em: 
https://nationaloilcompanydata.org/api/publications/content/BWEOxwl3qpbpPk5RkZmWr3g 5TEvNgLD4LD21 foHP.pdf

HELM, D. Government failure, rent-seeking, and capture: The design of climate change policy. Oxford Review of Economic Policy, v. 26, n. 2, pp. 182-196, 2010.

HELMS, T. Asset transformation and the challenges to servitize a utility business model. Energy Policy, v. 91, pp. 98-112, abr. 2016. Disponível em: https://linkinghub.elsevier.com/retrieve/pii/S0301421515302597.

HEPTONSTALL, P.; GROSS, R.; STEINER, F. The costs and impacts of intermittency 2016 update. [s.l: s.n.]. Disponível em: http://www.ukerc.ac.uk/publications/the-costs-andimpacts-of-intermittency-2016-update.html.

HO, E. et al. Not all carbon dioxide emission scenarios are equally likely: a subjective expert assessment. Climatic Change, v. 155, n. 4, pp. 545-561, 2019.

IEA. World energy outlook 2018. Paris: 2018

IEA. Energy Transitions Indicators. 2019a. Disponível em: https://www.iea.org/articles/energy-transitions-indicators. Acesso em: 27 ago. 2020.

IEA. Offshore Wind Outlook 2019. 2019b. Disponível em: https://webstore.iea.org/download/direct/2886?fileName=Offshore_Wind_Outlook_2019.pdf \%0Ahttps://www.iea.org/reports/offshore-wind-outlook-2019

IEA. World Energy Outlook 2019 International Energy Agency. 2019c. Disponível em: https://www.iea.org/reports/world-energy-outlook-2019.

IEA. The Future of Hydrogen. Seizing today's opportunitiesReport prepared by the IEA for the G20, Japan. 2019d. Disponível em: https://webstore.iea.org/download/direct/2803.

IEA. Global EV Outlook 2020: Entering the decade of electric drive? 2020a. Disponível em: https://webstore.iea.org/download/direct/3007

IEA. Energy Technology PerspectivesEnergy Technology Perspectives. 2020b. Disponível em: https://webstore.iea.org/energy-technology-perspectives-2020-special-report-on-cleanenergy-innovation.

IEA. The Oil and Gas Industry in Energy Transitions. 2020c. Disponível em: https://www.iea.org/reports/the-oil-and-gas-industry-in-energy-transitions

IPCC. Definition of Terms Used Within the DDC Pages. Disponível em: https://www.ipccdata.org/guidelines/pages/glossary/glossary_b.html.

IPCC. Special Report on Emissions Scenarios. Cambridge: Cambridge University Press, 2000 .

IPCC. Climate Change 2014 Synthesis Report: Summary Chapter for Policymakers. 2014. 
IRENA. Future of solar photovoltaic:Deployment, investment, technology, grid integration and socio-economic aspects. 2019a. Disponível em: https://www.irena.org//media/Files/IRENA/Agency/Publication/2019/Nov/IRENA_Future_of_Solar_PV_2019.pdf.

IRENA. Future of Wind: Deployment, investment, technology, grid integration and socioeconomic aspectsInternational Renewable Energy Agency (IRENA). 2019b.

Disponível

em:

https://www.irena.org/documentdownloads/publications/re_technologies_cost_analysishydropower.pdf.

IRENA. Renewable Power Generation Costs in 2019. 2020. Disponível em: https://www.irena.org/publications/2020/Jun/Renewable-Power-Costs-in-2019. JACKSON, TIM. Prosperity without grow: foundations for the economy of tomorrow. 2. ed. Abingdon: Routledge, 2017.

JACOBSON, Mark Z. et al. Low-cost solution to the grid reliability problem with $100 \%$ penetration of intermittent wind, water, and solar for all purposes. Proceedings Of The National Academy Of Sciences, [s.1.], v. 112, n. 49, pp.15060-15065, 23 nov. 2015. Proceedings of the National Academy of Sciences. http://dx.doi.org/10.1073/pnas.1510028112.

JACOBSON, M. Z. et al. 100\% Clean and Renewable Wind, Water, and Sunlight All-Sector Energy Roadmaps for 139 Countries of the World 100\% Clean and Renewable Wind, Water, and Sunlight All-Sector Energy Roadmaps for 139 Countries of the World. Joule, p. 202, 2019. Disponível em: http://dx.doi.org/10.1016/j.joule.2017.07.005.

JAFFE, A. B.; NEWELL, R. G.; STAVINS, R. N. A tale of two market failures: Technology and environmental policy. Ecological Economics, v. 54, n. 2-3, pp. 164-174, ago. 2005. Disponível em: https://linkinghub.elsevier.com/retrieve/pii/S0921800905000303.

JAMASB, T. Technical change theory and learning curves: Patterns of progress in electricity generation technologies. Energy Journal, v. 28, n. 3, pp. 51-71, 2007.

JOHNSTONE, P.; STIRLING, A.; SOVACOOL, B. Policy mixes for incumbency: Exploring the destructive recreation of renewable energy, shale gas 'fracking,' and nuclear power in the United Kingdom. Energy Research and Social Science, v. 33, n. August, pp. 147-162, 2017. Disponível em: http://dx.doi.org/10.1016/j.erss.2017.09.005.

JONES, D.; GRAHAM, E.; TUNBRIDGE, P. Wind And Solar Now Generate One-Tenth Of Global Electricity - Ember. 2020. Disponível em: https:/emberclimate.org/project/global-electricity-h12020/.

KAHN, H.; WIENER, An. J. The Next Thirty Three Years: A Framework for Specuation. Daedalus, v. Summer, pp. 705-732, 1967.

KERN, F.; ROGGE, K. S. The pace of governed energy transitions: Agency, international dynamics and the global Paris agreement accelerating decarbonisation processes? Energy Research \& Social Science, v. 22, pp. 13-17, dez. 2016. Disponível em: https://linkinghub.elsevier.com/retrieve/pii/S2214629616301992. 
KING, L. C.; VAN DEN BERGH, J. C. J. M. Implications of net energy-return-on-investment for a low-carbon energy transition. Nature Energy, v. 3, n. 4, pp. 334-340, 19 abr. 2018. Disponível em: http://www.nature.com/articles/s41560-018-0116-1.

KOWARSCH, M. et al. A road map for global environmental assessments. Nature Climate Change, v. 7, n. 6, pp. 379-382, jun. 2017. Disponível em: http://www.nature.com/articles/nclimate3307.

KUNZ, H.; HAGENS, N. J.; BALOGH, S. B. The influence of output variability from renewable electricity generation on net energy calculations. Energies, v. 7, n. 1, pp. 150-172, 2014.

LANGLEY, K. Exxon's Departure From Dow Highlights Market's Retreat From Energy Bets. The Wall Street Journal, 25 ago. 2020. Disponível em https://www.wsj.com/articles/exxonsdeparture-from-dow-highlights-markets-retreat-from-energy-bets-11598390465. Acesso em 07 set. 2020

LAWRENCE, A. et al. Where is the Evidence: realising the value of grey literature for public policy and practise. [s.l: s.n.]. 2014. Disponível em: https://apo.org.au/node/42299

LIEBREICH, M. Climate Wars Episode IV - a New Hope for the 2020s? 2019. Disponível em: https://about.bnef.com/blog/in-climate-wars-episode-4-the-2020s-will-bring-new-hope/. Acesso em: 1 ago. 2020.

MAZUR, C. et al. Technology is not a Barrier: A Survey of Energy System Technologies Required for Innovative Electricity Business Models Driving the Low Carbon Energy Revolution. Energies, v. 12, n. 3, p. 428, 29 jan. 2019. Disponível em: http://www.mdpi.com/1996-1073/12/3/428.

MCGLADE, C.; EKINS, P. The geographical distribution of fossil fuels unused when limiting global warming to $2{ }^{\circ} \mathrm{C}$. Nature, v. 517, n. 7533, pp. 187-190, 7 jan. 2015. Disponível em: http://www.nature.com/articles/nature14016.

MCKINSEY GLOBAL INSTITUTE. Climate risk and response. Physical hazards and socioeconomic impacts. 2020. Disponível em: https://www.mckinsey.com/ /media/McKinsey/Business\%20Functions/Sustainability/Our\%2 0Insights/Climate $\% 20$ risk $\% 20$ and $\% 20$ response $\% 20$ Physical $\% 20$ hazards $\% 20$ and $\% 20$ socioeco nomic\%20impacts/MGI-Climate-risk-and-response-Full-report-vF.pdf. Acesso em: 29 ago. 2020 .

MEYER, G.; HUME, N. Value of world's largest coal mine slashed by $\$ 1.4 \mathrm{bn}$. FT, 5 ago. 2020. Disponível em: https://www.ft.com/content/1ce6db64-ce52-40b7-825b-7e42a82f2d8c.

MILMAN, O. Rising temperatures will cause more deaths than all infectious diseases - study. The Guardian. Disponível em: https://www.theguardian.com/us-news/2020/aug/04/risingglobal-temperatures-death-toll-infectious-diseases-study. Acesso em: 29 ago. 2020.

MINAYO, M. C. de S. O desafio do Conhecimento. Sao Paulo: Hucitec, 1993.

MOHN, K. The gravity of status quo: A review of IEA's World Energy Outlook. Economics of Energy \& Environmental Policy, v. 9, n. 1, 1 jan. 2020. Disponível em: http://www.iaee.org/en/publications/eeeparticle.aspx?id=304. 
MOORE, J.; BULLARD, N. BNEF Executive Factbook. 2020. Disponível em: https://data.bloomberglp.com/promo/sites/12/678001-BNEF_2020-04-22ExecutiveFactbook.pdf?link=cta-text.

MOSS, R. H. et al. The next generation of scenarios for climate change research and assessment. Nature, v. 463, n. 7282, pp. 747-756, 2010. Disponível em: http://dx.doi.org/10.1038/nature08823.

NEMET, G. F. How Solar Energy Became Cheap: a model for low-carbon innovation. Abingdon: Routledge, 2019.

NGFS. NGFS_Technical Guide to climate scenario analysis for central banks and supervisors. $2020 . \quad$ Disponível em: https://www.ngfs.net/sites/default/files/medias/documents/ngfs_guide_scenario_analysis_fina 1.pdf. 2020

NOBRE, C. A.; NOBRE, A. D. O balanço de carbono da Amazônia brasileira. Estudos Avançados, v. 16, n. 45, pp. 81-90, ago. 2002. Disponível em: http://www.scielo.br/scielo.php?script=sci_arttext\&pid=S010340142002000200006\&lng=pt\&tlng=pt.

NREL. Best Research-Cell Efficiency Chart. Disponível em: https://www.nrel.gov/pv/cellefficiency.html. Acesso em: 7 jul. 2020.

O'NEILL, B. C. et al. The roads ahead: Narratives for shared socioeconomic pathways describing world futures in the 21 st century. Global Environmental Change, v. 42, pp. 169180, 2017. Disponível em: http://dx.doi.org/10.1016/j.gloenvcha.2015.01.004.

OPPENHEIMER, M. et al. Discerning Experts. Chicago: University of Chicago Press, 2019.

O'REILLY, J.; ORESKES, N.; OPPENHEIMER, M. The rapid disintegration of projections: The West Antarctic Ice Sheet and the Intergovernmental Panel on Climate Change. Social Studies of Science, v. 42, n. 5, pp. 709-731, 26 out. 2012. Disponível em: http://journals.sagepub.com/doi/10.1177/0306312712448130.

ORESKES, N. How earth science has become a social science. Historical Social Research, v. 40, n. 2, pp. 246-270, 2015.

OXFORD UNIVERSITY PRESS. Oxford Reference. Disponível em: https://www.oxfordreference.com/view/10.1093/oi/authority.20110803095538117.

PANIK, M. S. Hidrogênio Verde - Oportunidades de Negócios. Disponível em: https://brasilien.rio.ahk.de/pt/meio-ambiente/hidrogenio-verde-oportunidades-de-negocios. Acesso em: 8 set. 2020.

PIELKE JR., R. Understanding The Great Climate Science Scenario Debate. 2020. Disponível em: https://www.forbes.com/sites/rogerpielke/2020/02/03/understanding-thegreat-climate-science-scenario-debate/\#492e17cb26a7. Acesso em: 28 mar. 2020.

PINDYCK, R. S. The Use and Misuse of Models for Climate Policy. Review of Environmental Economics and Policy, v. 11, n. 1, pp. 100-114, 2017. Disponível em: https://academic.oup.com/reep/article/3066301/The. 
RAVAL, A. Shell warns of up to \$22bn hit on assets from oil and gas slump. FT, Londres: 2020a. Disponível em: https://www.ft.com/content/8c413183-098f-47bf-8f52-65727f818b1e Acesso em 05 set. 2020.

RAVAL, A. Repsol sets net-zero CO2 emissions target for 2050. FT, Londres: 2020b. Disponível em: https://www.ft.com/content/90f49a98-1528-11 ea-8d73-6303645ac406. Acesso em 05 set. 2020.

RAVAL, A. Oil majors face up to plunging asset values. FT, Londres: 2020c. Disponível em: https://www.ft.com/content/b7689fd1-5b06-42e9-bc9f-0a912c93924e. Acesso em 07 set. 2020 .

REGAN, HELEN C. Billions of people could live in areas too hot for humans by 2070, study says. CNN. Disponível em: https://edition.cnn.com/2020/05/05/world/global-warmingclimate-niche-temperatures-intl-hnk/index.html. Acesso em: 29 ago. 2020.

RIAHI, K.; GRÜBLER, A.; NAKICENOVIC, N. Scenarios of long-term socio-economic and environmental development under climate stabilization. Technological Forecasting and Social Change, v. 74, n. 7, pp. 887-935, 2007.

RIAHI, K. et al. RCP 8.5-A scenario of comparatively high greenhouse gas emissions. Climatic Change, v. 109, n. 1, pp. 33-57, 2011.

RIAHI, K. et al. The Shared Socioeconomic Pathways and their energy, land use, and greenhouse gas emissions implications: An overview. Global Environmental Change, v. 42, pp. 153-168, 2017.

ROGELJ, J. et al. IPCC 2018, cap2. Global warming of $\mathbf{1 . 5}^{\circ} \mathbf{C}$. An IPCC Special Report [...], p. 2, 2018a.

ROGELJ, J. et al. Scenarios towards limiting global mean temperature increase below $1.5^{\circ} \mathrm{C}$. Nature Climate Change, v. 8, n. 4, pp. 325-332, 5 abr. 2018b. Disponível em: http://www.nature.com/articles/s41558-018-0091-3.

ROLNICK, D. et al. Tackling Climate Change with Machine Learning. 2019. Disponível em: http://arxiv.org/abs/1906.05433.

RUBIN, E. S. et al. A review of learning rates for electricity supply technologies. Energy

Policy, v. 86, pp. 198-218, nov. 2015. Disponível em: https://linkinghub.elsevier.com/retrieve/pii/S0301421515002293.

SAE PRESIDÊNCIA DA REPÚLICA. Brasil 2040: Resumo executivo. 2015

SCHEFFER, M. et al. Catastrophic shifts in ecosystems. Nature, v. 413, n. 6856, pp. 591-596, out. 2001. Disponível em: http://www.nature.com/articles/35098000.

SCHMIDT, G. A.; SHERWOOD, S. A practical philosophy of complex climate modelling. European Journal for Philosophy of Science, v. 5, n. 2, pp. 149-169, 9 maio 2015. Disponível em: http://link.springer.com/10.1007/s13194-014-0102-9. 
SCHMIDT, T. S.; SEWERIN, S. Technology as a driver of climate and energy politics. Nature Energy, v. 2, n. 6, p. 17084, 26 jun. 2017. Disponível em: http://www.nature.com/articles/nenergy201784.

SCHWAB, K. The fourth Industrial revolution. 1. ed. Nova Iorque: Crown Business, 2016.

SCHWALM, C.; GLENDON, S.; DUFFY, P. RCP8.5 tracks cumulative CO2emissions. Proceedings of the National Academy of Sciences, v. 117, n. 33, pp. 19656-19657, 2020.

SEPUlVEDA, N. A. et al. The Role of Firm Low-Carbon Electricity Resources in Deep Decarbonization of Power Generation. Joule, v. 2, n. 11, pp. 2403-2420, nov. 2018. Disponível em: https://linkinghub.elsevier.com/retrieve/pii/S2542435118303866.

SEEG BRASIL. Emissões por setor. Disponível em: http://seeg.eco.br. Acesso em: 28 ago. 2020.

SGOURIDIS, S. et al. Comparative net energy analysis of renewable electricity and carbon capture and storage. Nature Energy, v. 4, n. 6, pp. 456-465, 8 jun. 2019. Disponível em: http://www.nature.com/articles/s41560-019-0365-7.

SHEPHERD, C.; FINDLAY, S. Virus drives shift away from coal except in China. FT, 2 ago. 2020.

SHIVA KUMAR, S.; HIMABINDU, V. Hydrogen production by PEM water electrolysis - A review. Materials Science for Energy Technologies, v. 2, n. 3, pp. 442-454, 2019. Disponível em: https://doi.org/10.1016/j.mset.2019.03.002.

SIMS, R. et al. Transport. In: Climate Change 2014: Mitigation of Climate Change. Contribution of Working Group III to the Fifth Assessment Report of the Intergovern- mental Panel on Climate Change. In: Springer Climate. Cambridge: Cambridge University Press, 2015.

SINGH, H. V. et al. The energy transitions index: An analytic framework for understanding the evolving global energy system. Energy Strategy Reviews, v. 26, n. January, p. 100382, 2019. Disponível em: https://doi.org/10.1016/j.esr.2019.100382.

SIVARAM, V. Unlocking Clean Energy. Issues in Science and TEchnology, v. 33, n. 2, 2017. Disponível em: https://issues.org/unlocking-clean-energy/.

SMIL, V. Energy Transitions: global and national perspectives. 2a. ed. Santa Barbara: PRAEGER, 2017.

SMIL, V. Growth: form microorganisms to megacities. 1. ed. Cambridge: The MIT Press, 2019.

SOVACOOL, B. K. How long will it take? Conceptualizing the temporal dynamics of energy transitions. Energy Research \& Social Science, v. 13, pp. 202-215, mar. 2016. Disponível em: https://linkinghub.elsevier.com/retrieve/pii/S2214629615300827.

STEFFEN, W. et al. Trajectories of the Earth System in the Anthropocene. Proceedings of the National Academy of Sciences, v. 115, n. 33, pp. 8252-8259, 14 ago. 2018. Disponível em: http://www.pnas.org/lookup/doi/10.1073/pnas.1810141115. 
STIRLING, A. Risk, precaution and science: towards a more constructive policy debate. Embo reports, v. 8, n. 4, pp. 309-312, 2007.

STOKES, L. C.; BREETZ, H. L. Politics in the U.S. energy transition: Case studies of solar, wind, biofuels and electric vehicles policy. Energy Policy, v. 113, pp. 76-86, fev. 2018. Disponível em: https://linkinghub.elsevier.com/retrieve/pii/S0301421517307322.

SUPRAN, G.; ORESKES, N. Assessing ExxonMobil's climate change communications (1977-2014). Environmental Research Letters, v. 12, n. 8, p. 084019, 1 ago. 2017. Disponível em: https://iopscience.iop.org/article/10.1088/1748-9326/aa815f.

SUTTER, M. B.; CARVALHO, D. E. de; POLO, E. F. Construção de Cenários: Apreciação de Métodos mais Utilizados na Administração Estratégica. Espacios, v. 33, n. 8, p. 13, 2012. Disponível em: http://www.scopus.com/inward/record.url?eid=2-s2.084874434217\&partnerID=40\&md5=3e768a433888eb61b07265771d9f8ef6.

TASK FORCE ON CLIMATE-RELATED FINANCIAL DISCLOURES. The Use of Scenario Analysis in Disclosure of Climate-Related Risks and Opportunities. 2017. Disponível em: https://www.fsb-tcfd.org/wp-content/uploads/2017/06/FINAL-TCFDTechnical-Supplement-062917.pdf. Acesso em: 29 ago. 2020

TAYLOR, M.; WATTS, J. Revealed: the 20 firms behind a third of all carbon emissions. The Guardian, 9 out. 92019.2 Disponível em: https://www.theguardian.com/environment/2019/oct/09/revealed-20-firms-third-carbonemissions. Acesso em 07 set. 2020

TENG, F.; XU, S. Q. Definition of business as usual and its impacts on assessment of mitigation efforts. Advances in Climate Change Research, v. 3, n. 4, pp. 212-219, 2012. Disponível em: http://dx.doi.org/10.3724/SP.J.1248.2012.00212

THE AES CORPORATION. AES Climate Scenario Report. [s.1: s.n.]. Disponível em: https://s2.q4cdn.com/825052743/files/doc_downloads/2018/11/AES_Climate_Scenario_Repo rt111318.pdf.

The CMIP6 landscape. Nature Climate Change, v. 9, n. 10, pp. 727-727, 25 out. 2019. Disponível em: http://www.nature.com/articles/s41558-019-0599-1.

THE SILVER INSTITUTE. World Silver Survey 2020. 2020. Disponível em: www.silverinstitute.org.

THOMAS, N. Britain breaks fresh coal power record as renewable use grows. FT, 9 jun. 2020. Disponível em: https://www.ft.com/content/02368a03-9673-4e34-adc3-d680c77ec051.

UNEP FINANCE INITIATIVE. The UN-Convened Net-Zero Asset Owner Alliance, [s.d.]. Disponível em: https://www.unepfi.org/net-zero-alliance/.

UNEP; BNEF; FRANKFURT SCHOOL. Global Trends in Renewable Energy. 2020.

Disponível em: https//www.fs-unep-centre.org/global-trends-in-renewable-energyinvestment-2020/.

UNITED NATIONS ENVIRONMENT PROGRAMME. Emissions Gap Report 2019. Nairobi: UNEP, 2019. Disponível em: 
https://www.unenvironment.org/resources/emissions-gap-report-2019. Acesso em: 01 jan. 2020.

\section{U.S. ENERGY INFORMATION ADMINISTRATION. Monthly Energy Review August} 2020. 2020. Disponível em: https://www.eia.gov/totalenergy/data/monthly/pdf/mer.pdf.

VAN VUUREN, D. P. et al. The representative concentration pathways: An overview. Climatic Change, v. 109, n. 1, pp. 5-31, 2011.

VAN VUUREN, D. P. et al. Scenarios in Global Environmental Assessments: Key characteristics and lessons for future use. Global Environmental Change, v. 22, n. 4, pp. 884895, 2012. Disponível em: http://dx.doi.org/10.1016/j.gloenvcha.2012.06.001.

VAN VUUREN, D. P. et al. A new scenario framework for Climate Change Research: Scenario matrix architecture. Climatic Change, v. 122, n. 3, pp. 373-386, 2014.

VASILEIADOU, E.; HEIMERIKS, G.; PETERSEN, A. C. Exploring the impact of the IPCC Assessment Reports on science. Environmental Science \& Policy, v. 14, n. 8, pp. 1052-1061, dez. 2011. Disponível em: https://linkinghub.elsevier.com/retrieve/pii/S1462901111001080.

WANG, Q. et al. Natural gas from shale formation - The evolution, evidences and challenges of shale gas revolution in United States. Renewable and Sustainable Energy Reviews, v. 30, pp. 1-28, fev. 2014. Disponível em: https://linkinghub.elsevier.com/retrieve/pii/S1364032113006059.

WARNER, T. T. Quality assurance in atmospheric modeling. Bulletin of the American Meteorological Society, v. 92, n. 12, pp. 1601-1610, 2011.

WCRP. WCRP Coupled Model Intercomparison Project. Disponível em: https://www.wcrp-climate.org/wgcm-cmip.

WERNDL, Charlotte. On Defining Climate and Climate Change. The British Journal For The Philosophy Of Science, [S.L.], v. 67, n. 2, pp. 337-364, 17 jan. 2015. Oxford University Press (OUP). http://dx.doi.org/10.1093/bjps/axu048.

WILLIAMS, J. H. et al. The Technology Path to Deep Greenhouse Gas Emissions Cuts by 2050: The Pivotal Role of Electricity. Science, v. 335, n. 6064, pp. 53-59, 6 jan. 2012. Disponível em: https://www.sciencemag.org/lookup/doi/10.1126/science.1208365.

WORLD BANK. State and Trends of Carbon Pricing 2019State and Trends of Carbon Pricing 2019. Washington: The World Bank, jun. 2019. Disponível em: http://hdl.handle.net/10986/31755.

WORLD ECONOMIC FORUM. The Speed of the Energy Transition Gradual or Rapid Change? 2019. Disponível em: https://www.weforum.org/whitepapers/the-speed-of-theenergy-transition.

WRIGHT, James Terence C.; SPERS, Renata Giovinazzo. O país no futuro: aspectos metodológicos e cenários. Estudos Avançados, [S.L.], v. 20, n. 56, pp. 13-28, abr. 2006. FapUNIFESP (SciELO). http://dx.doi.org/10.1590/s0103-40142006000100003. 
XU, C. et al. Future of the human climate niche. Proceedings of the National Academy of Sciences, v. 117, n. 21, p. 11350-11355, 2020.

YUE, C. et al. Contribution of land use to the interannual variability of the land carbon cycle. Nature Communications, v. 11, n. 1, p. 3170, 23 dez. 2020. Disponível em: http://www.nature.com/articles/s41467-020-16953-8. 